Cochrane Database of Systematic Reviews

\title{
Cognitive training interventions for dementia and mild cognitive impairment in Parkinson's disease (Review)
}

Orgeta V, McDonald KR, Poliakoff E, Hindle JV, Clare L, Leroi I

Orgeta V, McDonald KR, Poliakoff E, Hindle JV, Clare L, Leroi I.

Cognitive training interventions for dementia and mild cognitive impairment in Parkinson's disease.

Cochrane Database of Systematic Reviews 2020, Issue 2. Art. No.: CD011961.

DOI: 10.1002/14651858.CD011961.pub2.

www.cochranelibrary.com 
TABLE OF CONTENTS

HEADER

ABSTRACT

PLAIN LANGUAGE SUMMARY

SUMMARY OF FINDINGS

BACKGROUND

OBJECTIVES

METHODS

RESULTS

Figure 1.

Figure 2.

Figure 3.

Figure 4.

Figure 5.

Figure 6.

Figure 7.

Figure 8.

Figure 9.

Figure 10.

DISCUSSION

AUTHORS' CONCLUSIONS

ACKNOWLEDGEMENTS

REFERENCES

CHARACTERISTICS OF STUDIES

DATA AND ANALYSES

Analysis 1.1. Comparison 1 Cognitive training versus control group, Outcome 1 Global cognition post-treatment.

Analysis 1.2. Comparison 1 Cognitive training versus control group, Outcome 2 Executive function post-treatment.

Analysis 1.3. Comparison 1 Cognitive training versus control group, Outcome 3 Attention post-treatment.

Analysis 1.4. Comparison 1 Cognitive training versus control group, Outcome 4 Verbal memory post-treatment.

Analysis 1.5. Comparison 1 Cognitive training versus control group, Outcome 5 Visual processing post-treatment. ..........................

Analysis 1.6. Comparison 1 Cognitive training versus control group, Outcome 6 Activities of daily living post-treatment. .........

Analysis 1.7. Comparison 1 Cognitive training versus control group, Outcome 7 Quality of life post-treatment.

Analysis 1.8. Comparison 1 Cognitive training versus control group, Outcome 8 Global cognition long term.

Analysis 1.9. Comparison 1 Cognitive training versus control group, Outcome 9 Executive function long term.

Analysis 1.10. Comparison 1 Cognitive training versus control group, Outcome 10 Attention long term.

Analysis 1.11. Comparison 1 Cognitive training versus control group, Outcome 11 Verbal memory long term.

Analysis 2.1. Comparison 2 Sensitivity analyses: cognitive training versus control group, Outcome 1 Attention post-treatment.

Analysis 2.2. Comparison 2 Sensitivity analyses: cognitive training versus control group, Outcome 2 Verbal memory posttreatment.

APPENDICES

CONTRIBUTIONS OF AUTHORS

DECLARATIONS OF INTEREST

SOURCES OF SUPPORT

DIFFERENCES BETWEEN PROTOCOL AND REVIEW

INDEX TERMS 
[Intervention Review]

\section{Cognitive training interventions for dementia and mild cognitive impairment in Parkinson's disease}

Vasiliki Orgeta ${ }^{1}$, Kathryn R McDonald², Ellen Poliakoff ${ }^{3}$, John Vincent Hindle ${ }^{4}$, Linda Clare ${ }^{5}$, Iracema Leroi6

1Division of Psychiatry, University College London, London, UK. 2Division of Neuroscience and Experimental Psychology, School of Biological Sciences, Faculty of Biology, Medicine and Health, University of Manchester, Manchester, UK. ${ }^{3}$ Division of Neuroscience and Experimental Psychology, School of Biological Sciences, Manchester, UK. ${ }^{4}$ Care of the Elderly Department, Llandudno Hospital, Betsi Cadwaladr University Health Board, Llandudno, UK. ${ }^{5}$ REACH: The Centre for Research in Ageing and Cognitive Health, University of Exeter, Exeter, UK. ${ }^{6}$ Global Brain Health Institute, Trinity College Dublin, Dublin, Ireland

Contact address: Vasiliki Orgeta, Division of Psychiatry, University College London, 6th Floor, Maple House,, 149 Tottenham Court Road,, London, W1T7NF, UK.v.orgeta@ucl.ac.uk.

Editorial group: Cochrane Dementia and Cognitive Improvement Group. Publication status and date: New, published in Issue 2, 2020.

Citation: Orgeta V, McDonald KR, Poliakoff E, Hindle JV, Clare L, Leroi I. Cognitive training interventions for dementia and mild cognitive impairment in Parkinson's disease. Cochrane Database of Systematic Reviews 2020, Issue 2. Art. No.: CD011961. DOI: 10.1002/14651858.CD011961.pub2.

Copyright @ 2020 The Cochrane Collaboration. Published by John Wiley \& Sons, Ltd.

\section{A B S T R A C T}

\section{Background}

Approximately $60 \%$ to $80 \%$ of people with Parkinson's disease (PD) experience cognitive impairment that impacts on their quality of life. Cognitive decline is a core feature of the disease and can often present before the onset of motor symptoms. Cognitive training may be a useful non-pharmacological intervention that could help to maintain or improve cognition and quality of life for people with PD dementia (PDD) or PD-related mild cognitive impairment (PD-MCI).

\section{Objectives}

To determine whether cognitive training (targeting single or multiple domains) improves cognition in people with PDD and PD-MCI or other clearly defined forms of cognitive impairment in people with PD.

\section{Search methods}

We searched the Cochrane Dementia and Cognitive Improvement Group Trials Register (8 August 2019), the Cochrane Central Register of Controlled Trials (CENTRAL), MEDLINE, Embase, CINAHL, and PsycINFO. We searched reference lists and trial registers, searched relevant reviews in the area and conference proceedings. We also contacted experts for clarifications on data and ongoing trials.

\section{Selection criteria}

We included randomised controlled trials where the participants had PDD or PD-MCl, and where the intervention was intended to train general or specific areas of cognitive function, targeting either a single domain or multiple domains of cognition, and was compared to a control condition. Multicomponent interventions that also included motor or other elements were considered eligible.

\section{Data collection and analysis}

Two review authors independently screened titles, abstracts, and full-text articles for inclusion in the review. Two review authors also independently undertook extraction of data and assessment of methodological quality. We used GRADE methods to assess the overall quality of the evidence. 


\section{Main results}

Seven studies with a total of 225 participants met the inclusion criteria for this review. All seven studies compared the effects of a cognitive training intervention to a control intervention at the end of treatment periods lasting four to eight weeks. Six studies included people with PD living in the community. These six studies recruited people with single-domain (executive) or multiple-domain mild cognitive impairment in PD. Four of these studies identified participants with $\mathrm{MCl}$ using established diagnostic criteria, and two included both people with PD-MCl and people with PD who were not cognitively impaired. One study recruited people with a diagnosis of PD dementia who were living in long-term care settings. The cognitive training intervention in three studies targeted a single cognitive domain, whilst in four studies multiple domains of cognitive function were targeted. The comparison groups either received no intervention or took part in recreational activities (sports, music, arts), speech or language exercises, computerised motor therapy, or motor rehabilitation combined with recreational activity.

We found no clear evidence that cognitive training improved global cognition. Although cognitive training was associated with higher scores on global cognition at the end of treatment, the result was imprecise and not statistically significant (6 trials, 178 participants, standardised mean difference (SMD) $0.28,95 \%$ confidence interval ( $\mathrm{Cl})-0.03$ to 0.59 ; low-certainty evidence). There was no evidence of a difference at the end of treatment between cognitive training and control interventions on executive function ( 5 trials, 112 participants; SMD $0.10,95 \% \mathrm{Cl}-0.28$ to 0.48 ; low-certainty evidence) or visual processing ( 3 trials, 64 participants; SMD $0.30,95 \% \mathrm{Cl}-0.21$ to 0.81 ; lowcertainty evidence). The evidence favoured the cognitive training group on attention ( 5 trials, 160 participants; SMD $0.36,95 \% \mathrm{Cl} 0.03$ to 0.68; low-certainty evidence) and verbal memory ( 5 trials, 160 participants; SMD $0.37,95 \% \mathrm{Cl} 0.04$ to 0.69 ; low-certainty evidence), but these effects were less certain in sensitivity analyses that excluded a study in which only a minority of the sample were cognitively impaired. There was no evidence of differences between treatment and control groups in activities of daily living ( 3 trials, 67 participants; SMD 0.03, $95 \% \mathrm{Cl}-0.47$ to 0.53 ; low-certainty evidence) or quality of life ( 5 trials, 147 participants; SMD $-0.01,95 \% \mathrm{Cl}-0.35$ to 0.33 ; low-certainty evidence). There was very little information on adverse events. We considered the certainty of the evidence for all outcomes to be low due to risk of bias in the included studies and imprecision of the results.

We identified six ongoing trials recruiting participants with PD-MCI, but no ongoing trials of cognitive training for people with PDD.

\section{Authors' conclusions}

This review found no evidence that people with PD-MCI or PDD who receive cognitive training for four to eight weeks experience any important cognitive improvements at the end of training. However, this conclusion was based on a small number of studies with few participants, limitations of study design and execution, and imprecise results. There is a need for more robust, adequately powered studies of cognitive training before conclusions can be drawn about the effectiveness of cognitive training for people with PDD and PD-MCI. Studies should use formal criteria to diagnose cognitive impairments, and there is a particular need for more studies testing the efficacy of cognitive training in people with PDD.

\section{PLAIN LANGUAGE SUMMARY}

\section{Cognitive training interventions for dementia and mild cognitive impairment in Parkinson's disease}

\section{Review question}

We wanted to know whether cognitive training interventions are effective in improving cognition (thinking) in people with Parkinson's disease dementia or mild cognitive impairment.

\section{Background}

Approximately $60 \%$ to $80 \%$ of people with Parkinson's disease (PD) develop some degree of cognitive impairment, meaning that they may have difficulties with thinking and reasoning, memory, language, or perception. If these difficulties are severe enough to affect the person's ability to carry out daily activities, then the person is said to have Parkinson's disease dementia (PDD). If someone has cognitive problems but their daily activities are not significantly affected, then he or she is said to have mild cognitive impairment in Parkinson's disease (PD$\mathrm{MCl}$ ). Cognitive training involves practising cognitive skills such as memory, attention, and language through specific tasks. It may be able to help people with PDD or PD-MCI maintain better cognitive skills.

\section{What we did}

This review examined whether cognitive training is effective in improving outcomes such as overall cognitive skills ('global cognition'), memory, attention, or ability to carry out daily activities in people with PD and either dementia or $\mathrm{MCl}$. We searched the medical literature for research studies that compared people receiving a cognitive training intervention to those not receiving the intervention (a 'control group'). We only included studies in which the decision about whether or not someone received the cognitive training intervention was made randomly; such studies are called randomised controlled clinical trials and are considered to be the fairest method to test whether or not a treatment is effective. We did not examine other types of studies.

\section{What we found}


We found seven studies that randomly allocated a total of 225 participants to cognitive training or to a control group. Treatment lasted from four to eight weeks. All the cognitive training interventions were delivered by computer. The control groups received either no intervention or a control intervention such as language or motor exercises or participation in recreational activities. We found no difference between people who received cognitive training and people in the control groups in global cognition shortly after treatment ended. There was no convincing evidence of benefit in specific cognitive skills and no benefit shown in activities of daily living or quality of life. However, these findings were based on a small number of participants in a small number of studies. The overall certainty of the evidence was low, meaning that the results of further research could differ from the results of this review.

\section{Conclusion}

We found no good evidence that cognitive training is helpful for people with Parkinson's disease and dementia or MCl. The included studies were small and had flaws that may have affected the findings. The certainty of the results was low, and further studies are needed before we can be confident whether or not cognitive training is effective for this group of people. 


\section{SUMMARY OF FINDINGS}

\section{Summary of findings for the main comparison. Cognitive training compared to control intervention for cognition in PDD and PD-MCI}

\section{Cognitive training compared to control intervention for cognition in PDD and PD-MCI}

Patient or population: cognition in PDD and PD-MCI

Setting: community and long-term care

Intervention: cognitive training

Comparison: control intervention (no intervention, participating in recreational activities, receiving speech or language exercises, computerised motor therapy, or motor rehabilitation combined with recreational activity)

\begin{tabular}{|c|c|c|c|c|}
\hline Outcomes & $\begin{array}{l}\text { SMD } \\
(95 \% \mathrm{CI}) \\
\text { meta-analysis }\end{array}$ & $\begin{array}{l}\text { № of par- } \\
\text { ticipants } \\
\text { (studies) }\end{array}$ & $\begin{array}{l}\text { Certainty } \\
\text { of the ev- } \\
\text { idence } \\
\text { (GRADE) }\end{array}$ & Comments \\
\hline $\begin{array}{l}\text { Global cognition post-treatment } \\
\text { Assessed with: MMSE, CERAD } \\
\text { Follow-up: range } 4 \text { weeks to } 8 \text { weeks }\end{array}$ & $\begin{array}{l}\text { SMD } 0.28 \text { higher } \\
\text { ( } 0.03 \text { lower to } 0.59 \\
\text { higher) }\end{array}$ & $\begin{array}{l}178 \\
\text { (6 RCTs) }\end{array}$ & $\begin{array}{l}\oplus \oplus \Theta \ominus \\
\text { LOW } 12\end{array}$ & $\begin{array}{l}\text { A higher score is indica- } \\
\text { tive of improved cogni- } \\
\text { tion. }\end{array}$ \\
\hline $\begin{array}{l}\text { Executive function post-treatment } \\
\text { Assessed with: Trail Making Test B, Stockings of Cam- } \\
\text { bridge } \\
\text { Follow-up: range } 4 \text { weeks to } 6 \text { weeks }\end{array}$ & $\begin{array}{l}\text { SMD } 0.1 \text { higher } \\
\text { ( } 0.28 \text { lower to } 0.48 \\
\text { higher) }\end{array}$ & $\begin{array}{l}112 \\
\text { (5 RCTs) }\end{array}$ & $\begin{array}{l}\oplus \oplus \Theta \ominus \\
\text { LOW } 12\end{array}$ & $\begin{array}{l}\text { A higher score is indica- } \\
\text { tive of improved execu- } \\
\text { tive function. }\end{array}$ \\
\hline $\begin{array}{l}\text { Attention post-treatment } \\
\text { Assessed with: Stroop Task and Brief Test of Attention } \\
\text { Follow-up: range } 4 \text { weeks to } 6 \text { weeks }\end{array}$ & $\begin{array}{l}\text { SMD } 0.36 \text { higher } \\
\text { (0.03 higher to } \\
0.68 \text { higher) }\end{array}$ & $\begin{array}{l}160 \\
\text { (5 RCTs) }\end{array}$ & $\begin{array}{l}\oplus \oplus \Theta \Theta \\
\text { LOW } 12\end{array}$ & $\begin{array}{l}\text { A higher score is indica- } \\
\text { tive of improved atten- } \\
\text { tion. }\end{array}$ \\
\hline $\begin{array}{l}\text { Verbal memory post-treatment } \\
\text { Assessed with: WMS Logical Memory test, Selective Re- } \\
\text { minding Test, Hopkins Verbal Learning Test-Revised, Ver- } \\
\text { bal short-term memory DemTect } \\
\text { Follow-up: range } 4 \text { weeks to } 6 \text { weeks }\end{array}$ & $\begin{array}{l}\text { SMD } 0.37 \text { higher } \\
\text { (0.04 higher to } \\
0.69 \text { higher) }\end{array}$ & $\begin{array}{l}160 \\
\text { (5 RCTs) }\end{array}$ & $\begin{array}{l}\oplus \oplus \Theta \ominus \\
\text { LOW } 12\end{array}$ & $\begin{array}{l}\text { A higher score is indica- } \\
\text { tive of improved memo- } \\
\text { ry. }\end{array}$ \\
\hline $\begin{array}{l}\text { Visual processing post-treatment } \\
\text { Assessed with: Judgement Line Orientation Test } \\
\text { Follow-up: range } 4 \text { weeks to } 6 \text { weeks }\end{array}$ & $\begin{array}{l}\text { SMD } 0.3 \text { higher } \\
\text { ( } 0.21 \text { lower to } 0.81 \\
\text { higher) }\end{array}$ & $\begin{array}{l}64 \\
\text { (3 RCTs) }\end{array}$ & $\begin{array}{l}\oplus \oplus \Theta \ominus \\
\text { LOW } 12\end{array}$ & $\begin{array}{l}\text { A higher score is indica- } \\
\text { tive of improved visual } \\
\text { processing. }\end{array}$ \\
\hline $\begin{array}{l}\text { Activities of daily living post-treatment } \\
\text { Assessed with: Barthel Index, Unified Parkinson's Dis- } \\
\text { ease Rating Scale, Cognitive Difficulties Scale } \\
\text { Follow-up: range } 4 \text { weeks to } 8 \text { weeks }\end{array}$ & $\begin{array}{l}\text { SMD } 0.03 \text { higher } \\
\text { ( } 0.47 \text { lower to } 0.53 \\
\text { higher) }\end{array}$ & $\begin{array}{l}67 \\
\text { (3 RCTs) }\end{array}$ & $\begin{array}{l}\oplus \oplus \Theta \Theta \\
\text { LOW } 12\end{array}$ & $\begin{array}{l}\text { A higher score is indica- } \\
\text { tive of improved activi- } \\
\text { ties of daily living. }\end{array}$ \\
\hline $\begin{array}{l}\text { Quality of life post-treatment } \\
\text { Assessed with: Parkinson's Disease Questionnaire, } \\
\text { QUALIDEM } \\
\text { Follow-up: range } 4 \text { weeks to } 8 \text { weeks }\end{array}$ & $\begin{array}{l}\text { SMD } 0.01 \text { lower } \\
\text { (0.35 lower to } 0.33 \\
\text { higher) }\end{array}$ & $\begin{array}{l}147 \\
\text { (5 RCTs) }\end{array}$ & $\begin{array}{l}\oplus \oplus \Theta \Theta \\
\text { LOW } 12\end{array}$ & $\begin{array}{l}\text { A higher score is indica- } \\
\text { tive of improved quality } \\
\text { of life. }\end{array}$ \\
\hline
\end{tabular}

${ }^{*}$ The risk in the intervention group (and its $95 \%$ confidence interval) is based on the assumed risk in the comparison group and the relative effect of the intervention (and its $95 \% \mathrm{Cl}$ ).

Cl: confidence interval; RCT: randomised controlled trial; SMD: standardised mean difference

High certainty: We are very confident that the true effect lies close to that of the estimate of the effect. 
Moderate certainty: We are moderately confident in the effect estimate: the true effect is likely to be close to the estimate of the effect, but there is a possibility that it is substantially different.

Low certainty: Our confidence in the effect estimate is limited: the true effect may be substantially different from the estimate of the effect.

Very low certainty: We have very little confidence in the effect estimate: the true effect is likely to be substantially different from the estimate of effect.

1Downgraded one point due to risk of bias (all studies have at least two domains at unclear risk of bias with none of the studies at low risk of bias in all domains).

2Downgraded one point for imprecision due to small sample size ( $<400$ participants) and wide confidence intervals.

PDD: Parkinson's disease dementia

PD-MCl: Parkinson's Disease-Mild Cognitive Impairment

MMSE: Mini-Mental State Examination

CERAD: Consortium to Establish a Registry for Alzheimer's Disease test battery

WMS: Wechsler Memory Scale 


\section{B A C K G R O U N D}

Parkinson's disease (PD) is a common neurodegenerative disorder characterised by motor features such as resting tremor, rigidity, bradykinesia, and postural instability (Hughes 1992). It is now widely accepted that in addition to the motor symptoms, cognitive impairment is a core feature of the disease and should be considered when managing symptoms (Meireles 2012). Cognitive impairment in PD increases in frequency over time, but is already common in the early stages of the disease (Dubois 1997), and may even be present prior to the onset of motor symptoms (Pont-Sunyer 2015). Longitudinal studies show that people with Parkinson's disease have a three to six times higher risk of developing dementia than the general population without PD (Aarsland 2001). Cognitive impairment negatively affects patient quality of life (Leroi 2012a; Schrag 2000), and increases the risk of developing psychosis (Aarsland 2007; Giladi 2000). Once PD dementia (PDD) develops, the risk of requiring long-term care increases (Vossius 2011), with substantially higher healthcare costs compared to people living with PD but no dementia (Aarsland 2000).

Current pharmacological treatments include the cholinesterase inhibitors rivastigmine and donepezil. These may reduce some of the direct effects of the disease, including cognitive symptoms (Emre 2004; Ravina 2005; Rolinski 2012), but may be associated with adverse effects (Cutson 1995; van Laar 2011). Memantine is also used. It has a small clinical benefit, is generally safe and welltolerated (Leroi 2009; McShane 2019), and may prolong survival (Leroi 2014; Stubendorff 2014). However, clinical responses to drug treatments can vary (Cutson 1995; van Laar 2011). Given the limited number of treatment options and the negative impact of cognitive symptoms in PD, there may be a therapeutic role for nonpharmacological interventions that target cognitive symptoms. Despite numerous cognition-based interventions such as cognitive training being investigated in dementia due to Alzheimer's disease (AD) and in mild cognitive impairment (MCI) (Bahar-Fuchs 2019; Neely 2009; Rojas 2013), less research has focused on the efficacy of cognition-based interventions in people with cognitive impairment in PD.

\section{Description of the condition}

Parkinson's disease is a neurodegenerative disorder affecting approximately $1 \%$ to $2 \%$ of people aged 60 years and over (de Rijk 2000). Although widely regarded as a motor disorder, it is frequently associated with dementia (Emre 2003; Levy 2002b), which may be a distinct syndrome (Aarsland 2001; Buter 2008). Populationbased studies show that point prevalence of PDD is close to $30 \%$, with dementia incidence rates four to six times higher than in otherwise healthy older people (Emre 2007; Hely 2008). Estimates vary, but the incidence rate of dementia per 1000 persons-per year amongst people with PD is around 30 (Williams-Gray 2007), with a cumulative prevalence rate up to $80 \%$ (Buter 2008; Hely 2008). The rate of cognitive decline can be represented as an average of a one-point decrease per year on the Mini-Mental State Examination (MMSE) (Aarsland 2004). Key risk factors for developing dementia are older age, male sex, more severe stage of parkinsonism, presence of depression, and cognitive symptoms severe enough to meet criteria for MCl (Dubois 2007; Emre 2007; Marinus 2018). PDD is associated with high levels of disability, impaired quality of life, and greater burden of care (Bassett 2005; Leroi 2012a; Vatter 2018). The clinical features of PDD are similar to those in dementia with Lewy bodies (DLB), with both typically involving progressive executive dysfunction, difficulties with visuo-spatial tasks, and memory impairment Lippa 2007. DLB is diagnosed when cognitive impairment precedes parkinsonian motor signs or is evident within one year from its onset, whereas in PDD, cognitive impairment develops within the context of a well-established PD diagnosis Emre 2007.

The Movement Disorder Society (MDS) has proposed clinical diagnostic criteria for possible and probable PDD (Emre 2007), providing practical guidance for clinicians and researchers Dubois 2007. These include: (i) a diagnosis of Parkinson's disease according to the Queen Square Brain Bank criteria (Hughes 1992); and (ii) development of motor symptoms prior to dementia onset (McKeith 2002). Dementia is defined as: (a) impairment in at least two cognitive domains, representing a decline from premorbid functioning; and (b) cognitive deficits severe enough to impair daily life, independent of impairment in PD-related motor symptoms (Dubois 2007). The cognitive profile of PDD is distinct from that of $A D$, characterised primarily by impairments in attention, executive, and visuo-spatial functions, but fewer impairments in language compared to AD (Bronnick 2007; Emre 2003). Memory impairment also differs (Aretouli 2010), with greater deficits in retrieval and fewer difficulties with encoding (Aarsland 2003b; Jacobs 1995). A further clinical feature distinguishing PDD from $A D$ is cognitive fluctuations, which are more frequent in PDD (Galvin 2006). Neuropsychiatric symptoms differ between the two populations, with visual hallucinations and sleep disorders occurring more often in PDD (Aarsland 2001).

Lewy body-type degeneration is considered to be the main pathology (Halliday 2014; Irwin 2012); however, cortical changes typical of $A D$ and frontal atrophy may also be present (Lashley 2008; Sabbagh 2009). Neurochemically, cholinergic deficits are also found in PDD as well as in AD. This provides the rationale for the use of cholinesterase inhibitors in PDD (Aarsland 2003a; Emre 2004; Leroi 2004; Reading 2001), which may improve cognition and activities of daily living (Rolinski 2012).

Cognitive impairment severe enough to meet criteria for mild cognitive impairment is frequent in Parkinson's disease (Aarsland 2010), and increases the risk of developing PDD (Pedersen 2013). The term 'Parkinson's disease with mild cognitive impairment' (PD$\mathrm{MCl}$ ) has been proposed by the Movement Disorder Society Task Force alongside consensus-derived clinical diagnostic criteria that remain to be validated (Litvan 2012). PD-MCl criteria include the following:

- subjective report of cognitive problems by the patient or carer;

- performance at least 1.5 standard deviations (SDs) below the age-corrected mean score in one cognitive domain;

- no impairments in activities of daily living that can be attributed to cognitive impairment.

Approximately $50 \%$ of people with PD have mild cognitive impairment (Aarsland 2010; Janvin 2005), with more than $40 \%$ presenting with PD-MCl at time of diagnosis (Aarsland 2010; Yarnall 2014). PD-MCI primarily affects memory, visuo-spatial, and executive functions and may be a transitional state between normal ageing and dementia (Backman 2005). There may also be a subtype of PD-MCl that is non-progressive and does not convert to dementia (Williams-Gray 2007), although the majority of individuals with PD-MCI progress to PDD over time (Caviness 2007; Janvin 2006; 
Williams-Gray 2009). As with PDD, PD-MCl is associated with older age at disease onset, being male, experiencing depression, and having severe motor symptoms (Aarsland 2010).

\section{Description of the intervention}

For the purposes of this review, we systematically reviewed cognitive training interventions in people with PDD and PD$\mathrm{MCl}$. Cognition-based interventions differ from other nonpharmacological interventions in that they specifically aim to enhance cognition, as opposed to other behavioural or functional outcomes, either directly or indirectly. Given that terminology describing these interventions can be confusing, in this review we followed the classification of Bahar-Fuchs 2019, dividing these interventions into three types:

1. cognitive stimulation;

2. cognitive training;

3. cognitive rehabilitation.

Interventions that involve non-specific stimulation of cognitive and social functioning, engaging patients in general activities and discussions are termed 'cognitive stimulation' approaches, whereas 'cognitive training' interventions use guided practice on standardised paper and pencil or computerised tasks to target specific areas of cognition (single or multiple domains). 'Cognitive rehabilitation' uses individualised approaches to target restrictions in everyday life and improve functioning in relation to individualised goals. Interventions may also use mixed approaches, combining elements across cognition-based approaches or by adding additional physical or motor components. In this review we included studies of cognitive training targeting either a single cognitive domain or multiple cognitive domains.

Depending on the protocol used, cognitive training targets a single or multiple cognitive domains, for example memory, executive, attention, and visuo-spatial functions, and is delivered face-to-face or remotely, with sessions lasting from 30 minutes to an hour. Tasks may vary in complexity, and may be individually tailored (taking into account baseline cognitive performance or level of cognitive impairment) (Calleo 2012). Standardised programmes have been developed, as well as multimodal interventions, incorporating training in everyday activities and practising daily tasks using mnemonics, planning, and memory training. Interventions may take place in various settings (outpatient clinics, hospital settings, person's own home), on an individual or group basis, using either paper and pencil or multimedia computer software.

\section{How the intervention might work}

Cognition-based interventions in people with cognitive impairment of any aetiology (e.g. neurodegenerative disorders, traumatic brain injury, stroke), have been guided theoretically by restorative or compensatory approaches; these involve respectively either improving specific cognitive functions or using contextualised perspectives in which training is adapted to accommodate cognitive impairment (Ylvisaker 2002). For example, people engage in specific tasks that target one or more areas of cognitive function through guided practice (Bahar-Fuchs 2019). These types of interventions have been associated with improvements in memory in healthy older people and people with non-PD-related mild cognitive impairment, although they have not been shown to outperform active control interventions (Lampit
2014; Martin 2011). Generalisation of effects to other outcomes such as activities of daily living is still limited in both cognitively healthy older people and in people with mild cognitive impairment (Kelly 2014; Reijnders 2007).

In line with restorative approaches, cognitive training strengthens neural networks of attentional and control processes via neuroplasticity, as a result of experience or environmental stimulation (Raz 2006; Shaw 1994). Cognitive training may enhance frontal lobe function by activating mechanisms of brain plasticity (Boller 2004). Animal and human studies have shown that sensory systems in the cerebral cortex can improve through learning and practising tasks and that brain changes in cortical areas mediate cognitive improvements (Buonomano 1998; Gilbert 2001). Training in specific tasks increases grey matter volume (Driemeyer 2008). Cognitive training exercises increase memory-related activation in several brain areas in people with non-PD-related mild cognitive impairment such as memory-related hippocampal function (Belleville 2011; Hampstead 2012), consistent with the notion that cognitive training may encourage neuroplasticity of the brain.

\section{Why it is important to do this review}

Whilst treatment for motor symptoms in PD has improved considerably, treatment of cognitive symptoms remains limited. In clinical practice, PDD is often under-recognised and not optimally managed. The effects of drug treatments on symptoms are modest (Aarsland 2009; Emre 2010; Horstink 2006; Leroi 2009; Rolinski 2012), and no disease-modifying therapy is available. Polypharmacy, high medical comorbidity, and the side effect profile of the drugs all contribute to problems with tolerability of cholinesterase inhibitors, limiting access to evidence-based treatments for some people with PDD and PD-MCI (Rolinski 2012).

Cognitive impairment in the context of Parkinson's disease increases morbidity and mortality and experiences of neuropsychiatric symptoms (Buter 2008; Hughes 1992; Leroi 2012b), and is a marker of rapid functional decline (Hely 1995). Cognitive decline decreases patient quality of life (Leroi 2012a; Levy 2002a), and increases carer burden (Leroi 2012b), therefore any interventions that alleviate cognitive symptoms have the potential to reduce disability and improve quality of life for people with PDD and their carers.

Although cognitive training may be useful in improving cognitive outcomes in PDD, its effectiveness has not been systematically reviewed. It is important to describe the effects of these interventions in this population separately from others with dementia, as cognitive deficits are different to those observed in other dementias, and therefore interventions may need to be tailored to the cognitive domains commonly affected in PD. Since many people with $\mathrm{PD}$ present with $\mathrm{MCl}$ at the time of diagnosis (Smith 1999), identifying cognitive training approaches that can help manage cognitive symptoms in PD-MCl would be very useful clinically. The current review aims to benefit clinical practice by identifying whether cognitive training interventions improve cognitive function in people with PDD and PD-MCl, and to make recommendations for future research. 


\section{O B JECTIVES}

\section{Primary objective}

To determine whether cognitive training (targeting single or multiple domains) improves cognition in people with PDD and $\mathrm{PD}-\mathrm{MCl}$ or other clearly defined forms of cognitive impairment in people with PD.

\section{Secondary objectives}

To determine the effect of cognitive training on quality of life, activities of daily living, neuropsychiatric symptoms, adverse events, carer quality of life, and carer burden.

\section{METHODS}

\section{Criteria for considering studies for this review}

\section{Types of studies}

We included studies that fulfilled the following criteria:

- were randomised controlled trials (RCTs), including clusterrandomised trials;

- included a control or comparison group receiving no specific cognitive intervention.

\section{Types of participants}

People of any age, from any setting (e.g. home, community, longterm care, or rehabilitation settings), diagnosed with PDD (Emre 2007), or people with PD-MCl (Litvan 2012). We included studies that used the criteria for $\mathrm{MCl}$ proposed by Petersen 1999 or similar criteria.

\section{Types of interventions}

We included studies that reported a comparison between a cognitive training intervention and a control intervention. Cognitive training was defined as any intervention that targeted cognition (single or multiple cognitive domains) using a cognitive training approach involving guided practice (Bahar-Fuchs 2019; Davis 2001). Cognitive training interventions could be of any intensity, duration, or frequency, conducted on an individual or group basis, with or without the involvement of carers. We did not exclude trials on the basis of the language used to describe the intervention in the trial paper. Cognitive training interventions meeting criteria for inclusion in this review could also be described as 'memory therapy' or 'cognitive therapy', 'cognitive groups', 'cognitive training or retraining', 'cognitive support', or 'cognitive stimulation'.

Eligible control conditions could include no treatment (usual care), a waiting list for cognitive training, or an active control condition in which the comparison group engaged in non-specific activity (i.e. an attention control, controlling for effects of staff attention or social contact). 'Usual care' refers to what would usually be provided to people with cognitive impairment in Parkinson's disease in the setting in which the study was conducted (including medication, day care, and support, but no specific structured cognitive training intervention). Multicomponent interventions were considered eligible as long as one component was a clearly defined cognitive training intervention. We imposed no restrictions regarding additional physical or motor components. We excluded treatments identified as exercise, music, art, befriending, or bibliotherapy.

\section{Types of outcome measures}

We included studies that reported a cognitive outcome or outcomes, measured by a standardised test or any test that has acceptable psychometric properties.

\section{Primary outcomes}

Measures of cognitive function: global cognition, executive function, attention, memory (specifically verbal memory), and visual processing.

\section{Secondary outcomes}

- Measures of function (e.g. activities of daily living)

- Measures of quality of life

- Measures of neuropsychiatric symptoms including depression, anxiety, and apathy assessed by a validated rating scale

- Measures of carer outcomes including quality of life, experience of carer burden, well-being, or mood

- Adverse effects (e.g. on mood, awareness of cognitive difficulties)

We included studies assessing outcomes during or immediately after the intervention period.

\section{Search methods for identification of studies}

\section{Electronic searches}

We searched ALOIS (alois.medsci.ox.ac.uk/), the Cochrane Dementia and Cognitive Improvement Group's Specialised Register, on 8 August 2019. ALOIS is maintained by the Information Specialists of the Cochrane Dementia and Cognitive Improvement Group and contains studies in the areas of dementia (prevention and treatment), mild cognitive impairment, and cognitive improvement. The studies are identified from:

- monthly searches of a number of major healthcare databases: MEDLINE, Embase, CINAHL (Cumulative Index to Nursing and Allied Health Literature), PsycINFO, and LILACS (Latin American and Caribbean Health Science Information database);

- monthly searches of a number of trial registers: ISRCTN, UMIN (Japan's trial register), and the World Health Organization International Clinical Trials Registry Platform (WHO ICTRP) (which covers the US National Institutes of Health Ongoing Trials Register ClinicalTrials.gov, ISRCTN, the Chinese Clinical Trials Register, the German Clinical Trials Register, the Iranian Registry of Clinical Trials, and the Netherlands National Trials Register, plus others);

- quarterly search of the Cochrane Central Register of Controlled Trials (CENTRAL) in the Cochrane Library;

- six-monthly searches of a number of grey literature sources from ISI Web of Science Core Collection.

To view a list of all sources searched for ALOIS see 'About ALOIS' on the ALOIS website. Details of the search strategies used for the retrieval of reports of trials from the healthcare databases, CENTRAL, and conference proceedings can be viewed in the 'Methods used in reviews' section within the editorial information about the Dementia and Cognitive Improvement Group. We 
performed additional searches in many of the sources listed above to cover the time frame from the last searches performed for ALOIS to ensure that the search for the review was as up-to-date and comprehensive as possible. We also searched relevant reviews in the area and conference proceedings.

The search strategies used are described in Appendix 1. We have run five separate searches to date, the latest one on 8 August 2019.

\section{Searching other resources}

We contacted corresponding authors of identified ongoing trials for additional references and unpublished data. We scanned the reference lists of identified publications for additional trials, and all review papers related to cognitive training interventions in cognitive impairment in PD, PDD, and PD-MCI.

\section{Data collection and analysis}

\section{Selection of studies}

Two review authors (VO, KM) independently assessed the titles and abstracts of records identified by the search for potential eligibility. Any disagreements were resolved by discussion with a third review author (IL). We excluded studies that did not meet the inclusion criteria and obtained full-text copies of those references deemed potentially relevant. We documented reasons for the exclusion of studies. Where necessary, we requested additional information from the original study authors, specifically for ongoing trials and studies reporting mixed data on people with PD with or without cognitive impairment. We repeatedly contacted authors to request further information and were successful in one instance.

\section{Data extraction and management}

We extracted information about methods, participants, interventions, outcomes, and results as described below for all studies meeting the inclusion criteria, ongoing studies, and studies awaiting classification.

- Participants: Characteristics of the sample (age, diagnostic criteria, severity of cognitive impairment, and exclusion criteria).

- Methods: Data were extracted on methodologies used for randomisation, blinding, and participant dropout.

- Interventions: Duration, intensity, type, and frequency of cognitive training and control interventions.

- Outcomes: Primary outcomes included measures of cognition. Secondary outcomes were activities of daily living, quality of life, and adverse events. Secondary outcome measures for carers were quality of life, experience of carer burden, carer well-being or mood.

- Results: Where data were available, we collected the number of participants on whom the outcome was measured in each group, means and SDs. We used change from baseline scores for all of the analyses reported and calculated the change scores manually. Calculations of the SD of change scores were based on an assumption that the correlation between measurements at baseline and those at subsequent time points is zero. This method overestimates the SD of the change from baseline, but is considered preferable in a meta-analysis to take a conservative approach. For one study (three analyses) (Folkerts 2018), we used median scores of outcomes and calculated the SD from the interquartile range.

\section{Assessment of risk of bias in included studies}

We used Cochrane's tool for assessing risk of bias to evaluate the methodological quality of the included studies (Higgins 2011). The tool addresses six specific domains: sequence generation, allocation concealment, blinding, incomplete outcome data, selective reporting, and other sources of bias. Two review authors (VO, KM) independently assessed each domain, resolving any differences by discussion with a third review author (IL). In cases where no information was available to make a judgement, this is explicitly stated.

\section{Measures of treatment effect}

All outcomes were continuous, and a variety of different scales contributed data to each meta-analysis, therefore we used the standardised mean difference (SMD) as the measure of treatment effect.

\section{Unit of analysis issues}

Where trials had multiple treatment groups, we combined all relevant experimental groups into a single group and all relevant control groups into a single control group. We did not identify any cluster-RCTs.

\section{Dealing with missing data}

We reported the number of participants included in the final analysis as a proportion of all participants in the study.

\section{Assessment of heterogeneity}

We used the $I^{2}$ statistic to assess heterogeneity amongst studies. We defined substantial heterogeneity as an $\mathrm{I}^{2}$ of more than $50 \%$. We observed no or minimal heterogeneity in all of our analyses $\left(\mathrm{I}^{2} \leq\right.$ $1 \%)$.

\section{Assessment of reporting biases}

We only identified seven RCTs and pooled data from a maximum of six studies in total, therefore we did not use a funnel plot to assess for publication bias (Egger 1997).

\section{Data synthesis}

Had data permitted, we would had performed separate analyses on PDD and PD-MCl and analysed cognitive training interventions separately from multicomponent interventions. We did conduct analyses by cognitive domain: specifically, we separately analysed effects of cognitive training on global cognition, executive function, attention, verbal memory, and visual processing ability.

\section{Subgroup analysis and investigation of heterogeneity}

We had planned to conduct subgroup analyses comparing the effects of cognitive training versus active or passive control conditions, and comparing the effects of single-domain versus multiple-domain cognitive training interventions. However, there were too few studies and participants to permit any meaningful subgroup analyses..

\section{Sensitivity analysis}

We conducted sensitivity analyses excluding studies where fewer than $50 \%$ of participants had PD dementia, mild cognitive impairment, or other form of clinically significant cognitive decline as verified by a neuropsychological test. 


\section{Summary of findings and assessment of the certainty of the evidence}

We used the GRADE approach to assess the certainty of the evidence for the included studies reporting on the treatment effect of cognitive training in PD-MCl and PDD compared to a control condition for a total of seven outcomes (Guyatt 2011). We used risk of bias, imprecision, inconsistency, indirectness, and publication bias to rate the overall certainty of the evidence. We have presented key findings of the review in the Summary of findings for the main comparison, which includes ratings of the certainty of evidence for all outcomes.

\section{RESULT S}

\section{Description of studies}

\section{Results of the search}

We identified a total of 3849 results via the electronic searching and five articles via other sources. After a first assessment of the search results performed by the Cochrane Dementia and Cognitive Improvement Group Information Specialists, 456 results remained for evaluation (first search: 126 results, four studies identified via handsearch; second search: 21 results, one study identified by handsearch; third search: 54 results; fourth search: 165 results; fifth search: 85 results). We screened a total of 63 full-text articles for eligibility, of which 47 were excluded with reasons; seven studies met the inclusion criteria (Alloni 2018; Cerasa 2014; Costa 2014; Folkerts 2018; Lawrence 2018; París 2011; Petrelli 2014); six studies are ongoing (NCT03582670; ACTRN12618000999235; NCT02225314; NCT03285347; NCT02525367; van de Weijer 2016); and three studies are awaiting classification until further information is obtained (NCT01647698; NCT01646333; NCT02920632); (see Figure 1). 
Figure 1. Study flow diagram.

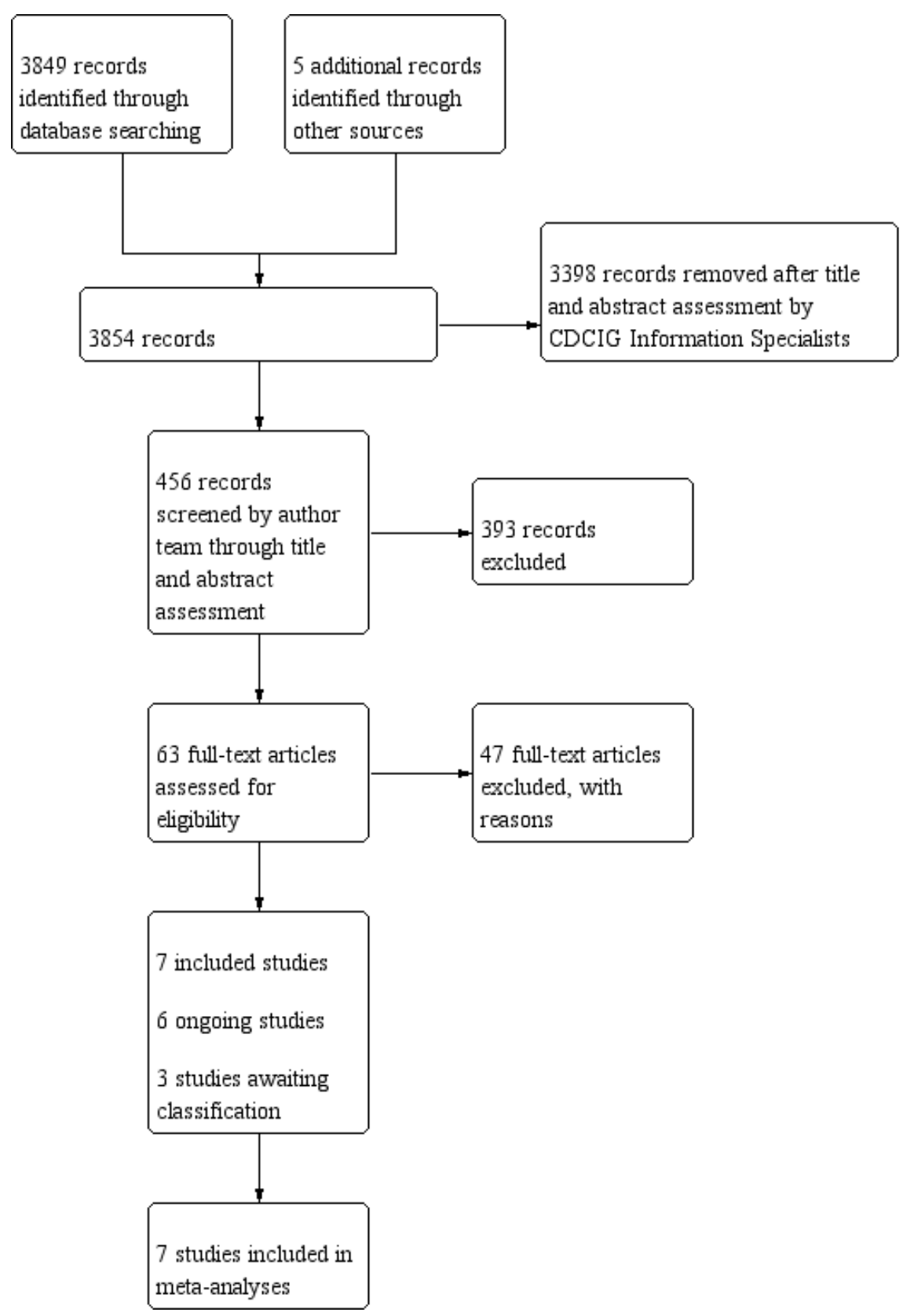

\section{Included studies}

See Characteristics of included studies.

Of the seven studies meeting the inclusion criteria (Alloni 2018; Cerasa 2014; Costa 2014; Folkerts 2018; Lawrence 2018; París 2011; Petrelli 2014), all studies except Costa 2014 contributed to the analysis of effects of cognitive training on global cognition. Five studies contributed to the analysis of effects of cognitive training on executive function (Alloni 2018; Cerasa 2014; Costa 2014; Lawrence 2018; París 2011). Five studies contributed to the analysis of effects on attention and verbal memory (Alloni 2018; Cerasa 2014; Lawrence 2018; París 2011; Petrelli 2014). Three studies contributed to analyses of visual processing ability (Cerasa 2014; Lawrence 2018; París 2011). Three studies contributed to the analysis of activities of daily living (Folkerts 2018; Lawrence 2018; París 2011), and five studies contributed to the analyses of effects of cognitive training on quality of life (Cerasa 2014; Folkerts 2018; Lawrence 2018; París 2011; Petrelli 2014).

\section{Design}

All seven studies were RCTs that evaluated the effects of a cognitive training intervention aimed at training one or more domains of cognitive function.

\section{Setting}

Alloni 2018, Cerasa 2014, and Costa 2014 were conducted in Italy and recruited outpatients in neurorehabilitation or academic units. Folkerts 2018 recruited residents of a PDD-specific long-term care 
unit in the Netherlands. The study by Lawrence 2018 was conducted in Western Australia and recruited outpatients. París 2011 was conducted in Spain and recruited outpatients from movement disorders clinics. Petrelli 2014 was conducted in Germany and recruited participants from a university hospital, an outpatient movement disorders clinic, and regional PD support groups.

\section{Participants}

Thirty-one participants were randomised in Alloni 2018; 20 in Cerasa 2014; 17 in Costa 2014; 12 in Folkerts 2018; 42 in Lawrence 2018; 33 in París 2011; and 70 in Petrelli 2014.

In the study by Alloni 2018, participants had a diagnosis of idiopathic PD (United Kingdom Parkinson's Disease Society Brain Bank (UKPDBB) criteria) (Hughes 1992), and scored $\leq 4$ on the Hoehn and Yahr scale (Hoehn 1967). All participants experienced single-domain (executive) or multiple-domain mild cognitive impairment with executive involvement (Litvan 2012). People with pre-existing cognitive impairment (e.g. aphasia, neglect), severe disturbances in consciousness, psychiatric or neurological conditions, or severe motor or sensory disorders were excluded. The mean Mini-Mental State Exam (MMSE) score of participants at baseline was 25.35 (SD = 2.59).

In Cerasa 2014, participants had a clinical diagnosis of PD (UKPDBB criteria) and predominant deficits in either attention and/or information processing speed, working memory and/or executive functioning (demonstrated in at least one of the following tests: Symbol Digit Modalities Test (SDMT), Trail Making Test (TMT A-B), Paced Auditory Serial Addition Test (PASAT), digit span forward and backward, and Stroop word-colour task (ST), but no additional impairment in other cognitive domains (i.e. language, verbal and spatial long-term memory) or motor complications (i.e. levodopa-induced dyskinesias) (Hughes 1992). People with dementia (Diagnostic and Statistical Manual of Mental Disorders, fourth edition (DSM-IV) criteria), psychiatric history (assessed by structured clinical interview of the DSM-IV), vascular brain lesions, brain tumour and/or marked brain atrophy were excluded. The mean MMSE score of participants at baseline was $29.05(\mathrm{SD}=1.00)$.

In Costa 2014, idiopathic PD was defined according to UKPDBB criteria (treated with levodopa or dopamine agonists, or both) (Hughes 1992); all participants had MCl according to Litvan 2012 criteria and performed 1.5 SD below the normative population in two tests of a neuropsychological screening battery (one of which investigated executive functioning). People with psychiatric disorders, neurological conditions other than PD, vascular brain lesions, metabolic disease, or people with significant changes in routine activities (measured by standardised tests) were excluded. The mean MMSE score of participants at baseline was 28.25 (SD = 1.60).

In the study by Folkerts 2018, all participants had PDD according to the MDS criteria (Emre 2007). Inclusion criteria were being a resident in the unit, having idiopathic PD (diagnosed by a neurologist/psychiatrist), experiencing cognitive dysfunction (MMSE score between 10 to 25), good language, vision, and hearing, and consent from a legal representative. People with a history of alcohol or drug abuse, a life-threatening illness, psychotic symptoms, or those who were bedridden were excluded. The mean MMSE score of participants at baseline was 17.83 (SD = 5.55).
In Lawrence 2018, participants were diagnosed with idiopathic PD (UKPDBB criteria) and $\mathrm{MCl}$ in accordance with the MDS PD-MCI level II diagnostic criteria (Hughes 1992; Litvan 2012), were on a stable response to antiparkinsonian medication, and cognitive deficits did not interfere with functional independence (Unified Parkinson's Disease Rating Scale (UPDRS-II) score less than 3). People with PDD, a recent history of brain surgery, migraine, or epilepsy were excluded. The mean MMSE score of participants at baseline was $25.66(\mathrm{SD}=2.08)$.

In the study by París 2011, participants were diagnosed with PD (UKPDBB criteria) (Hughes 1992), with disease severity of Hoehn and Yahr stages I to III and not receiving any other cognitive, psychological, or physical treatment (Hoehn 1967). People with significant cognitive impairment (MMSE < 23), belowaverage premorbid intelligence (vocabulary subtest, Wechsler Adult Intelligence Scale-III (WAIS-III) typical score < 40), on cholinesterase inhibitors, or having any change in their medication were excluded. People with major depression (Geriatric Depression Scale (GDS-15) > 10), severe sensory deficits, or a psychiatric/ neurological condition were excluded. Fifty per cent (14 of 28 participants) met Petersen 2005 and Artero 2006 criteria for $\mathrm{MCl}$ and demonstrated a decrement of more than 1.5 SDs on a cognitive test or subtest. The mean MMSE score of participants at baseline was $27.85(\mathrm{SD}=1.37)$.

In Petrelli 2014, participants had idiopathic PD (UKPDBB criteria) (Hughes 1992). People with suspected dementia (MMSE < 25), other neurological or psychiatric diseases, or impaired hearing or sight were excluded. Twenty per cent of the sample fulfilled criteria for PD-MCI (Litvan 2011). The mean MMSE score of participants at baseline was $27.90(\mathrm{SD}=1.93)$.

\section{Cognitive training interventions and control comparisons}

Alloni 2018 evaluated computerised cognitive training (CoRe Alloni 2015) consisting of patient-tailored exercises aimed primarily at stimulating executive function versus a control intervention incorporating motor rehabilitation combined with recreational activity. The cognitive training was individual sessions of 45 minutes 3 times a week over 4 weeks (12 sessions in total).

Cerasa 2014 investigated the effectiveness of individually tailored group computer-based attention-training (RehaCom Cerasa 2013) versus computerised motor therapy consisting of simple visuomotor co-ordination tasks. Cognitive training was 1-hour group sessions twice a week for 6 weeks ( 12 sessions in total).

Costa 2014 compared a cognitive training intervention aimed at practising shifting ability (prospective memory) versus simple language and respiratory exercises (Macdonald 2011). Cognitive training was delivered in 45-minute sessions, 3 times per week for 4 weeks ( 12 sessions in total).

Folkerts 2018 evaluated a modified version of the NEUROvitalis senseful programme, which targeted executive and visual spatial function versus treatment as usual, which incorporated a variety of non-pharmacological interventions such as sports, music, and arts open to all residents (Baller 2009; Middelstadt 2016). The intervention was delivered for 60 minutes twice weekly for 8 weeks (16 sessions in total).

Lawrence 2018 evaluated an interactive online computer-based cognitive training known as Smartbrain Pro (www.smartbrain.net) 
(Tárraga 2006), which aims to train several cognitive domains (attention, working memory, psychomotor speed, executive function, and visuo-spatial ability). The training was delivered in sessions of 45 minutes each, 3 times per week for 4 weeks (12 sessions in total). This was an RCT with six parallel intervention arms: standard cognitive training, tailored cognitive training, transcranial direct current stimulation (tDCS), standard cognitive training $+t D C S$, or tailored cognitive training $+t D C S$. We combined the standard cognitive training and the tailored cognitive training intervention groups and compared them to the no-intervention control group in the meta-analysis.

París 2011 evaluated the same Smartbrain Pro training, also in 45-minute sessions, 3 times per week for 4 weeks (12 sessions in total). In París 2011, participants completed additional homework exercises stimulating specific and non-specific cognitive areas. The comparator was group speech therapy.

Petrelli 2014 compared structured training using the same NEUROvitalis programme as Folkerts 2018, unstructured cognitive training using a programme called "Mentally fit", and a waiting-list control group. The interventions were delivered as group sessions of 90 minutes, twice a week for 6 weeks (12 sessions in total). We combined the structured and unstructured cognitive training groups and compared them with the waiting-list control group in the meta-analysis.

For further details see Characteristics of included studies.

\section{Adherence}

Folkerts 2018 reported the highest level of adherence (92.7\%) across all studies, followed by Alloni 2018 (90\%) and Cerasa 2014 (80\%). In both París 2011 and Petrelli 2014, at least 88\% of the sample completed over $75 \%$ of sessions. Costa 2014 and Lawrence 2018 did not provide details regarding adherence to the intervention.

\section{Outcomes}

All studies reported outcomes immediately after the intervention was finished, with two studies also reporting later follow-up: Alloni 2018 at 24 weeks and Lawrence 2018 at 12 weeks. End-of-treatment time points were: four weeks for Alloni 2018, Costa 2014, Lawrence 2018, and París 2011; six weeks for Cerasa 2014 and Petrelli 2014; and eight weeks for Folkerts 2018.

We classified cognitive measures used in each of the studies by considering which instrument contributed most to each outcome in line with the primary outcomes set for the review and the similarity of instruments used across studies. This task involved judgement, as many of the measures in the included studies can relate to several cognitive domains. We extracted change from baseline values for all analyses and outcomes due to imbalances at baseline and small sample sizes across all studies. Details of which outcome measures contributed to each of the analyses appear below.

\section{Primary outcome - Cognition}

\section{Global cognition}

Global cognition was measured by the MMSE, Folstein 1975, in five studies (Alloni 2018; Cerasa 2014; Lawrence 2018; París 2011; Petrelli 2014); scores on the MMSE range from 0 to 30 , with lower scores indicative of greater impairment in cognition.
Folkerts 2018 used the Consortium to Establish a Registry for Alzheimer's Disease (CERAD) (Welsh 1994), where higher scores indicate better performance. Three studies, Alloni 2018; París 2011; Petrelli 2014, additionally used the Montreal Cognitive Assessment (MoCA) (Nasreddine 2005), Addenbrooke's Cognitive Examination (ACE) (Mathuranath 2000), and the DemTect (Kalbe 2004), respectively, to measure global cognition. Lower scores indicate greater impairment in cognition in all instruments. Lawrence 2018 also measured cognition using the Parkinson's disease-cognitive rating scale (Pagonabarraga 2008); higher scores indicate better performance in this scale.

In our meta-analysis of effects of cognitive training on global cognition, we used the MMSE where possible to reduce heterogeneity and make results comparable to the wider literature on cognitive-based interventions and pharmacological trials. We used an alternative only if a study had not used the MMSE. For our meta-analysis on global cognition we included the following measures.

1. MMSE for Alloni 2018, Cerasa 2014, and Lawrence 2018 (combining the two treatment arms of standard and tailored cognitive training); París 2011 and Petrelli 2014 (combining the two treatment arms of structured and unstructured cognitive training).

2. CERAD for Folkerts 2018.

\section{Cognitive subdomains}

Alloni 2018 measured executive function using the Raven's Matrices 47 test (RM47) (Raven 1988); the Weigl's Colour-Form Sorting Test (WCFT) (Weigl 1941); the Frontal Assessment Battery (FAB) (Dubois 2000); and the F-A-S Test (Spreen 1977). Attention was measured using the Attentive Matrices (Spinnler 1987); Trail Making Tests A and B (Reitan 1985); and the Stroop task (Stroop 1935). Verbal memory was measured with the verbal and digit span tests (Wechsler 2001); Rey's 15-words test (Rey-15) (Lezak 1983); and the Wechsler Memory Scale (WMS) Logical Memory test measuring immediate and delayed recall (Wechsler 1945). Spatial memory was assessed using the Corsi Block-Tapping Test and the Rey-Osterrieth Complex Figure Test (Corsi 1972; Rey 1941). Visuo-spatial ability was measured using the Rey-Osterrieth Complex Figure Copy test (Meyers 1995).

Cerasa 2014 measured executive function using the Controlled Oral Word Association Test (COWAT) (Benton 1983). Attention and working memory were measured by the Symbol Digit Modalities Test (SDMT) (Smith 2007), the Paced Auditory Serial Addition Test (PASAT) (Gronwall 1974), the digit span test (Wechsler 2001), the Trail Making Test A and B and B-A (Reitan 1985); and the Stroop task (Stroop 1935). Verbal memory was assessed using the Selective Reminding Test (Buschke 1973), spatial memory with the ReyOsterrieth Complex Figure Test (Rey 1941), and visuo-spatial ability with the Judgment of Line Orientation (JLO) test (Benton 1994).

Costa 2014 measured executive function using tasks of phonemic, semantic and alternating (phonemic/semantic) fluency and attention with the Trail Making Test A and B (Downes 1993; Reitan 1985).

Lawrence 2018 assessed executive function with the Stockings of Cambridge (SOC) test, Robbins 1998, and the Controlled Oral Word Association Test (COWAT), Benton 1983. Attention was measured by 
the Letter Number Sequencing test, Wechsler 1945, and the Stroop task, Stroop 1935. Verbal memory was assessed by the Hopkins Verbal Learning Test-Revised, Brandt 2001, and the Paragraph Recall Test (PRT), Wilson 1989. Language was assessed with the Boston Naming Test (BNT), Kaplan 1983, and the Similarities Test, Wechsler 1945. Visuo-spatial ability was measured by the JLO test, Benton 1994, and the Hooper Visual Organization Test (HVOT), Hooper 1983.

París 2011 measured executive function using the Tower of London (TOL), Culberston 2001, and the F-A-S Test, Spreen 1977. Attention and working memory were measured with the Wechsler Adult Intelligence Scale (WAIS-III) Digit Span test (Wechsler 2001), the SDMT (Smith 2007), Trail Making Tests A and B (Reitan 1985), and the Stroop task (Stroop 1935). Verbal memory was assessed by the California Verbal Learning Test Revised, Delis 2000, and the WMS Logical Memory test, Wechsler 1945. Spatial memory was assessed with the Rey-Osterrieth Complex Figure Copy test, Meyers 1995, and visuo-spatial ability with the JLO test, Benton 1994.

Petrelli 2014 measured executive function with the digit span reverse test of the DemTect and verbal and semantic fluency with fluency tasks of the same instrument (Kalbe 2004). The Brief test of attention was used to measure attention (Schretlen 1996). Verbal short- and long-term memory and visual long-term memory were assessed by the DemTect (Kalbe 2004). Visuo-spatial ability was measured with the Rey-Osterrieth Complex Figure Copy test (Meyers 1995).

We thoroughly reviewed all tests to ensure there was as much overlap as possible across domains and instruments used.

For analyses addressing effects of cognitive training on executive function, we selected the following tests: Trail Making Test B for Alloni 2018, Cerasa 2014, Costa 2014, and París 2011; and Stockings of Cambridge (SOC) for Lawrence 2018 (combining the two treatment groups).

For analyses of effects on attention, we used the following tests: the Stroop task for Alloni 2018, Cerasa 2014, and Lawrence 2018 (combining the two treatment groups) and París 2011; and the Brief test of attention for Petrelli 2014 (combining the two treatment groups).

For analyses of effects on verbal memory, we used the following tests: the WMS Logical Memory test (Immediate Recall) for Alloni 2018 and París 2011; the Selective Reminding Test-long-term storage for Cerasa 2014; the Hopkins Verbal Learning Test-Revised Immediate Recall subtest for Lawrence 2018 (combining the two treatment groups); and the verbal memory test of short-term memory of the DemTect for Petrelli 2014 (combining the two treatment groups).

For analyses of effects of cognitive training on visual processing, we included studies that used the JLO test, which were Cerasa 2014, Lawrence 2018 (combining the two treatment groups), and París 2011.

\section{Secondary outcomes}

\section{Activities of daily living}

Folkerts 2018 measured ADLs using the Barthel Index (Barthel 1965), where higher scores are indicative of greater independence in activities of daily living. Lawrence 2018 used the UPDRS Part II
(Goetz 2008), in which higher scores are indicative of more severe impairment. París 2011 evaluated cognitive difficulties in ADLs using the Cognitive Difficulties Scale (CDS) (McNair 1983), where higher total summed scores indicate worse cognitive complaints associated with ADLs. We combined these three studies for our analyses on effects of cognitive training on ADLs (Folkerts 2018; Lawrence 2018 (combining the two treatment groups); París 2011).

\section{Quality of life}

Four studies, Cerasa 2014; Lawrence 2018; París 2011; Petrelli 2014, used the Parkinson's Disease Questionnaire (PDQ-39) to measure quality of life (Jenkinson 1997); lower scores in this scale indicate higher quality of life. Folkerts 2018 used the QUALIDEM scale (Ettema 2007), in which higher scores are indicative of higher quality of life. We pooled data from all five of these studies to investigate the effects of cognitive training on quality of life (Cerasa 2014; Folkerts 2018; Lawrence 2018 (combining the two treatment groups); París 2011; Petrelli 2014 (combining the two treatment groups)).

\section{Depression}

Cerasa 2014 and Petrelli 2014 used the Beck Depression Inventory II to measure depressive symptoms (Beck 1996); París 2011 used the Geriatric Depression Scale (GDS) (Sheikh 1986); Folkerts 2018 used the GDS and the Cornell Scale for Depression in Dementia (CSDD) Alexopoulos 1988. Higher scores indicate more symptoms in all measures.

\section{Other outcomes}

Cerasa 2014 measured anxiety symptoms with the State-Trait Anxiety Inventory (STAI) Spielberger 1983. Folkerts 2018 measured health-related quality of life with the EQ-5D-5L EuroQoL Group 1990, and neuropsychiatric symptoms with the Neuropsychiatric Inventory (NPI) Cummings 1997. None of the studies included outcome measures for carers.

For further details see Characteristics of included studies.

\section{Ongoing trials}

We identified six ongoing trials, which on the basis of the information available meet the inclusion criteria for this review. These are described in the Characteristics of ongoing studies table.

\section{Studies awaiting classification}

We found three studies that are awaiting classification. These are all ongoing trials, but it is unclear whether or not they will meet our review inclusion criteria. For two trials, we await further information regarding the inclusion criteria of participants (whether participants meet criteria for PD-MCI). In the third trial, it is currently uncertain whether the intervention is best classified as cognitive training or cognitive rehabilitation (or possibly a combination of both of these approaches) due to limited information provided. These three trials are described in the Characteristics of studies awaiting classification table.

\section{Excluded studies}

We excluded a total of 47 studies (see Characteristics of excluded studies). Further information regarding these studies appears below. 
RCTs of cognitive training or other interventions in PD-MCI with no control group

Two studies evaluated cognitive training in people with PD-MCI in which there was no control comparison group (Reuter 2012; Biundo 2015). Reuter 2012 tested the effects of cognitive training (targeting attention, executive function, and memory training) versus cognitive and transfer training versus cognitive, transfer, and psychomotor training. The study by Biundo 2015 evaluated cognitive training (RehaCom; attention, concentration, planning, and memory exercises) as a stand-alone intervention versus cognitive training with non-invasive brain stimulation. Mahmoud 2018 evaluated cognitive remediation therapy versus motor imagery training for people with PD and cognitive dysfunction diagnosed by a cognitive assessment on RehaCom; in this RCT there was no control group. Vlagsma 2020 examined the effects of computerised cognitive training for attention (CogniPlus) with a cognitive rehabilitation intervention as the comparison group in people with PD and executive dysfunction. Maggio 2018 tested the effects of virtual reality cognitive rehabilitation versus standard cognitive training in people with PD and mild to moderate cognitive impairment (MMSE from 11 to 26). An onoing RCT NCT03836963 is testing effects of cognitive and memory strategy training in veterans with $\mathrm{PD}-\mathrm{MCl}$. Active comparators in this three-arm RCT are cognitive and memory training as stand-alone interventions.

\section{Other cognition-based interventions in people with PDD and PD- $\mathrm{MCl}$}

Quayhagen 2000 evaluated a carer-led cognitive stimulation intervention (incorporating memory/problem solving and fluency activities) in people with AD, cardiovascular dementia, or PDD. In this study no separate data for PDD were provided, and diagnosis of PDD was not made using clinical criteria. Hindle 2016 evaluated cognitive rehabilitation in people with PDD, and Farzana 2015 the effects of a home-based cognitive stimulation intervention in people with PD and mild to moderate cognitive impairment, in which diagnosis of PDD and PD-MCl was not reported. This study employed a pre-post design. McCormick 2018 tested the feasibility and acceptability of individual cognitive stimulation therapy for people with PD-related dementias. We found one ongoing RCT NCT03335150 of cognitive rehabilitation (CogSMART-PD) for people with PD-MCl versus a support group control intervention.

\section{Non-RCTs of cognitive training or other cognition-based interventions in people with PD-MCI}

Naismith 2013 evaluated the effects of computerised cognitive training (based on individually tailored cognitive exercises) alongside education versus a waiting-list control condition in a controlled trial design (non randomised) in a mixed sample of people with $\mathrm{PD}$, of which some had no cognitive impairment and some had PD-MCl. Stiver 2015 tested the efficacy of a mobile gaming engine aimed at reducing cognitive interference via a prepost design. Kim 2016 used a pre-post design to test the effects of cognitive training (PD-CORE) in people with PD and executive dysfunction.

\section{Cognitive training in people with PD without dementia or MCI}

We identified nine RCTs of cognitive training in people with PD where people with dementia or $\mathrm{MCl}$, or both, were excluded.
Zimmermann 2014 tested the effects of computer-based cognitive training (versus a non-cognition-specific computer sports game; Nintendo Wii) in PD without cognitive impairment; Sammer 2006 examined the effects of working memory training targeting executive function (versus a control intervention) in people with PD and no cognitive impairment. Peña 2014 tested the effects of integrative structured cognitive training (REHACOP) (targeting attention, memory, processing speed, language, and executive function) versus occupational group activities in PD excluding people with dementia. One ongoing RCT NCT01469741 investigates effects of prospective memory training in PD but no dementia.

Edwards 2013 tested the effects of a self-administered speed of information processing training excluding people with dementia, and Strouwen 2017 examined the effects of integrated versus consecutive dual task practice cognitive training aimed at increasing gait performance (in this study people with MMSE scores $\leq 24$ were excluded). Pompeu 2012 evaluated the effects of a Wiibased motor and cognitive training intervention (training attention and working memory) versus balance exercise therapy, in which people with dementia were excluded (MMSE $\geq 23$ ). Piemonte 2016 tested a declarative memory training intervention aimed at improving gait and activities of daily living in people with PD with no cognitive impairment. We found one ongoing study NCT02922530 testing effectiveness of a mobile cognitive training intervention for depression and quality of life in people with PD without cognitive impairment. Valdés 2017 examined the effects of information processing training versus a delayed control group in people with PD without dementia or $\mathrm{MCI}(\mathrm{MMSE} \geq 24)$. Fernandezdel-Olmo 2018 examined the effects of cognitive training versus cognitive training with concurrent physical exercise in people with PD without cognitive impairment. We further excluded two ongoing studies; NCT03680170 and NCT04048122; which evaluate effects of web-based working memory training versus low-dose shortterm memory training in PD without cognitive impairment and the feasibility of cognitive rehabilitation (MC4PD strategy training) versus standard care for people with $P D$ and subjective cognitive decline (MoCA $<21$; primary outcome goal attainment).

\section{Multicomponent interventions or cognitive interventions targeting other domains in people with PD without dementia or MCI}

Peters 2012 is an ongoing study evaluating a multidisciplinary intervention incorporating exercise rehabilitation and cognitive and speech activities versus standard exercise in people with PD (excluding people with cognitive impairment). Monticone 2015 tested the effects of a multidisciplinary intervention incorporating task-oriented activities, cognitive-behavioural therapy, and occupational therapy (people with a MMSE $<24$ were excluded). The study by Pompeu 2016 tests the effects of a physiotherapy guideline in people with $\mathrm{PD}$ and no dementia or $\mathrm{MCl}$ versus Microsoft Kinect games training (Kinect-Adventures-based training; KABT) on postural control, cognition, and quality of life. Walton 2016 evaluates the effects of a cognitive training intervention targeting executive function, processing speed, and attention, where freezing of gait is the primary outcome; cognition is not measured in this study. In an ongoing RCT ACTRN12617000634370, a cognitive-plus-exercise-enrichment intervention is compared to standard care in people with PD and no cognitive impairment. Fellman 2018 examined the effects of cognitive training on working memory versus quiz training in people with PD and no cognitive impairment; in this RCT people with dementia were excluded. 
Goedeken 2018 is testing the effects of encoding strategy training versus verbal rehearsal (control group) for people with PD; in this RCT people with PDD are excluded. An ongoing trial NCT01156714 investigates the effects of exercise training versus computerised memory training versus combined exercise and motor training versus a comparison control group in people with PD and no cognitive impairment. The study by Motlagh 2017 compares cognitive training for freezing of gait to a control comparison group in people with PD and no cognitive impairment.

\section{Non-RCTs of cognitive training or other interventions targeting cognition in people with PD without dementia or $\mathrm{MCl}$}

Mirelman 2011 examined the feasibility of virtual reality training incorporating cognitive components in people with PD and no dementia; Disbrow 2012 tested the effects of computerised cognitive and motor training aimed at improving motor-related executive function in PD without dementia, whereas Canning 2008 examined multiple task walking training incorporating cognitive activities. Both Atias 2015 and Adamski 2016 used pre-post methodology to assess the feasibility of cognitive training in people with PD without dementia or MCl. Nombela 2011 tested the feasibility of Sudoku-based cognitive training; this study neither commented on the cognitive level of the participants nor reported whether people with cognitive impairment were excluded.
We found three studies using pre-post test methodology to evaluate the feasibility of cognitive training in people with PD and subjective cognitive complaints. Mohlman 2011 tested the feasibility of attention process training in PD and subjective cognitive complaints of working memory; Sinforiani 2004 tested the effects of cognitive training targeting multiple domains (attention, abstract reasoning, visuo-spatial abilities, and motor training) in people with PD and mild cognitive deficits (defined by neuropsychological evaluation) using prepost methodology; people with severe cognitive impairment and dementia were excluded. An ongoing study NCT02826785 used prepost methodology to examine the effects of cognitive training in PD; participants reported at least one problem with their daily cognitive performance (but had no dementia). Both Díez-Cirarda 2017 and Fearon 2017 employed a non-RCT design: the feasibility of cognitive training was tested in Díez-Cirarda 2017, and of a virtual reality-based intervention combining motor and cognitive training in Fearon 2017. Both studies included people with PD and no cognitive impairment.

\section{Risk of bias in included studies}

Two review authors independently assessed risk of bias for all seven included studies (see Characteristics of included studies). None of the included studies met criteria for low risk of bias in all domains. See Figure 2 and Figure 3.

Figure 2. Risk of bias graph: review authors' judgements about each risk of bias item presented as percentages across all included studies.

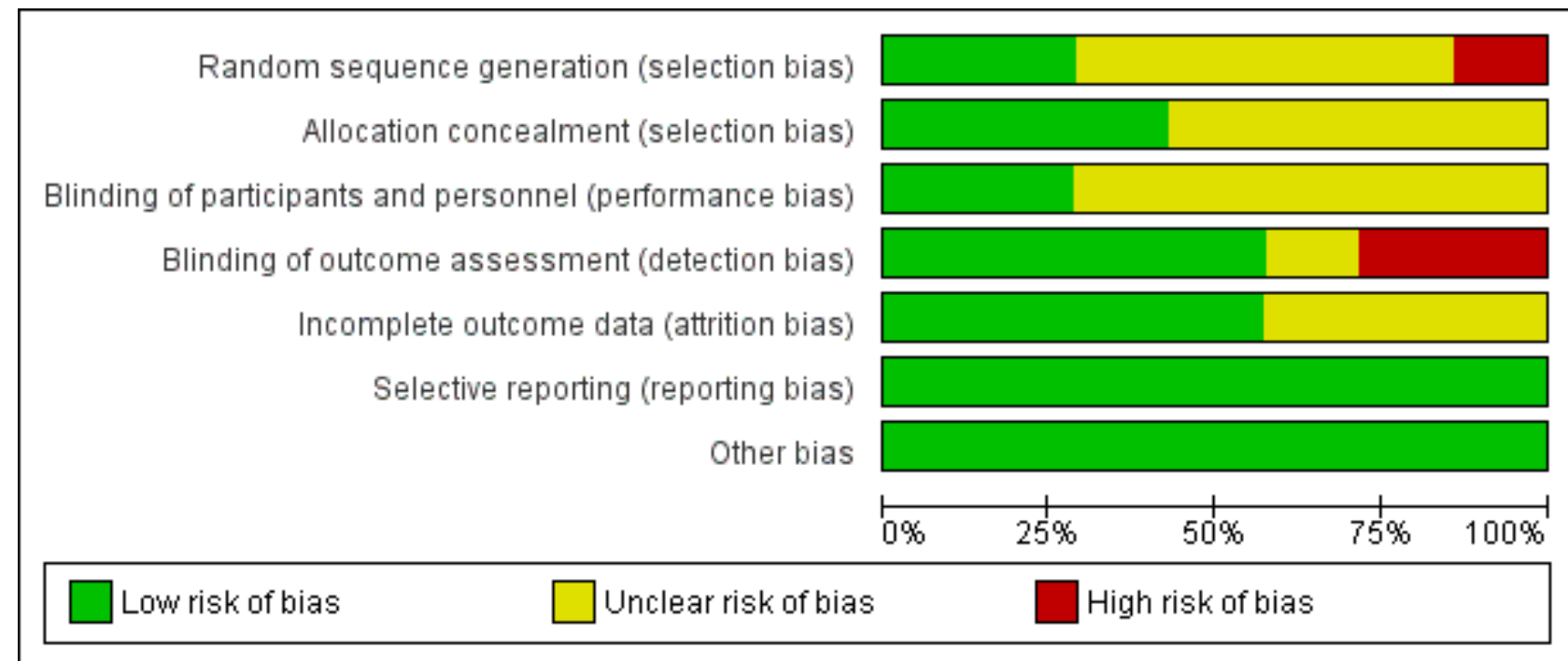


Figure 3. Risk of bias summary: review authors' judgements about each risk of bias item for each included study.

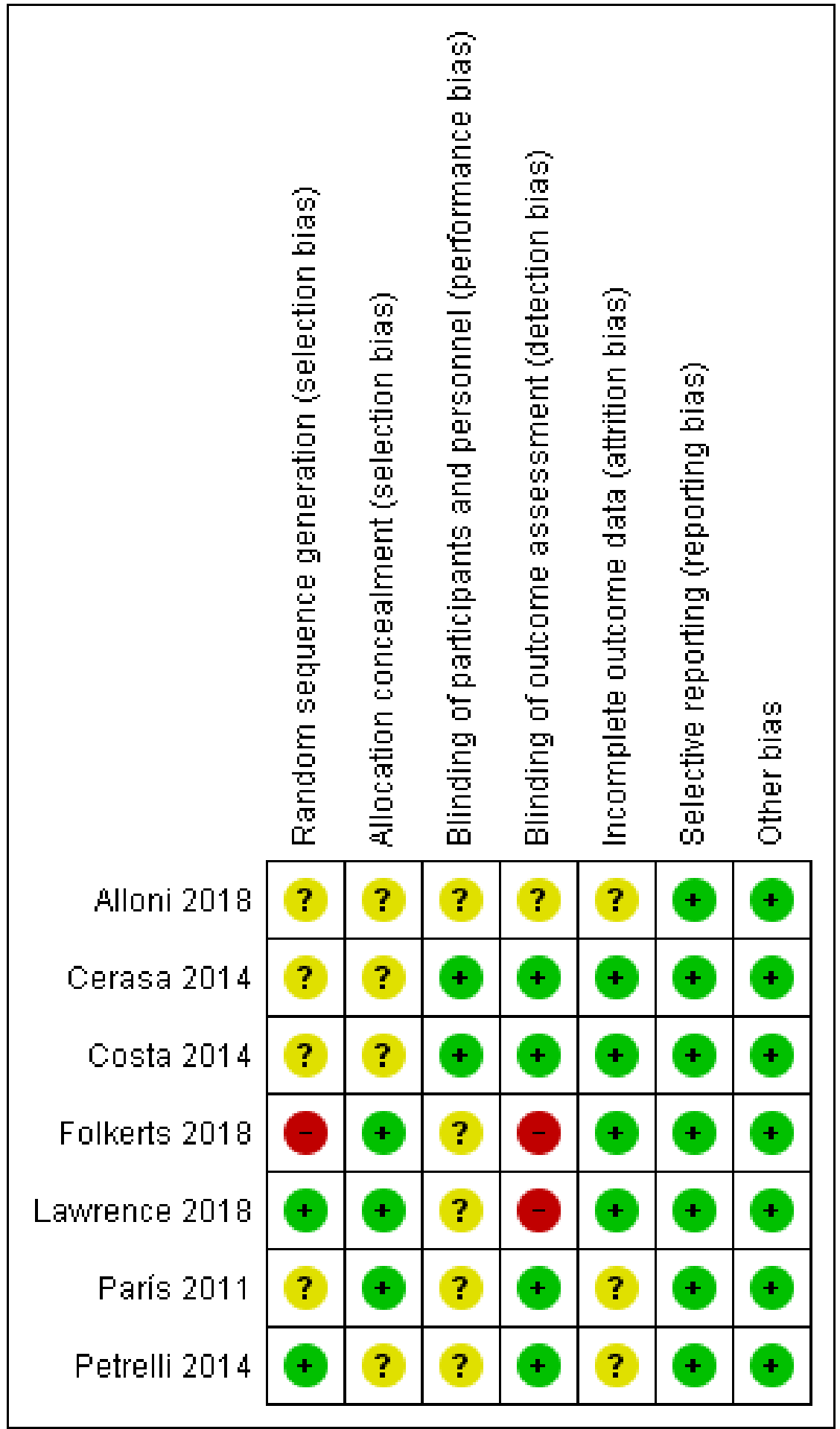

\section{Allocation}

For the domain of random sequence generation, we considered two studies to be at low risk (Lawrence 2018; Petrelli 2014), one study at high risk (Folkerts 2018), and four studies at unclear risk of bias due to insufficient information on how the random assignment was performed (Alloni 2018; Cerasa 2014; Costa 2014; París 2011). For the allocation concealment domain, we judged three studies to be at low risk, Folkerts 2018; Lawrence 2018; París 2011, and four studies to be at unclear risk of bias, again due to insufficient detail in the published reports (Alloni 2018; Cerasa 2014; Costa 2014; Petrelli 2014). 


\section{Blinding}

We judged two studies to be at low risk of performance bias; in these studies both the intervention (cognitive training) and control (sham cognitive intervention) groups were not informed about their group assignment or the rationale behind their training and could therefore be considered blind to the intervention (Cerasa 2014; Costa 2014). We considered the risk of bias for the other five studies to be unclear for this domain. We judged four studies to be at low risk, Cerasa 2014; Costa 2014; París 2011; Petrelli 2014, one study to be at unclear risk, Alloni 2018, and the remaining two studies to be at high risk of detection bias, Folkerts 2018; Lawrence 2018 , because they reported that not all assessors were blind to treatment allocation or that it was not possible to blind assessors.

\section{Incomplete outcome data}

We judged three of the seven included studies to be at unclear risk of attrition bias. One of these studies reported the number of participants who did not complete the study (Alloni 2018), but not the reasons for withdrawal. Two studies reported excluding participants who completed fewer than $75 \%$ of sessions from the analyses (París 2011 Petrelli 2014). We assessed the remaining four studies as at low risk of attrition bias.

\section{Selective reporting}

We found no evidence of selective reporting in any study, therefore we classified all studies as being at low risk of bias for this domain.

\section{Other potential sources of bias}

We did not identify any other sources of bias in the included studies.

\section{Effects of interventions}

See: Summary of findings for the main comparison Cognitive training compared to control intervention for cognition in PDD and PD-MCl

Positive results favour cognitive training for all outcomes. A summary of findings and assessment of the certainty of the evidence is presented in the Summary of findings for the main comparison.

\section{Primary outcomes}

\section{Global cognition}

The meta-analysis on effects of cognitive training on global cognition at the end of the intervention period included six studies (Alloni 2018; Cerasa 2014; Folkerts 2018; Lawrence 2018; París 2011; Petrelli 2014) with 178 participants (Analysis 1.1). We found no clear evidence of a difference between cognitive training and control interventions. The result favoured cognitive training, but did not reach statistical significance (standardised mean difference (SMD) $0.28,95 \%$ confidence interval $(\mathrm{Cl})-0.03$ to $0.59 ; \mathrm{I}^{2}=0 \%$; lowcertainty evidence; Figure 4).

Figure 4. Forest plot of comparison: 1 Cognitive training versus control group, outcome: $1.1 \mathrm{Global}$ cognition posttreatment.

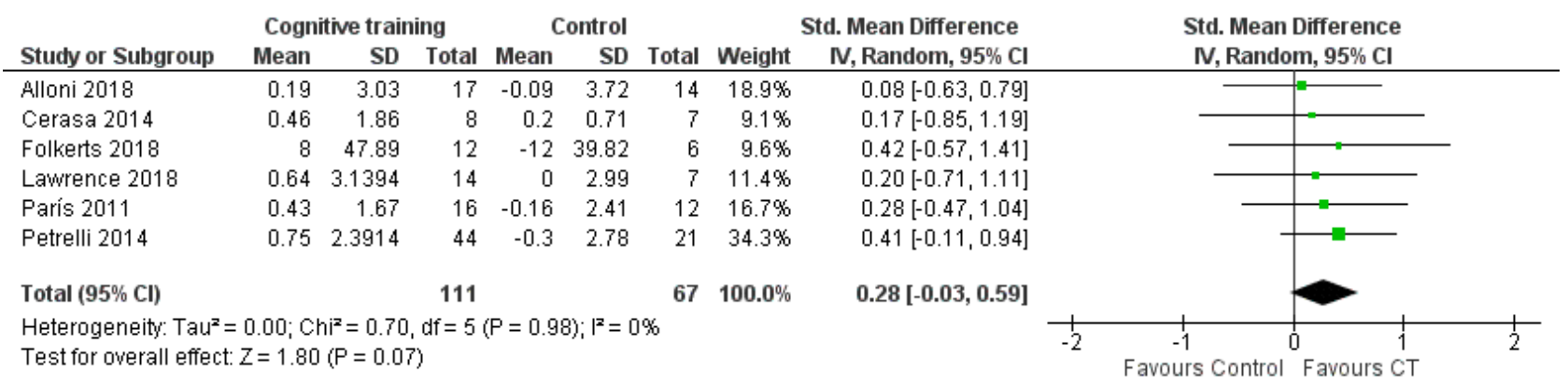

\section{Executive function}

We pooled five studies (Alloni 2018; Cerasa 2014; Costa 2014; Lawrence 2018; París 2011) to examine the effects of cognitive training on executive function measured immediately after the end of the intervention (Analysis 1.2). We found no evidence of a difference between cognitive training and control interventions (SMD $0.10,95 \% \mathrm{Cl}-0.28$ to $0.48 ; \mathrm{I}^{2}=1 \% ; 112$ participants; lowcertainty evidence; Figure 5).

\section{Figure 5. Forest plot of comparison: 1 Cognitive training versus control group, outcome: 1.2 Executive function} post-treatment.

\begin{tabular}{|c|c|c|c|c|c|c|c|c|c|c|c|}
\hline \multirow[b]{2}{*}{ Study or Subgroup } & \multicolumn{3}{|c|}{ Cognitive training } & \multicolumn{3}{|c|}{ Control } & \multicolumn{2}{|c|}{ Std. Mean Difference } & \multirow{2}{*}{\multicolumn{2}{|c|}{$\begin{array}{l}\text { Std. Mean Difference } \\
\text { N, Random, } 95 \% \mathrm{Cl}\end{array}$}} & \\
\hline & Mean & SD & Total & Mean & SD & Total & Weight & IV, Random, 95\% Cl & & & \\
\hline Alloni 2018 & 39.38 & 114.49 & 17 & 2.44 & 126 & 14 & $28.5 \%$ & $0.30[-0.41,1.01]$ & & & \\
\hline Cerasa 2014 & 10.72 & 81.91 & 8 & 26 & 69.6 & 7 & $14.0 \%$ & $-0.19[-1.21,0.83]$ & & & \\
\hline Costa 2014 & 71.9 & 81.92 & 9 & 20.1 & 93.13 & 8 & $15.2 \%$ & $0.56[-0.41,1.54]$ & & & \\
\hline Lawrence 2018 & -0.81 & 2.8666 & 14 & 1.28 & 3.63 & 7 & $16.7 \%$ & $-0.64[-1.57,0.29]$ & & & \\
\hline París 2011 & 26.75 & 117.1 & 16 & -11.9 & 197.06 & 12 & $25.6 \%$ & $0.24[-0.51,0.99]$ & & & \\
\hline Total $(95 \% \mathrm{Cl})$ & & & 64 & & & 48 & $100.0 \%$ & $0.10[-0.28,0.48]$ & & & \\
\hline \multicolumn{9}{|c|}{$\begin{array}{l}\text { Heterogeneity: } \operatorname{Tau}^{2}=0.00 ; \mathrm{Chi}^{2}=4.04, \mathrm{df}=4(\mathrm{P}=0.40) ; \mathrm{I}^{2}=1 \% \\
\text { Test for overall effect: } Z=0.51(P=0.61)\end{array}$} & -2 & $\begin{array}{ccc}-1 & 0 & 1 \\
\text { urs Control } & \text { Favours } \mathrm{C}\end{array}$ & $\frac{1}{2}$ \\
\hline
\end{tabular}




\section{Attention}

Pooling data from five studies (Alloni 2018; Cerasa 2014; Lawrence 2018; París 2011; Petrelli 2014) showed that cognitive training was superior to control in effects on attention at the end of treatment, although the result was imprecise and compatible with a large or with very little effect (SMD $0.36,95 \% \mathrm{Cl} 0.03$ to $0.68 ; I^{2}=0 \%$;
160 participants; low-certainty evidence; Analysis 1.3; Figure 6). Imprecision was increased in a sensitivity analysis excluding Petrelli 2014, where fewer than 50\% of participants had PD-MCl, and the result was no longer statistically significant (SMD $0.41,95 \% \mathrm{Cl}-0.01$ to $0.83 ; \mathrm{I}^{2}=0 \%$; 4 studies; 95 participants; low-certainty evidence; Analysis 2.1).

\section{Figure 6. Forest plot of comparison: 1 Cognitive training versus control group, outcome: 1.3 Attention post-} treatment.

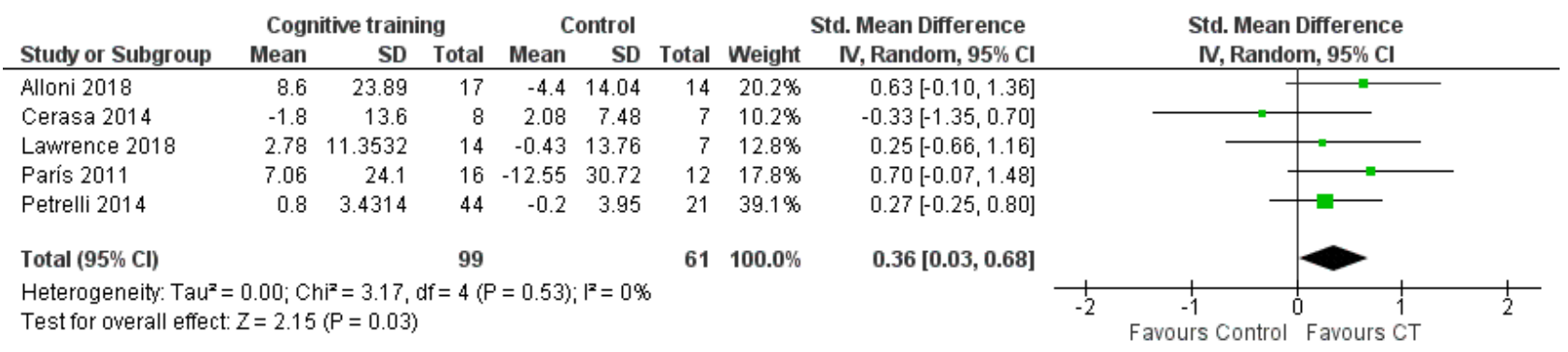

\section{Verbal memory}

Our analysis of effects on verbal memory showed that cognitive training was superior to control at the end of treatment, although this result was also imprecise and compatible with large or very small effects (SMD 0.37, $95 \% \mathrm{Cl} 0.04$ to $0.69 ; 1^{2}=0 \%$; five studies
(Alloni 2018; Cerasa 2014; Lawrence 2018; París 2011; Petrelli 2014); 160 participants; low-certainty evidence; Analysis 1.4; Figure 7). In the sensitivity analysis excluding Petrelli 2014, there was no clear evidence of any effect (estimate smaller and more imprecise) (SMD $0.25,95 \% \mathrm{Cl}-0.16$ to $0.66 ; \mathrm{I}^{2}=0 \%$; 4 studies; 95 participants; lowcertainty evidence; Analysis 2.2).

Figure 7. Forest plot of comparison: 1 Cognitive training versus control group, outcome: 1.4 Verbal memory posttreatment.

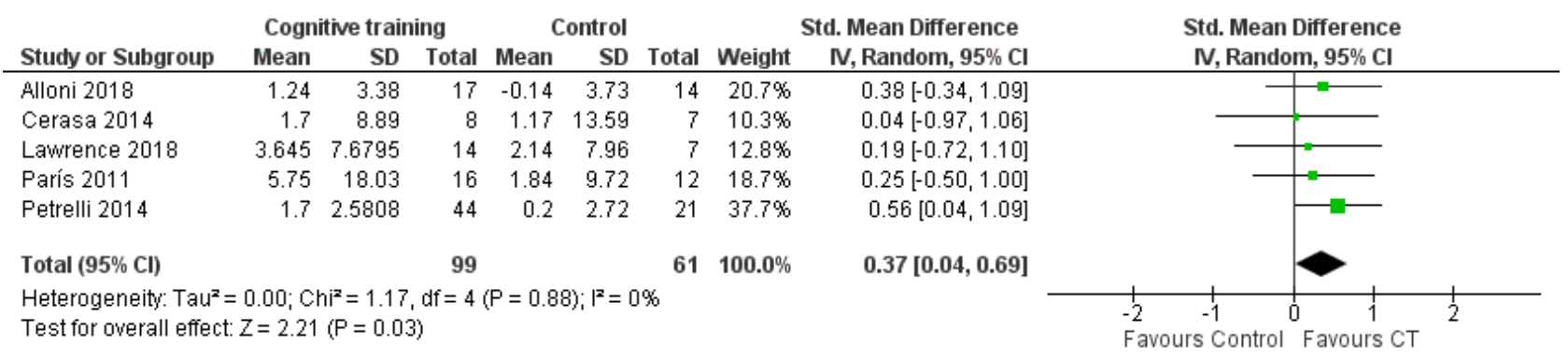

\section{Visual processing}

We found no evidence of an effect of cognitive training on visual processing ability at end of treatment (SMD $0.30,95 \% \mathrm{Cl}-0.21$ to
$0.81 ;\left.\right|^{2}=0 \%$; three studies (Cerasa 2014; Lawrence 2018; París 2011); 64 participants; low-certainty evidence; Analysis 1.5; Figure 8).

Figure 8. Forest plot of comparison: 1 Cognitive training versus control group, outcome: 1.5 Visual processing posttreatment.

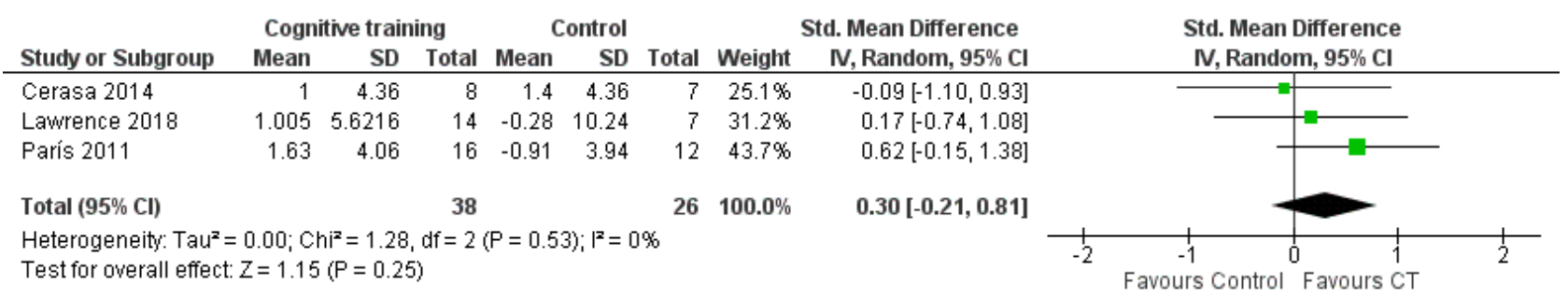




\section{Secondary outcomes}

\section{Activities of daily living}

We found no evidence of an effect of cognitive training on ADLs at the end of the intervention period (SMD $0.03,95 \% \mathrm{Cl}-0.47$ to 0.53 ;
$I^{2}=0 \%$; three studies (Folkerts 2018; Lawrence 2018; París 2011); 67 participants; low-certainty evidence; Analysis 1.6; Figure 9).

Figure 9. Forest plot of comparison: 1 Cognitive training versus control group, outcome: 1.6 Activities of daily living post-treatment.

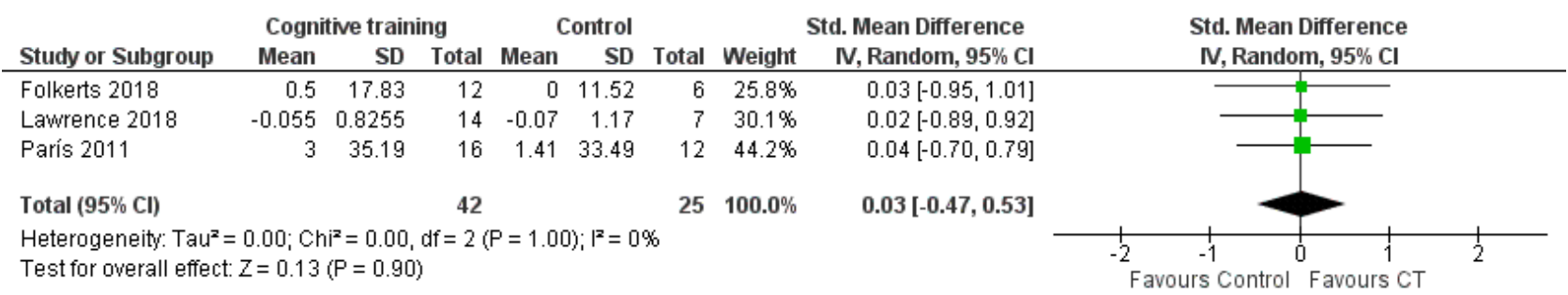

\section{Quality of life}

We found no evidence of an effect of cognitive training on quality of life immediately after the end of sessions (SMD $-0.01,95 \% \mathrm{Cl}$
-0.35 to $0.33 ; I^{2}=0 \%$; five studies (Cerasa 2014; Folkerts 2018; Lawrence 2018; París 2011; Petrelli 2014) 147 participants; lowcertainty evidence; Analysis 1.7; Figure 10).

Figure 10. Forest plot of comparison: 1 Cognitive training versus control group, outcome: 1.7 Quality of life posttreatment.

\begin{tabular}{|c|c|c|c|c|c|c|c|c|c|}
\hline \multirow[b]{2}{*}{ Study or Subgroup } & \multicolumn{3}{|c|}{ Cognitive training } & \multicolumn{3}{|c|}{ Control } & \multicolumn{2}{|r|}{ Std. Mean Difference } & \multirow{2}{*}{$\begin{array}{l}\text { Std. Mean Difference } \\
\text { N, Random, } 95 \% \mathrm{Cl}\end{array}$} \\
\hline & Mean & SD & Total & Mean & SD & Total & Weight & IV, Random, 95\% Cl & \\
\hline Cerasa 2014 & 2.4 & 25.74 & 8 & -4.5 & 33.05 & 7 & $11.1 \%$ & $0.22[-0.80,1.24]$ & \\
\hline Folkerts 2018 & 0.47 & 13.25 & 12 & -1.64 & 7.22 & 6 & $12.0 \%$ & $0.17[-0.81,1.15]$ & \\
\hline Lawrence 2018 & 3.42 & 11.744 & 14 & 0.26 & 20.82 & 7 & $13.9 \%$ & $0.20[-0.71,1.11]$ & \\
\hline París 2011 & -2.31 & 34.21 & 16 & 8.75 & 29.16 & 12 & $20.3 \%$ & $-0.33[-1.09,0.42]$ & \\
\hline Petrelli 2014 & 1.05 & 15.6487 & 44 & 1.6 & 15.56 & 21 & $42.7 \%$ & $-0.03[-0.55,0.49]$ & \\
\hline Total $(95 \% \mathrm{Cl})$ & & & 94 & & & 53 & $100.0 \%$ & $-0.01[-0.35,0.33]$ & \\
\hline \multicolumn{9}{|c|}{$\begin{array}{l}\text { Heterogeneity: } \operatorname{Tau}^{2}=0.00 ; \mathrm{Chi}^{2}=1.25, \mathrm{df}=4(\mathrm{P}=0.87) ; \mathrm{I}^{2}=0 \% \\
\text { Test for overall effect: } Z=0.06(P=0.96)\end{array}$} & $\begin{array}{ccc}-1 & 1 & 1 \\
-0.5 & 0 & 0.5 \\
\text { ours Control } & \text { Favours CT }\end{array}$ \\
\hline
\end{tabular}

\section{Adverse events}

Folkerts 2018 reported no adverse events. The remaining studies did not provide any information about adverse events (Alloni 2018; Cerasa 2014; Costa 2014; Lawrence 2018; París 2011; Petrelli 2014).

\section{Analyses on effects of cognitive training at longer-term follow-} up (12 to 24 weeks)

\section{Global cognition}

The meta-analysis on effects of cognitive training on global cognition at longer-term follow-up (12 to 24 weeks) included two studies (Alloni 2018; 24 weeks; Lawrence 2018; 12 weeks) with 41 participants. We found no evidence of a difference between groups (mean difference $0.28,95 \% \mathrm{Cl}-1.73$ to $2.28 ; \mathrm{I}^{2}=0 \%$; low-certainty evidence; Analysis 1.8).

\section{Executive function}

We found no evidence of an effect of cognitive training on executive function at longer-term follow-up (SMD $-0.22,95 \% \mathrm{Cl}-0.85$ to 0.41 ; $1^{2}=0 \%$; two studies (Alloni 2018; 24 weeks; Lawrence 2018; 12 weeks); 41 participants; low-certainty evidence; Analysis 1.9).

\section{Attention}

We found no evidence of an effect of cognitive training on attention at longer-term follow-up (SMD $0.21,95 \% \mathrm{Cl}-0.59$ to $1.01 ; I^{2}=36 \%$; two studies (Alloni 2018; 24 weeks; Lawrence 2018; 12 weeks) 41 participants; low-certainty evidence; Analysis 1.10).

\section{Verbal memory}

We found no evidence of an effect of cognitive training on verbal memory at longer-term follow-up (SMD $0.15,95 \% \mathrm{Cl}-0.47$ to $0.78 ; \mathrm{I}^{2}$ = 0\%; two studies (Alloni 2018; 24 weeks; Lawrence 2018; 12 weeks); 41 participants; low-certainty evidence; Analysis 1.11).

\section{DISCUSSION}

\section{Summary of main results}

The aim of this review was to evaluate the effectiveness of cognitive training interventions for people with PDD and PD-MCl and to report on the quality of the evidence. Our results do not support a beneficial effect of cognitive training on general cognition shortly after the intervention has ended. Although cognitive training was associated with better scores on attention and verbal memory, the differences between the intervention and control groups were not robust to the exclusion of a study where only $20 \%$ of the 
sample had PD-MCl. We found no evidence of benefit in other specific cognitive domains (executive function, visual processing ability) and no differences between cognitive training and control interventions in relation to ADLs and quality of life. Because most studies were in people with $\mathrm{PD}-\mathrm{MCl}$ who, by definition, have no significant functional impairment at baseline, effects on ADLs were unlikely to be detected. We considered the evidence to be of low certainty overall due to imprecision and study limitations (see Quality of the evidence).

\section{Overall completeness and applicability of evidence}

Only seven studies with a total of 225 participants met our inclusion criteria, therefore the evidence base remains very small. Only one study (and no identified ongoing studies) included people with PDD, reflecting an important gap in the evidence. Most of the included studies involved people with PD and mild cognitive impairment living in community settings. Uncertainty about the degree and nature of cognitive impairment in the study populations is an important limitation of our review. In one included study (Cerasa 2014), participants had significant cognitive impairment on a standard neuropsychological test, but their status against $\mathrm{MCl}$ criteria was unclear. We also included two studies in which the sample was a mixed population of people with and without $\mathrm{MCl}$ (París 2011; Petrelli 2014), as we were unable to access separate data. Given that diagnostic criteria for PD-MCI have only recently been defined, and the variability in diagnosis (Marras 2013), we considered it important to be inclusive in our approach and to consider studies with mixed samples of people with and without clinically significant cognitive decline (as verified by performance on a standardised test) as eligible. As our sensitivity analyses showed that results were influenced by the inclusion of a study in which only a small proportion of the sample had cognitive impairment, it will be important that data on participants with and without cognitive impairment can be separated in future versions of this review or in other evidence syntheses.

Cognitive training across studies targeted either one or many cognitive domains. Single-domain cognitive training focused on executive function in Alloni 2018, memory in Costa 2014 (prospective memory via training of shifting ability), and attention in Cerasa 2014. The remaining four studies evaluated cognitive training that targeted multiple domains of cognitive function (Folkerts 2018, executive function and visuo-spatial ability; Lawrence 2018 and París 2011, attention, working memory, psychomotor speed, executive function, and visuo-spatial ability; Petrelli 2014, attention, memory, and executive function, with additional psychoeducational elements). In all included studies cognitive training was computerised; in some studies this was augmented with paper and pencil homework assignments. To date we are unable to comment on whether multidomain or singledomain cognitive training may differentially affect cognition in people with PD-MCI and PDD.

Most of the included studies measured both general cognition and specific areas of cognitive function. Although outcomes were similar, studies used different measures, and in most studies primary outcome measures were not specified. It will be important that future research incorporates key core outcomes so that results across studies can be compared. We found only two studies reporting on long-term effectiveness of cognitive training, measuring outcomes at 12 and 24 weeks. We found no evidence that cognitive training benefits global or specific areas of cognitive function in the longer term. However, studies were small, and risk of bias identified in several areas limits any conclusions about whether these interventions could benefit people with PDD and PD$\mathrm{MCl}$ at long-term follow-up. Overall, the current evidence therefore provides limited information in terms of potential long-term benefit. Given the small number of studies and small sample sizes, our analyses may have had limited power to detect differences in cognition and in the secondary outcomes of ADLs and quality of life.

There was limited information on adverse events, with only one study reporting that the intervention was not associated with any adverse outcomes. This is in line with systematic reviews of cognitive training in older people and people with mild to moderate Alzheimer's disease and vascular dementia (Bahar-Fuchs 2019), which found few studies mentioning adverse effects.

Although retrospectively it appears that we excluded many studies, we considered it important to include only studies where participants with PD also had clinical cognitive impairment to ensure that our review did not replicate previous reviews of effectiveness of cognitive training in PD without cognitive impairment (Leung 2015).

We were not able to conduct any subgroup analyses due to the small number of studies identified. An important aim for future versions of this review will be to assess whether the nature of the comparator intervention influences efficacy, as was found in a review of cognitive training in mild to moderate dementia (BaharFuchs 2019).

\section{Quality of the evidence}

All of the included studies were at unclear or high risk of bias in two or more domains. Many of the studies did not report details of random sequence generation, allocation concealment, or blinding. In some studies participants were excluded from analyses, indicating that intention-to-treat principles were not applied. For example, in two studies participants who did not receive more than $75 \%$ of the treatment were excluded from analyses.

According to the GRADE criteria, we considered the overall certainty of the evidence to be low for all outcomes due to risk of bias and imprecision. The numbers of studies and participants were small, and the confidence intervals around all effect estimates were wide. This GRADE rating means that new evidence may substantially change the effect estimates. Despite clinical heterogeneity across studies, such as inclusion of people with varying degrees of cognitive impairment, there was no or limited statistical heterogeneity across all of our analyses.

\section{Potential biases in the review process}

Although we searched systematically several sources, including the Cochrane Central Register of Controlled Trials (CENTRAL), conference proceedings, and review articles, the possibility remains that we may have missed some studies. We found several RCTs that reported excluding people with moderate to severe dementia; although these studies did not meet our inclusion criteria, it is possible that they included people with PD-MCl and mild PDD. 


\section{Agreements and disagreements with other studies or reviews}

Leung 2015 conducted a systematic review on the effectiveness of cognitive training for people with PD but no cognitive impairment. Although in some of our analyses cognitive training was favoured, which was in line with this review, our results did not reach statistical significance after sensitivity analyses were conducted. Given the small number of studies to date and risk of bias identified in several areas, our confidence in the conclusions of our review is limited.

\section{AUTHORS' CONCLUSIONS}

\section{Implications for practice}

Given that many people with Parkinson's disease (PD) experience cognitive difficulties, the potential benefit of use of cognitive training interventions is large. It will be important that large-scale trials of effectiveness are conducted, especially in people with PD dementia (PDD). Evidence from this review suggests that cognitive training interventions are generally associated with high levels of adherence. Given the small evidence base, risk of bias, and overall low certainty of the evidence, implications for clinical practice cannot be identified without further research.

\section{Implications for research}

Interventions that aim to improve cognition for people with PDD and PD-related mild cognitive impairment (PD-MCl) are becoming increasingly important as pharmacological treatment for cognitive symptoms is limited. Our review highlights the paucity of research in the area and that further research is necessary in order to establish whether cognitive training interventions in people with PDD and PD-MCI may be beneficial. It is important that these trials follow the CONSORT statement. We await evidence from several ongoing trials evaluating the effectiveness of cognitive training in people with $\mathrm{PD}-\mathrm{MCI}$.

Despite some progress in definitions of cognition-based interventions, there is still confusion with regard to how these interventions are defined and described. Our review suggests overall that although most studies provide enough information to be able to separate interventions, treatment protocols are not provided, and often different approaches are grouped under the same definition. It will be important for future research to concentrate on large-scale trials of clinical effectiveness versus a control comparison intervention, as many studies had to be excluded because the comparison group was another intervention. Updates of this review could additionally examine effectiveness of cognitive training against other active interventions.

Future studies should define cognitive impairment and specify type of diagnosis. Most studies to date exclude 'people with severe cognitive impairment', so it is likely that in some studies people with mild dementia or $\mathrm{MCl}$ were included. It will be important for future research to address this limitation and describe samples in greater detail reporting diagnostic criteria. Future studies should also try to address variation in training period, tasks used (i.e. cognitive only, cognitive and motor tasks), and sensitivity to change of outcome measures.

It will be important to examine whether any effects observed are generalised to everyday function and tasks of daily living. In the current review we are unable to draw any conclusions as to whether cognitive training is associated with improvements in daily life due to the small number of included studies. Future studies should test whether type of intervention evaluated influences efficacy, and comparisons between multicomponent cognitive training interventions, incorporating additional elements such as transfer training and physical training, versus cognitive training alone.

It has been argued that cognitive training may activate mechanisms of cerebral plasticity and slow PD-associated cognitive decline (Boller 2004). Future studies should investigate the potential mechanisms through which cognitive training may mediate effects on cognition using structural and functional imaging methods, and the extent to which these interventions may slow the progression of cognitive decline (Boller 2004). Research in the area should also address heterogeneity in outcomes, which may hinder future metaanalyses. In conclusion, our review suggests that there is an urgent need for further large-scale studies of cognitive training for people with PDD and PD-MCI.

\section{ACKNOWLEDGEM NTS}

We would like to thank the Cochrane Dementia and Cognitive Improvement Group and the Group's Managing Editor, Sue Marcus.

We would like to thank peer reviewers Dag Aarsland and Alison Yarnall and consumer reviewer Cathie Hofstetter for their comments and feedback. 


\section{REFERE N CES}

\section{References to studies included in this review}

\section{Alloni 2018 \{published data only\}}

Alloni A, Quaglini S, Panzarasa S, Sinforiani E, Bernini S. Evaluation of an ontology-based system for computerized cognitive rehabilitation. International Journal of Medical Informatics 2018;115:64-72.

\section{Cerasa 2014 \{published data only\}}

Cerasa A, Gioia MC, Salsone M, Donzuso G, Chiriaco C, Realmuto $S$, et al. Neurofunctional correlates of attention rehabilitation in Parkinson's disease: an explorative study. Neurological Sciences 2014;35:1173-80.

\section{Costa 2014 \{published data only\}}

Costa A, Peppe A, Serafini F, Zabberoni S, Barban F, Caltagirone $\mathrm{C}$, et al. Prospective memory performance of patients with Parkinson's disease depends on shifting aptitude: evidence from cognitive rehabilitation. Journal of the International Neuropsychological Society 2014;20:717-26.

\section{Folkerts 2018 \{published data only\}}

Folkerts A, Dorn ME, Roheger M, Maassen M, Koerts J, Tucha O, et al. Cognitive stimulation for individuals with Parkinson's disease dementia living in long-term care: preliminary data from a randomized crossover pilot study. Hindawi Parkinson's Disease 2018;8104673:1-9.

\section{Lawrence 2018 \{published data only\}}

Lawrence BJ, Gasson N, Johnson AR, Booth L, Loftus AM. Cognitive training and transcranial direct current stimulation for mild cognitive impairment in Parkinson's disease: a randomized controlled trial. Parkinson's Disease 2018;4318475:1-13.

\section{París 2011 \{published data only\}}

París AP, Saleta HG, de la Cruz Crespo Maraver M, Silvestre E, Freixa MG, Torrellas CP, et al. Blind randomized controlled study of the efficacy of cognitive training in Parkinson's disease. Movement Disorders 2011;26:1251-8.

\section{Petrelli 2014 \{published data only\}}

Petrelli A, Kaesberg S, Barbe MT, Timmermann L, Fink G, Kessler J, et al. Effects of cognitive training in Parkinson's disease: a randomized controlled trial. Parkinsonism and Related Disorders 2014;20:1196-202.

\section{References to studies excluded from this review \\ ACTRN12617000634370 \{published data only\}}

ACTRN12617000634370. Combined cognitive and exercise enrichment to improve outcomes in patients with Parkinson's disease [Combined cognitive and exercise enrichment to improve outcomes in patients with Parkinson's disease]. anzctr.org.au/Trial/Registration/TrialReview.aspx?id=372582 (first received 2 May 2017).
Adamski 2016 \{published data only\}

Adamski N, Adler M, Opweis K, Penner IK. A pilot study on the benefit of cognitive rehabilitation in Parkinson's disease. Therapeutic Advances in Neurological Disorders 2016;9:153-64.

Atias 2015 \{published data only\}

Atias $\mathrm{H}$, Hausdorff JM, Milman U. Effects of computerized cognitive training on gait and mobility in patients with Parkinson's disease. Physiotherapy 2015;101:e95.

Biundo 2015 \{published data only\}

Biundo R, Weis L, Fiorenzato E, Gentile G, Giglio M, Schifano R, et al. Double-blind randomized trial of t-DCS versus sham in Parkinson patients with mild cognitive impairment receiving cognitive training. Brain Stimulation 2015;8:1223-5.

Canning 2008 \{published data only\} Canning CG, Ada L, Woodhouse E. Multiple-task walking training in people with mild to moderate Parkinson's disease: a pilot study. Clinical Rehabilitation 2008;22:226-33.

\section{Díez-Cirarda 2017 \{published data only\}}

Díez-Cirarda M, Ojeda N, Peña J, Cabrera-Zubizarreta A, LucasJiménez O, Gómez-Esteban JC, et al. Long-term effects of cognitive rehabilitation on brain, functional outcome and cognition in Parkinson's disease. European Journal of Neurology 2018;25(1):5-12.

\section{Disbrow 2012 \{published data only\}}

Disbrow EA, Russo KA, Higginson $\mathrm{Cl}$, Yund EW, Ventura MI, Zhang $\mathrm{L}$, et al. Efficacy of tailored computer-based neurorehabilitation for improvement of movement initiation in Parkinson's disease. Brain Research 2012;1452:151-64.

\section{Edwards 2013 \{published data only\}}

Edwards JD, Hauser RA, O'Connor ML, Valdés EG, Zesiewicz TA, Uc EY. Randomized trial of cognitive speed of processing training in Parkinson disease. Neurology 2013;81:1284-90.

\section{Farzana 2015 \{published data only\}}

Farzana F, Sreekanth V, Mohiuddin MK, Mohan V, Balakrishna N, Ahuja YR. Can individual home-based cognitive stimulation therapy benefit Parkinson's patients with mild to moderate cognitive impairment?. International Journal of Geriatric Psychiatry 2015;30:433-5.

\section{Fearon 2017 \{published data only\}}

Fearon C, Killane I, Newman L, Beck R, Munteanu T, Birsanu D, et al. Combined motor and cognitive training improves motor and cognitive function in people with Parkinson's disease and freezing of gait. Movement Disorders 2017;32(Suppl 2).

\section{Fellman 2018 \{published data only\}}

Fellman D, Salmi J, Ritakallio L, Ellfolk U, Rinne JO, Laine M. Training working memory updating in Parkinson's disease: a randomised controlled trial. Neuropsychological Rehabilitation 2018;3:1-36. 


\section{Fernandez-del-Olmo 2018 \{published data only\}}

Fernandez-del-Olmo M, Sánchez-Molina JA, Fernandez-Lago H, Morenilla-Burlo L, Gómez-Varela J, Fogelson N. Effects of computerized cognitive training, with and without concurrent exercise, on executive functions in Parkinson's disease. Movement Disorders 2018;33(Suppl 2).

\section{Goedeken 2018 \{published data only\}}

Goedeken S, Potempa C, Prager EM, Foster ER. Encoding strategy training and self-reported everyday prospective memory in people with Parkinson disease: a randomizedcontrolled trial. Clinical Neuropsychology 2018;32(7):1282-302.

\section{Hindle 2016 \{published data only\}}

Hindle JV, Watermeyer TJ, Roberts J, Martyr A, Lloyd-Williams H, Brand $A$, et al. Cognitive rehabilitation for Parkinson's disease dementia: a study protocol for a pilot randomised controlled trial. Trials 2016;17:152.

\section{Kim 2016 \{published data only\}}

Kim S, Renn B, Sander A, Jimenez-Shahed J, York M. Pilot outcomes and patient satisfaction of a novel cognitive rehabilitation program: parkinson's disease-cognitive rehabilitation for executive functioning (PD-CoRE). Movement Disorders 2016;31(9):e1-e13.

\section{Maggio 2018 \{published data only\}}

Maggio MG, De Cola MC, Latella D, Maresca G, Finocchiaro C, La Rosa G, et al. What about the role of virtual reality in Parkinson disease's cognitive rehabilitation? preliminary findings from a randomized clinical trial. Journal of Geriatric Psychiatry and Neurology 2018;31(6):312-8.

\section{Mahmoud 2018 \{published data only\}}

Mahmoud LSE, Shady NAEA, Hafez ES. Motor imagery training with augmented cues of motor learning on cognitive functions in patients with Parkinsonism. International Journal of Therapy and Rehabilitation 2018;25:13-9.

\section{McCormick 2018 \{published data only\}}

McCormick SA, Vatter S, Carter LA, Smith SJ, Orgeta V, Poliakoff E, et al. Parkinson's-adapted cognitive stimulation therapy: feasibility and acceptability in Lewy body spectrum disorders. Journal of Neurology 2019;266(7):1756-70.

\section{Mirelman 2011 \{published data only\}}

Mirelman A, Maidan I, Herman T, Deutsch JE, Giladi N, Hausdorff JM. Virtual reality for gait training: can it induce motor learning to enhance complex walking and reduce fall risk in patients with Parkinson's disease?. Journals of Gerontology. Series A, Biological Sciences and Medical Sciences 2011;66:234-40.

\section{MohIman 2011 \{published data only\}}

Mohlman J, Chazin D, Georgescu B. Feasibility and acceptance of a nonpharmacological cognitive remediation intervention for patients with Parkinson disease. Journal of Geriatric Psychiatry and Neurology 2011;24(2):91-97.

\section{Monticone 2015 \{published data only\}}

Monticone M, Ambrosini E, Laurini A, Rocca B, Foti C. In-patient multidisciplinary rehabilitation for Parkinson's disease: a randomized controlled trial. Movement Disorders 2015;30:10501058.

\section{Motlagh 2017 \{published data only\}}

Motlagh MZ, Alhosseini MN, Salehi H, Chitsaz A. The effect of cognitive training on freezing of gait in patients with Parkinson's disease. Advances in Cognitive Science 2017;18.

\section{Naismith 2013 \{published data only\}}

Naismith SL, Mowszowski L, Diamond K, Lewis SJ. Improving memory in Parkinson's disease: a healthy brain ageing cognitive training program. Movement Disorders 2013;28:1097-103.

\section{NCT01156714 \{published data only\}}

NCT01156714. Exercise and cognitive training in Parkinson's disease [Effects of exercise and cognitive training on executive function in Parkinson's disease]. clinicaltrials.gov/ct2/show/ NCT01156714 (first received 5 July 2010).

\section{NCT01469741 \{published data only\}}

NCT01469741. Rehabilitation of everyday memory impairment in Parkinson disease: a pilot study (REMI-PD) [Rehabilitation of everyday memory impairment in Parkinson disease: a pilot study]. clinicaltrials.gov/ct2/show/NCT01469741 (first received 10 November 2011).

\section{NCT02826785 \{published data only\}}

NCT02826785. Feasibility and optimization of a cognitive intervention for Parkinson disease (FOCI-PD) [Feasibility and optimization of a cognitive intervention for Parkinson disease]. clinicaltrials.gov/ct2/show/NCT02826785 (first received 11 July 2016).

\section{NCT02922530 \{published data only\}}

NCT02922530. Piloting a novel, mobile cognitive tracking and training tool for patients with Parkinson's disease (PD) [Piloting a novel, mobile cognitive tracking and training tool for patients with Parkinson's disease (PD)]. clinicaltrials.gov/ct2/show/ NCT02922530 (first received 4 October 2016).

\section{NCT03335150 \{published data only\}}

NCT03335150. Cognitive rehabilitation for PD-MCI (CogSMARTPD) [Cognitive rehabilitation for individuals with Parkinson's disease and MCl]. clinicaltrials.gov/ct2/show/NCT03335150 (first received 7 November 2017).

\section{NCT03680170 \{published data only\}}

NCT03680170. Cognitive training in Parkinson's disease, the iPARK study (iPARK) [The effect of home-based working memory updating training on cognition and health in patients With Parkinson's disease]. clinicaltrials.gov/ct2/show/ NCT03680170 (first received 21 September 2018).

\section{NCT03836963 \{published data only\}}

NCT03836963. Cognitive rehab for Parkinson's [Cognitive rehabilitation for veterans with Parkinson's disease]. clinicaltrials.gov/ct2/show/NCT03836963 (first received 11 February 2019). 


\section{NCT04048122 \{published data only\}}

NCT04048122. Feasibility and effect of a strategy-based cognitive intervention for Parkinson disease [Strategy-based cognitive intervention for Parkinson disease: a pilot randomized controlled trial]. clinicaltrials.gov/ct2/show/NCT04048122 (first received 7 August 2019).

\section{Nombela 2011 \{published data only\}}

Nombela C, Bustillo PJ, Castell PF, Sanchez I, Medina V, Herrero MT. Cognitive rehabilitation in Parkinson's disease: evidence from neuroimaging. Frontiers in Neurology 2011;2:82.

Peña 2014 \{published data only\}

Peña J, Ibarretxe-Bilbao N, García-Gorostiaga I, GomezBeldarrain MA, Díez-Cirarda M, Ojeda N. Improving functional disability and cognition in Parkinson disease: randomized controlled trial. Neurology 2014;83:2167-2174.

\section{Peters 2012 \{published data only\}}

Peters C, Currin M, Tyson S, Rogers A, Healy S, McPhail S, et al. A randomized controlled trial of an enhanced interdisciplinary community based group program for people with Parkinson's disease: study rationale and protocol. Neurology International 2012;9:e3.

\section{Piemonte 2016 \{published data only\}}

Piemonte MEP, Okamoto E, Cardoso KR, Oliveira TP, Miranda CS, Pikel $\mathrm{M}$, et al. Novel training based on declarative memory cues improves gait performance in patients with Parkinson's disease: a randomized clinical trial. Movement Disorders 2016;31 (suppl 2).

\section{Pompeu 2012 \{published data only\}}

Pompeu JE, Mendes FA, Silva KG, Lobo AM, Oliveira Tde P, Zomignani AP, et al. Effect of Nintendo Wii ${ }^{\mathrm{TM}}$-based motor and cognitive training on activities of daily living in patients with Parkinson's disease: a randomised clinical trial. Physiotherapy 2012;98(3):196-204.

\section{Pompeu 2016 \{published data only\}}

Pompeu JE, Silva KG, Freitas TB, Nuvolini RA, Doná F, TorrianiPasin C, et al. Effect of European physiotherapy guideline for Parkinson's disease and Microsoft Kinect ${ }^{\circledR}$ adventures games training on postural control, cognition and quality of life: randomized clinical trial. Movement Disorders 2016:S184.

\section{Quayhagen 2000 \{published data only\}}

Quayhagen MP, Quayhagen M, Corbeil R, Hendrix R, Jackson E, Snyder L, et al. Coping with dementia: evaluation of four nonpharmacologic interventions. International Psychogeriatrics 2000;12:249-265.

\section{Reuter 2012 \{published data only\}}

Reuter I, Mehnert S, Sammer G, Oechsner M, Engelhardt M. Efficacy of a multimodal cognitive rehabilitation including psychomotor and endurance training in Parkinson's disease. Journal of Aging Research 2012;2012:1-15.

\section{Sammer 2006 \{published data only\}}

Sammer G, Reuter I, Hullmann K, Kaps M, Vaitl D. Training of executive functions in Parkinson's disease. Journal of the Neurological Sciences 2006;25(248):115-9.

\section{Sinforiani 2004 \{published data only\}}

Sinforiani E, Banchieri L, Zucchella C, Pacchetti C, Sandrini G. Cognitive rehabilitation in Parkinson's disease. Archives of Gerontology and Geriatrics 2014;9(Suppl):387-91.

Stiver 2015 \{published data only\}

Stiver J, Wynn M, Pressman P, Saloner R, Dutt S, Kramer J. A pilot study of adaptive brain gaming in cognitively impaired older adults. Neurology 2016;86 (16 Supplement):6.215.

\section{Strouwen 2017 \{published data only\}}

Strouwen C, Molenaar EALM, Münks L, Keus SHJ, Zijlmans JCM, Vandenberghe W, et al. Training dual tasks together or apart in Parkinson's disease: results from the DUALITY trial. Movement Disorders 2017;32:1201-1210.

Valdés 2017 \{published data only\} Valdés EG, O'Connor ML, Uc EY, Hauser RA, Andel R, Edwards JD. Use, maintenance and dose effects of cognitive speed of processing training in Parkinson's disease. International Journal of Neuroscience 2017;127(10):841-848.

Vlagsma 2020 \{published data only\}

Vlagsma TT, Duits AA, Dijkstra HT, van Laar T, Spikman JM. Effectiveness of ReSET; a strategic executive treatment for executive dysfunctioning in patients with Parkinson's disease. Neuropsychological Rehabilitation 2020;30(1):67-84.

Walton 2016 \{published data only\}

Walton CC, Mowszowski L, Shine JM, Gilat M, Hall JM, $\mathrm{O}^{\prime}$ Callaghan $\mathrm{C}$, et al. A double-blind randomized controlled trial of cognitive training for freezing of gait in Parkinson's disease. Movement Disorders 2016;31 (suppl 2):694-5.

Zimmermann 2014 \{published data only\}

Zimmermann R, Gschwandtner U, Benz N, Hatz F, Schindler C, Taub E, et al. Cognitive training in Parkinson disease: cognition-specific vs nonspecific computer training. Neurology 2014;82(14):1219-1226.

\section{References to studies awaiting assessment}

NCT01646333 \{published data only\}

NCT01646333. A trial of neurocognitive and supportive therapy interventions for individuals with Parkinson's disease [A randomized controlled trial of neurocognitive and supportive therapy interventions for individuals with Parkinson's disease]. clinicaltrials.gov/ct2/show/NCT01646333 (first received 20 July 2012).

NCT01647698 \{published data only\}

NCT01647698. Pilot study to determine if working memory training aids cognitive functioning in patients with Parkinson's disease (PDWM) [Beyond the physical: enhancing psychosocial 
functioning in Parkinson's disease]. clinicaltrials.gov/ct2/show/ NCT01647698 (first received 23 July 23 2012).

\section{NCT02920632 \{published data only\}}

NCT02920632. Cognitive training in Parkinson study (cogtips) [COGTIPS (COGnitive Training In Parkinson Study): the effect of online cognitive training on cognition and brain networks in Parkinson's disease]. clinicaltrials.gov/ct2/show/NCT02920632 (first received 30 September 2016).

\section{References to ongoing studies \\ ACTRN12618000999235 \{published data only\}}

ACTRN12618000999235. A randomised control trial of cognitive training and non-invasive brain stimulation in Parkinson's: the impact on cognition (thinking skills) and quality of life [A randomised control trial of cognitive training and non-invasive brain stimulation in PD: the impact on cognition and quality of life]. anzctr.org.au/Trial/Registration/TrialReview.aspx? id=375321 (first received 14 June 2018).

\section{NCT02225314 \{published data only\}}

NCT02225314. Computer-based cognitive training for individuals with Parkinson's disease [Computer-based cognitive training for individuals with Parkinson's disease]. clinicaltrials.gov/ct2/show/NCT02225314 (first received 26 August 2014).

\section{NCT02525367 \{published data only\}}

NCT02525367. Online cognitive training in PD, MS and depressed patients treated with electroconvulsive therapy [Clinical pilot study in the feasibility and effect of online cognitive training on cognitive functions in patients with Parkinson's disease, multiple sclerosis and depressive patients treated with electroconvulsive therapy]. clinicaltrials.gov/ct2/ show/NCT02525367 (first received 17 August 2015).

\section{NCT03285347 \{published data only\}}

NCT03285347. Effect of computer-based cognitive training on attention and executive functions in patients with Parkinson's disease [The effect of computer-based cognitive training on attention and executive functions in patients with Parkinson's disease]. clinicaltrials.gov/ct2/show/NCT03285347 (first received 18 September 2017).

\section{NCT03582670 \{published data only\}}

NCT03582670. Prospective memory training in Parkinson disease [Prospective memory training in Parkinson disease]. clinicaltrials.gov/ct2/show/NCT03582670 (first received 11 July 2018).

\section{van de Weijer 2016 \{published data only\}}

van de Weijer SC, Duits AA, Bloem BR, Kessels RP, Jansen JF, Köhler S, et al. The Parkin'Play study: protocol of a phase II randomized controlled trial to assess the effects of a health game on cognition in Parkinson's disease. BMC Neurology 2016;16(1):1-11.

\section{Additional references}

\section{Aarsland 2000}

Aarsland D, Larsen JP, Tandberg E, Laake K. Predictors of nursing home placement in Parkinson's disease: a population based prospective study. Journal of American Geriatrics Society 2000;48:938-42.

\section{Aarsland 2001}

Aarsland D, Cummings JL, Larsen JP. Neuropsychiatric differences between Parkinson's disease with dementia and Alzheimer's disease. International Journal of Geriatric Psychiatry 2001;16:184-91.

\section{Aarsland 2003a}

Aarsland D, Hutchinson M, Larsen JP. Cognitive, psychiatric and motor response to galantamine in Parkinson's disease with dementia. International Journal of Geriatric Psychiatry 2003;18:937-41.

\section{Aarsland 2003b}

Aarsland D, Andersen K, Larsen JP, Lolk A, Kragh-Sorensen P. Prevalence and characteristics of dementia in Parkinson's disease: an 8-year prospective study. Archives of Neurology 2003;60:387-92.

\section{Aarsland 2004}

Aarsland D, Andersen K, Larsen JP, Perry R, Wentzel-Larsen T, Lolk A, et al. The rate of cognitive decline in Parkinson disease. Archives of Neurology 2004;61:1906-11.

\section{Aarsland 2007}

Aarsland D, Brønnick K, Ehrt U, De Deyn PP, Tekin S, Emre M, et al. Neuropsychiatric symptoms in patients with Parkinson's disease and dementia: frequency, profile and associated care giver stress. Journal of Neurology, Neurosurgery, and Psychiatry 2007;78:36-42.

\section{Aarsland 2009}

Aarsland D, Ballard C, Walker Z, Bostrom F, Alves G, Kossakowski K, et al. Memantine in patients with Parkinson's disease dementia or dementia with Lewy bodies: a doubleblind, placebo-controlled, multicentre trial. Lancet Neurology 2009;8:613-8.

\section{Aarsland 2010}

Aarsland D, Bronnick K, Williams-Gray C, Weintraub D, Marder K, Kulisevsky J, et al. Mild cognitive impairment in Parkinson disease: a multicenter pooled analysis. Neurology 2010;75:1062-9.

\section{Alexopoulos 1988}

Alexopoulos GA, Abrams RC, Young RC, Shamoian CA. Cornell scale for depression in dementia. Biological Psychiatry 1988;23:271-284

\section{Alloni 2015}

Alloni A, Tost D, Panzarasa S, Zucchella C, Quaglini S. Applying 3D graphics to computerized cognitive rehabilitation. Communications in Computer and Information Science 2015;515:115-128. 


\section{Aretouli 2010}

Aretouli E, Brandt J. Episodic memory in dementia: characteristics of new learning that differentiate Alzheimer's, Huntington's, and Parkinson's diseases. Archives of Clinical Neuropsychology 2010;25:296-309.

\section{Artero 2006}

Artero S, Petersen R, Touchon J, Ritchie K. Revised criteria for mild cognitive impairment: validation within a longitudinal population study. Dementia and Geriatric Cognitive Disorders 2006;22:465-470.

\section{Backman 2005}

Bäckman L, Jones S, Berger AK, Laukka EJ, Small BJ. Cognitive impairment in preclinical Alzheimer's disease: a meta-analysis. Neuropsychology 2005;19:520-31.

\section{Bahar-Fuchs 2019}

Bahar-Fuchs A, Martyr A, Goh AM, Sabates J, Clare L. Cognitive training for people with mild to moderate dementia. Cochrane Database of Systematic Reviews 2019, Issue 3. [DOI: 10.1002/14651858.CD013069.pub2]

\section{Baller 2009}

Baller G, Kalbe E, Kaesberg S, Kessler J. NEUROvitalis. Cologne, Germany: Ein Neuropsychologisches Gruppenprogramm zur Förderung der Geistigen Leistungsfähigkeit ProLog, 2009.

\section{Barthel 1965}

Mahoney F, Barthel D. Functional evaluation: the Barthel Index. Maryland State Medicine Journal 1965;14:61-65.

\section{Bassett 2005}

Bassett SS. Cognitive impairment in Parkinson's disease. Primary Psychiatry 2005;12:50-5.

\section{Beck 1996}

Beck AT, Steer RA, Brown GK. BDI-II: Beck Depression Inventory Manual. 2nd Edition. San Antonio, TX: Psychological Corporation, 1996.

\section{Belleville 2011}

Belleville S, Clement F, Mellah S, Gilbert B, Fontaine F, Gauthier S. Training-related brain plasticity in subjects at risk of developing Alzheimer's disease. Brain 2011;134:1623-34.

\section{Benton 1983}

Benton AL, Hamsher de SK, Sivan AB. Multilingual Aplasia Examination. 2nd Edition. Iowa City, IA: AJA Associates, 1983.

\section{Benton 1994}

Benton AL, Sivan A, Hamsher K, Varney N, Spreen O. Contributions to Neuropsychology Assessment: a Clinical Manual 2. New York: Oxford University Press, 1994.

\section{Boller 2004}

Boller F. Rational basis of rehabilitation following cerebral lesions: a review of the concept of cerebral plasticity. Functional Neurology 2004;19:65-72.

\section{Brandt 2001}

Brandt J, Benedict RH. Hopkins Verbal Learning Test-Revised: professional Manual. Lutz, FL: Psychological Assessment Resources, 2001.

\section{Bronnick 2007}

Bronnick K, Emre M, Lane R, Tekin S, Aarsland D. Profile of cognitive impairment in dementia associated with Parkinson's disease compared with Alzheimer's disease. Journal of Neurology, Neurosurgery, and Psychiatry 2007;78:1064-8.

\section{Buonomano 1998}

Buonomano DV, Merzenich MM. Cortical plasticity: from synapses to maps. Annual Review of Neuroscience 1998;21:14986.

\section{Buschke 1973}

Buschke H. Selective reminding analysis of memory and learning. Journal of Verbal Learning and Verbal Behavior 1973;12:543-50.

\section{Buter 2008}

Buter TC, van den Hout A, Matthews FE, Larsen JP, Brayne C, Aarsland D. Dementia and survival in Parkinson disease: a 12year population study. Neurology 2008;70:1017-22.

\section{Calleo 2012}

Calleo J, Burrows C, Levin H, Marsh L, Lai E, York MK. Cognitive rehabilitation for executive dysfunction in Parkinson's disease: application and current directions. Parkinson's Disease 2012;2012:512892.

\section{Caviness 2007}

Caviness JN, Driver-Dunckley E, Connor DJ, Sabbagh MN, Hentz JG, Noble B, et al. Defining mild cognitive impairment in Parkinson's disease. Movement Disorders 2007;22:1272-7.

\section{Cerasa 2013}

Cerasa A, Gioia MC, Valentino P, Nisticò R, Chiriaco C, Pirritano $D$, et al. Computer-assisted cognitive rehabilitation of attention deficits for multiple sclerosis: a randomized trial with FMRI correlates. Neurorehabilitation and Neural Repair 2013;27(4):284-295.

\section{Corsi 1972}

Corsi PM. Human memory and the medial temporal region of the brain. Unpublished doctoral dissertation; McGill University, Montreal; 1972

\section{Culberston 2001}

Culberston W, Zillmer E. TOL: Tower of London. Drexel University. Chicago: Multi-Health Systems, 2005.

\section{Cummings 1997}

Cummings JL. The Neuropsychiatric Inventory: assessing psychopathology in dementia patients. Neurology 1997;48:S10S16. 


\section{Cutson 1995}

Cutson TM, Laub KC, Schenkman M. Pharmacological and nonpharmacological interventions in the treatment of Parkinson's Disease. Physical Therapy 1995;75:363-73.

\section{Davis 2001}

Davis RN, Massman PJ, Doody RS. Cognitive intervention in Alzheimer disease: a randomized placebo-controlled study. Alzheimer Disease \& Associated Disorders 2001;15:1-9.

\section{de Rijk 2000}

de Rijk MC, Launer LJ, Berger K, Breteler MM, Dartigues JF, Baldereschi M, et al. Prevalence of Parkinson's disease in Europe: a collaborative study of population-based cohorts. Neurologic Diseases in the Elderly Research Group. Neurology 2000;54(11 Suppl 5):S21-3.

\section{Delis 2000}

Delis DC, Kramer JH, Kaplan E, Ober BA. California Verbal Learning Test. Adult Version Manual. 2nd Edition. San Antonio, TX: Psychological Corporation, 2000.

\section{Downes 1993}

Downes JJ, Sharp HM, Costall BM, Sagar HJ, Howe J. Alternating fluency in Parkinson's disease. Brain 1993;116:887-902.

\section{Driemeyer 2008}

Driemeyer J, Boyke J, Gaser C, Büchel C, May A. Changes in gray matter induced by learning - revisited. PLOS ONE 2008;3(7):e2669.

\section{Dubois 1997}

Dubois B, Pillon B. Cognitive deficits in Parkinson's disease. Journal of Neurology 1997;244:2-8.

\section{Dubois 2000}

Dubois B, Slachevsky A, Litvan I, Pillon B. The FAB A frontal assessment battery at bedside. Neurology 2000;55:1621-6.

\section{Dubois 2007}

Dubois B, Burn D, Goetz C, Aarsland D, Brown RG, Broe GA, et al. Diagnostic procedures for Parkinson's disease dementia: recommendations from the Movement Disorder Society task force. Movement Disorders 2007;22(16):2314-24.

\section{Egger 1997}

Egger M, Davey Smith G, Schneider M, Minder C. Bias in meta-analysis detected by a simple, graphical test. BMJ 1997;315(7109):629-34.

\section{Emre 2003}

Emre M. Dementia associated with Parkinson's disease. Lancet Neurology 2003;2:229-37.

\section{Emre 2004}

Emre M, Aarsland D, Albanese A, Byrne EJ, Deuschl G, De Deyn PP, et al. Rivastigmine for dementia associated with Parkinson's disease. New England Journal of Medicine 2004;351:2509-18.

\section{Emre 2007}

Emre M, Aarsland D, Brown R. Clinical diagnostic criteria for dementia associated with Parkinson's disease. Movement Disorders 2007;22:1689-707.

\section{Emre 2010}

Emre M, Tsolaki M, Bonuccelli U, Destée A, Tolosa E, Kutzelnigg A, et al. Memantine for patients with Parkinson's disease dementia or dementia with Lewy bodies: a randomised, double-blind, placebo-controlled trial. Lancet Neurology 2010;9:969-77.

\section{Ettema 2007}

Ettema TP, Droes RM, de Lange J, Mellenbergh GJ, Ribbe MW. QUALIDEM: Development and evaluation of a dementia specific quality of life instrument - validation. International Journal of Geriatric Psychiatry 2007;22(5):424-430.

\section{EuroQoL Group 1990}

EuroQol Group. EuroQol-a new facility for the measurement of health-related quality of life. Health Policy 1990;16:199-208.

\section{Folstein 1975}

Folstein MF, Folstein SE, McHugh PR. "Mini-Mental State": a practical method for grading the cognitive state of patients for the clinician. Journal of Psychiatric Research 1975;12:189-98.

\section{Galvin 2006}

Galvin JE, Pollack J, Morris JC. Clinical phenotype of Parkinson disease dementia. Neurology 2006;67:1605-11.

\section{Giladi 2000}

Giladi N, Treves TA, Paleacu D, Shabtai H, Orlov Y, Kandinov B, et al. Risk factors for dementia, depression and psychosis in longstanding Parkinson's disease. Journal of Neural Transmission 2000;107:59-71.

\section{Gilbert 2001}

Gilbert CD, Sigman M, Crist RE. The neural basis of perceptual learning. Neuron 2001;31:681-97.

\section{Goetz 2008}

Goetz CG, Tilley BC, Shaftman SR, Stebbins GT, Fahn S, MartinezMartin P, et al. Movement Disorder Society UPDRS Revision Task Force. Movement Disorder Society-sponsored revision of the Unified Parkinson's Disease Rating Scale (MDS-UPDRS): scale presentation and clinimetric testing results. Movement Disorders 2008;23:2129-70.

\section{Gronwall 1974}

Gronwall D, Sampson H. The Psychological Effects of Concussion. Auckland, New Zealand: Auckland University Press, 1974.

\section{Guyatt 2011}

Guyatt GH, Oxman AD, Schünemann HJ, Tugwell P, Knottnerus A. GRADE guidelines: a new series of articles in the Journal of Clinical Epidemiology. Journal of Clinical Epidemiology 2011;64:380-2. 


\section{Halliday 2014}

Halliday GM, Leverenz JB, Schneider JS, Adler CH. The neurobiological basis of cognitive impairment in Parkinson's disease. Movement Disorders 2014;29:634-50.

\section{Hampstead 2012}

Hampstead BM, Stringer AY, Stilla RF, Giddens M, Sathian K. Mnemonic strategy training partially restores hippocampal activity in patients with mild cognitive impairment. Hippocampus 2012;22:1652-8.

\section{Hely 1995}

Hely MA, Morris JG, Reid WG, O'Sullivan DJ, Williamson PM, Broe GA, et al. Age at onset: the major determinant of outcome in Parkinson's disease. Acta Neurologica Scandinavica 1995;92:455-63.

\section{Hely 2008}

Hely MA, Reid WG, Adena MA, Halliday GM, Morris JG. The Sydney multicenter study of Parkinson's disease: the inevitability of dementia at 20 years. Movement Disorders 2008;6:837-44.

\section{Higgins 2011}

Higgins JPT, Green S, editor(s). Cochrane Handbook for Systematic Reviews of Interventions Version 5.1.0 (updated March 2011). The Cochrane Collaboration, 2011. Available from handbook.cochrane.org.

\section{Hoehn 1967}

Hoehn M, Yahr M. Parkinsonism: onset, progression and mortality. Neurology 1967;17(5):427-442.

\section{Hooper 1983}

Hooper H. Hooper Visual Organization Test: manual. Los Angeles: Western Psychological Services, 1983.

\section{Horstink 2006}

Horstink M, Tolosa E, Bonuccelli U, Deuschl G, Friedman A, Kanovsky P, et al. Review of the therapeutic management of Parkinson's disease. Report of a joint task force of the European Federation of Neurological Societies (EFNS) and the Movement Disorder Society-European Section (MDS-ES). Part II: late (complicated) Parkinson's disease. European Journal of Neurology 2006;13:1186-202.

\section{Hughes 1992}

Hughes AJ, Daniel SE, Kilford L, Lees AJ. Accuracy of clinical diagnosis of idiopathic Parkinson's disease: a clinicopathological study of 100 cases. Journal of Neurology, Neurosurgery, and Psychiatry 1992;55:181-4.

\section{Irwin 2012}

Irwin DJ, White MT, Toledo JB, Xie SX, Robinson JL, Van Deerlin V, et al. Neuropathologic substrates of Parkinson disease dementia. Annals of Neurology 2012;72:587-98.

\section{Jacobs 1995}

Jacobs DM, Marder K, Côté LJ, Sano M, Stern Y, Mayeux R. Neuropsychological characteristics of preclinical dementia in Parkinson's disease. Neurology 1995;45:1691-6.

\section{Janvin 2005}

Janvin CC, Aarsland D, Larsen JP. Cognitive predictors of dementia in Parkinson's disease: a community-based, 4-year longitudinal study. Journal of Geriatric Psychiatry and Neurology 2005;18:149-54.

\section{Janvin 2006}

Janvin CC, Larsen JP, Aarsland D, Hugdahl K. Subtypes of mild cognitive impairment in Parkinson's disease: progression to dementia. Movement Disorders 2006;21:1343-9.

\section{Jenkinson 1997}

Jenkinson C, Fitzpatrick R, Peto V, Harris R, Saunder P. Parkinson's Disease Questionnaire (PDQ-39). Age and Ageing 1997;26:353-357.

\section{Kalbe 2004}

Kalbe E, Kessler J, Calabrese P, Smith R, Passmore AP, Brand M, et al. DemTect: A new, sensitive cognitive screening test to support the diagnosis of mild cognitive impairment and early dementia. International Journal of Geriatric Psychiatry 2004;19:136-43.

\section{Kaplan 1983}

Kaplan E, Goodglass H, Weintraub S. The Boston Naming Test. Pro-Ed. Philadelphia: Lea \& Febiger, 1983.

\section{Kelly 2014}

Kelly ME, Loughrey D, Lawlor BA, Robertson IH, Walsh C, Brennan S. The impact of cognitive training and mental stimulation on cognitive and everyday functioning of healthy older adults: a systematic review and meta-analysis. Ageing Research Reviews 2014;15:28-43.

\section{Lampit 2014}

Lampit A, Hallock H, Valenzuela M. Computerized cognitive training in cognitively healthy older adults: a systematic review and meta-analysis of effect modifiers. PLoS Medicine 2014;11:e1001756.

\section{Lashley 2008}

Lashley T, Holton JL, Gray E, Kirkham K, O'Sullivan SS, Hilbig A et al. Cortical alpha-synuclein load is associated with amyloidbeta plaque burden in a subset of Parkinson's disease patients. Acta Neuropathologica 2008;115:417-25.

\section{Leroi 2004}

Leroi I, Brandt J, Reich SG, Lyketsos CG, Grill S, Thompson R, et al. Randomized placebo-controlled trial of donepezil in cognitive impairment in Parkinson's disease. International Journal of Geriatric Psychiatry 2004;19:1-8.

\section{Leroi 2009}

Leroi I, Overshott R, Byrne EJ, Daniel E, Burns A. Randomized controlled trial of memantine in dementia associated with Parkinson's disease. Movement Disorders 2009;15:1217-21.

\section{Leroi 2012a}

Leroi I, Pantula H, McDonald K, Harbishettar V. Neuropsychiatric symptoms in Parkinson's disease with mild cognitive 
impairment and dementia. Parkinson's Disease 2012;2012:308097.

\section{Leroi 2012b}

Leroi I, McDonald K, Pantula H, Harbishettar V. Cognitive impairment in Parkinson disease: impact on quality of life, disability, and caregiver burden. Journal of Geriatric Psychiatry and Neurology 2012;25:208-14.

\section{Leroi 2014}

Leroi I, Atkinson R, Overshott R. Memantine improves goal attainment and reduces caregiver burden in Parkinson's disease with dementia. International Journal of Geriatric Psychiatry 2014;29:899-905.

\section{Leung 2015}

Leung $\mathrm{H}$, Walton CC, Hallock H, Lewis SJ, Valenzuela M, Lampit A. Cognitive training in Parkinson disease: a systematic review and meta-analysis. Neurology 2015;85:1843-51.

\section{Levy 2002a}

Levy G, Tang MX, Louis ED, Côté LJ, Alfaro B, Mejia H, et al. The association of incident dementia with mortality in PD. Neurology 2002;59:1708-13.

\section{Levy 2002b}

Levy G, Schupf N, Tang MX, Cote LJ, Louis ED, Mejia H, et al. Combined effect of age and severity on the risk of dementia in Parkinson's disease. Annals of Neurology 2002;51:722-9.

\section{Lezak 1983}

Lezak M. Neuropsychological Assessment. 2nd Edition. New York: Oxford University Press, 1983.

\section{Lippa 2007}

Lippa CF, Duda JE, Grossman M, Hurtig HI, Aarsland D, Boeve BF, et al. DLB/PDD Working Group. DLB and PDD boundary issues: diagnosis, treatment, molecular pathology, and biomarkers. Neurology 2007;68:812-9.

\section{Litvan 2011}

Litvan I, Aarsland D, Adler CH, Goldman JG, Kulisevsky J, Mollenhauer B. MDS task force on mild cognitive impairment in Parkinson's disease: critical review of PD-MCl. Movement Disorders 2011;26:1814e24.

\section{Litvan 2012}

Litvan I, Goldman JG, Tröster AI, Schmand BA, Weintraub D, Petersen RC, et al. Diagnostic criteria for mild cognitive impairment in Parkinson's disease: movement Disorder Society Task Force guidelines. Movement Disorders 2012;27:349-56.

\section{Macdonald 2011}

Macdonald PA, Monchi O. Differential effects of dopaminergic therapies on dorsal and ventral striatum in Parkinson's disease: implications for cognitive function. Parkinson's Disease 2011;2011:572743.

\section{Marinus 2018}

Marinus J, Zhu K, Marras C, Aarsland D, van Hilten JJ. Risk factors for non-motor symptoms in Parkinson's disease. Lancet Neurology 2018;17(6):559-568.

\section{Marras 2013}

Marras C, Armstrong MJ, Meaney CA, Fox S, Rothberg B, Reginold W, et al. Measuring mild cognitive impairment in patients with Parkinson's disease. Movement Disorders 2013;28:626-633.

\section{Martin 2011}

Martin M, Clare L, Altgassen AM, Cameron MH, Zehnder F. Cognition-based interventions for healthy older people and people with mild cognitive impairment. Cochrane Database of Systematic Reviews 2011, Issue 1. [DOI: 10.1002/14651858.CD006220.pub2]

\section{Mathuranath 2000}

Mathuranath PS, Nestor PJ, Berrios GE, Rakowicz W, Hodges JR. A brief cognitive test battery to differentiate Alzheimer's disease and frontotemporal dementia. Neurology 2000;55:1613-1620.

\section{McKeith 2002}

McKeith IG. Dementia with Lewy bodies. British Journal of Psychiatry 2002;180:144-7.

\section{McNair 1983}

McNair DM, Kahn RJ. Self-assessment of cognitive deficits. In: Crook T editor(s). Assessment in Geriatric Psychopharmacology. New Canaan, CT: Mark Powley Associates, 1983:137-43.

\section{McShane 2019}

McShane R, Westby MJ, Roberts E, Minakaran N, Schneider L, Farrimond LE, et al. Memantine for dementia. Cochrane Database of Systematic Reviews 2019, Issue 3. [DOI: 10.1002/14651858.CD003154]

\section{Meireles 2012}

Meireles J, Massano J. Cognitive impairment and dementia in Parkinson's disease: clinical features, diagnosis, and management. Frontiers in Neurology 2012;3:88.

\section{Meyers 1995}

Meyers JE, Meyers KR. Rey Complex Figure Test and Recognition Trial: professional Manual. Odessa, FL: Psychological Assessment Resources, 1995.

\section{Middelstadt 2016}

Middelstadt J, Folkerts AK, Blawath S, Kalbe E. Cognitive stimulation for people with dementia in long-term care facilities: baseline cognitive level predicts cognitive gains, moderated by depression. Journal of Alzheimer's Disease 2016;54:253-268.

\section{Nasreddine 2005}

Nasreddine ZS, Phillips NA, Bedirian V. The Montreal Cognitive Assessment, MoCA: a brief screening tool for mild cognitive impairment. Journal of the American Geriatrics Society 2005;53:695-699. 


\section{Neely 2009}

Neely AS, Vikstrom S, Josephsson S. Collaborative memory intervention in dementia: caregiver participation matters. Neuropsychological Rehabilitation 2009;19:696-715.

\section{Pagonabarraga 2008}

Pagonabarraga J, Kulisevsky J, Llebaria G, García-Sánchez C, Pascual-Sedano B, Gironell A. Parkinson's disease-cognitive rating scale: a new cognitive scale specific for Parkinson's disease. Movement Disorders 2008;23(7):998-1005.

\section{Pedersen 2013}

Pedersen K, Larsen J, Tysnes O, Alves G. Prognosis of mild cognitive impairment in early Parkinson disease: the Norwegian ParkWest study. JAMA Neurology 2013;70(5):580-6.

\section{Petersen 1999}

Petersen RC, Smith GE, Waring SC, Ivnik RJ, Tangalos EG, Kokmen E. Mild cognitive impairment: clinical characterization and outcome. Archives of Neurology 1999;56:303-8.

\section{Petersen 2005}

Petersen RC, Morris JC. Mild cognitive impairment as a clinical entity and treatment target. Archives of Neurology 2005;62:1160-1163.

\section{Pont-Sunyer 2015}

Pont-Sunyer C, Hotter A, Gaig C, Seppi K, Compta Y, Katzenschlager $\mathrm{R}$, et al. The onset of nonmotor symptoms in Parkinson's disease (the ONSET PD study). Movement Disorders 2015;30:229-37.

\section{Raven 1988}

Raven JC, Court JH, Raven JHK. Manual for Raven's Progressive Matrices and Vocabulary Scales. London: Lewis, 1988.

\section{Ravina 2005}

Ravina B, Putt M, Siderowf A, Farrar JT, Gillespie M, Crawley A, et al. Donepezil for dementia in Parkinson's disease: a randomised, double blind, placebo controlled, crossover study. Journal of Neurology, Neurosurgery, and Psychiatry 2005;76:934-9.

\section{Raz 2006}

Raz A, Buhle J. Typologies of attentional networks. Nature Reviews Neuroscience 2006;7:367-79.

\section{Reading 2001}

Reading PJ, Luce AK, McKeith IG. Rivastigmine in the treatment of parkinsonian psychosis and cognitive impairment: preliminary findings from an open trial. Movement Disorders 2001;16:1171-4.

\section{Reijnders 2007}

Reijnders J, van Heugten C, van Boxtel M. Cognitive interventions in healthy older adults and people with mild cognitive impairment: a systematic review. Ageing Research Reviews 2007;12:263-75.

\section{Reitan 1985}

Reitan RM, Wolfson D. The Halstead-Reitan Neuropsychological Test Battery: therapy and Clinical Interpretation. Tucson, AZ: Neuropsychological Press, 1985.

\section{Rey 1941}

Rey A. Psychological examination of traumatic encephalopathy [L'examen psychologique dans les cas d'ecephalopathie traumatique]. Clinical Neuropsychologist 1941;28:286-340.

\section{Robbins 1998}

Robbins TW, James M, Owen AM, Sahakian BJ, Lawrence D, McInnes $L$, et al. A study of performance on tests from the CANTAB battery sensitive to frontal lobe dysfunction in a large sample of normal volunteers: implications for theories of executive functioning and cognitive aging. Journal of the International Neuropsychological Society 1998;4(5):474-490.

\section{Rojas 2013}

Rojas GJ, Villar V, Iturry M, Harris P, Serrano CM, Herrera JA, et al. Efficacy of a cognitive intervention program in patients with mild cognitive impairment. International Psychogeriatrics 2013;25:825-31.

\section{Rolinski 2012}

Rolinski M, Fox C, Maidment I, McShane R. Cholinesterase inhibitors for dementia with Lewy bodies, Parkinson's disease dementia and cognitive impairment in Parkinson's disease. Cochrane Database of Systematic Reviews 2012, Issue 3. [DOI: 10.1002/14651858.CD006504.pub2]

\section{Sabbagh 2009}

Sabbagh MN, Adler CH, Lahti TJ, Connor DJ, Vedders L, Peterson LK, et al. Parkinson disease with dementia: comparing patients with and without Alzheimer pathology. Alzheimer Disease \& Associated Disorders 2009;23:295-7.

\section{Schrag 2000}

Schrag A, Jahanshahi M, Quinn N. What contributes to quality of life in patients with Parkinson's disease?. Journal of Neurology, Neurosurgery, and Psychiatry 2000;69:308-12.

\section{Schretlen 1996}

Schretlen D, Bobholz JH, Brandt J. Development and psychometric properties of the Brief Test of Attention. Clinical Neuropsychologist 1996;10:80-89.

\section{Shaw 1994}

Shaw CA, Lanius RA, van den Doel K. The origin of synaptic neuroplasticity: crucial molecules or a dynamical cascade? Brain Research Reviews 1994;19:241-63.

\section{Sheikh 1986}

Sheikh JI, Yesavage JA. Geriatric Depression Scale (GDS): recent evidence and development of a shorter version. In: Brink TL editor(s). Clinical Gerontology: a Guide to Assessment and Intervention. New York: Haworth Press, 1986:165-173.

\section{Smith 1999}

Smith EE, Jonides J. Storage and executive processes in the frontal lobes. Science 1999;283:1657-61. 


\section{Smith 2007}

Smith A. Symbol Digits Modalities Test: Manual. Los Angeles: Western Psychological Services, 2007.

\section{Spielberger 1983}

Spielberger CD, Gorsuch RL, Lushene R, Vagg PR, Jacobs GA. Manual for the State-Trait Anxiety Inventory. Palo Alto, CA: Consulting Psychologists Press, 1983.

\section{Spinnler 1987}

Spinnler H, Tognoni G. Italian standardization and classification of Neuropsychological tests. The Italian Group on the Neuropsychological Study of Aging [Standardizzazione e taratura italiana di test neuropsicologici [Italian standardization and classification of Neuropsychological tests. The Italian Group on the Neuropsychological Study of Aging]]. Italian Journal of Neurological Sciences 1987;8:1-20.

\section{Spreen 1977}

Spreen O, Benton AL. Neurosensory Center Comprehensive Examination for Aphasia. Victoria, BC: University of Victoria, Neuropsychology Laboratory, 1977.

\section{Stroop 1935}

Stroop JR. Studies of interference in serial verbal reactions. Journal of Experimental Psychology: General 1935;18:643-662.

\section{Stubendorff 2014}

Stubendorff K, Larsson V, Ballard C, Minthon L, Aarsland D, Londos $\mathrm{E}$. Treatment effect of memantine on survival in dementia with Lewy bodies and Parkinson's disease with dementia: a prospective study. BMJ Open 2014;3:e005158.

\section{Tárraga 2006}

Tárraga L, Boada M, Modinos G. A randomized pilot study to assess the efficacy of Smartbrain, an interactive, multimedia tool of cognitive stimulation in Alzheimer's disease. Journal of Neurology, Neurosurgery, and Psychiatry 2006;77:1116-1121.

\section{van Laar 2011}

van Laar T, De Deyn PP, Aarsland D, Barone P, Galvin JE. Effects of cholinesterase inhibitors in Parkinson's disease dementia: a review of clinical data. CNS Neuroscience \& Therapeutics 2011;17:428-41.

\section{Vatter 2018}

Vatter S, McDonald KR, Stanmore E, Clare L, Leroi I. Multidimensional care burden in Parkinson-related dementia. Journal of Geriatric Psychiatry and Neurology 2018;31:319-328.

\section{Vossius 2011}

Vossius C, Larsen JP, Janvin C, Aarsland D. The economic impact of cognitive impairment in Parkinson's disease. Movement Disorders 2011;26:1541-4.

\section{Wechsler 1945}

Wechsler D. A standardized memory scale for clinical use. Journal of Psychology 1945;19:87-95.

\section{Wechsler 2001}

Wechsler D. Wechsler Adult Intelligence Scale (WAIS-III). 3rd Edition. Madrid: TEA, 2001.

\section{Weigl 1941}

Weigl E. On the psychology of so-called processes of abstraction [On the psychology of so-called processes of abstraction]. Journal of Abnormal and Social Psychology 1941;36(1):3-33.

\section{Welsh 1994}

Welsh KA, Butters N, Mohs RC, Beekly D, Edland S, Fillenbaum $\mathrm{G}$, et al. The Consortium to Establish a Registry for Alzheimer's Disease (CERAD). Part V. A normative study of the neuropsychological battery. Neurology 1994;44(4):609-14.

\section{Williams-Gray 2007}

Williams-Gray CH, Foltynie T, Brayne CE, Robbins TW, Barker RA. Evolution of cognitive dysfunction in an incident Parkinson's disease cohort. Brain 2007;130:1787-98.

\section{Williams-Gray 2009}

Williams-Gray CH, Evans JR, Goris A, Foltynie T, Ban M, Robbins TW, et al. The distinct cognitive syndromes of Parkinson's disease: 5 year follow-up of the CamPalGN cohort. Brain 2009;132:2958-69.

\section{Wilson 1989}

Wilson B, Cockburn J, Baddeley A, Hiorns R. The development and validation of a test battery for detecting and monitoring everyday memory problems. Journal of Clinical and Experimental Neuropsychology 1989;6:855-870.

\section{Yarnall 2014}

Yarnall AJ, Breen DP, Duncan GW, Khoo TK, Coleman SY, Firbank MJ, et al. Characterizing mild cognitive impairment in incident Parkinson disease: the ICICLE-PD study. Neurology 2014;28:308-16.

\section{Ylvisaker 2002}

Ylvisaker M, Hanks R, Johnson-Greene D. Perspectives on rehabilitation of individuals with cognitive impairment after brain injury: rationale for reconsideration of theoretical paradigms. Journal of Head Trauma Rehabilitation 2002;17:191-209.

\section{CHARACTERISTICS OF STUDIES}

Characteristics of included studies [ordered by study ID] 
Alloni 2018

\begin{tabular}{|c|c|}
\hline Methods & Randomised Controlled Trial (RCT) \\
\hline Participants & $\begin{array}{l}\text { Diagnosis of idiopathic Parkinson's disease (PD) according to UK Parkinson's Disease Society Brain } \\
\text { Bank (UKPDBB) diagnostic criteria, Hoehn and Yahr scale } \leq 4 \text {, and presence of single-domain (execu- } \\
\text { tive) or multiple-domain mild cognitive impairment (MCI) with executive involvement. } \\
\text { Number randomised } n=31 \text {. }\end{array}$ \\
\hline Interventions & $\begin{array}{l}\text { Computerised exercises of the CoRe tool tailored to individuals' performance aimed at training exec- } \\
\text { utive function (logical analogies and sequences, find the elements and functional planning); over } 4 \\
\text { weeks; } 12 \text { sessions lasting } 45 \text { minutes each. } \\
\text { Control group received an intervention incorporating motor rehabilitation combined with recreational } \\
\text { activity. }\end{array}$ \\
\hline Outcomes & $\begin{array}{l}\text { - Global cognitive function } \\
\text { 1. Mini-Mental State Examination (MMSE) } \\
\text { 2. Montreal Overall Cognitive Assessment (MoCA) } \\
\text { - Memory - Verbal and spatial memory } \\
\text { 1. Verbal and digit span } \\
\text { 2. Corsi's block-tapping test } \\
\text { 3. Logical Memory test with immediate and delayed recall } \\
\text { 4. Rey's 15-words test with immediate and delayed recall } \\
\text { 5. Rey's Complex Figure Test (ROCF) Delayed Recall } \\
\text { - Executive function: Logical-executive functions } \\
\text { 1. Raven's Progressive Matrices } \\
\text { 2. Weigl's Sorting test } \\
\text { 3. Frontal Assessment Battery } \\
\text { 4. Semantic fluency and phonological fluency (F-A-S Tests) } \\
\text { - Attention } \\
\text { 1. Attentive Matrices } \\
\text { 2. Trail Making Test Part A - (TMTa) - and Trail Making Test Part B (TMTb) - } \\
\text { 3. Stroop test } \\
\text { - Visuo-spatial abilities } \\
\text { 1. ROCF Copy }\end{array}$ \\
\hline
\end{tabular}

Notes

\section{Risk of bias}

Bias Authors' judgement Support for judgement

Random sequence genera- Unclear risk Mentions participants were randomly allocated. No further details. tion (selection bias)

\begin{tabular}{lll}
\hline $\begin{array}{l}\text { Allocation concealment } \\
\text { (selection bias) }\end{array}$ & Unclear risk & No details provided. \\
\hline $\begin{array}{l}\text { Blinding of participants } \\
\text { and personnel (perfor- } \\
\text { mance bias) }\end{array}$ & Unclear risk & Authors communicated that participants were not blinded \\
All outcomes &
\end{tabular}

Blinding of outcome as-
sessment (detection bias) $\quad$ Unclear risk further details.


Alloni 2018 (Continued)

All outcomes

Incomplete outcome data Unclear risk Numbers of completers provided but no reasons for attrition.
(attrition bias)

(attrition bias)

All outcomes

\begin{tabular}{lll}
\hline $\begin{array}{l}\text { Selective reporting (re- } \\
\text { porting bias) }\end{array}$ & Low risk & All outcomes reported. \\
\hline Other bias & Low risk & None identified. \\
\hline
\end{tabular}

\section{Cerasa 2014}

Methods RCT of intensive computerised attention-training vs control group

Participants People with a diagnosis of PD $(n=20)$, with no dementia (Diagnostic and Statistical Manual of Menta Disorders 4th edition) but predominant deficits in either attention or information processing speed, working memory, or executive function (but no deficit in other domains such as language, verbal and spatial long-term memory).

Number randomised: $\mathrm{n}=20$.

Interventions

Computerised 12 one-hour sessions over 6 weeks performing several attention ability and information processing tasks tailored to attention deficits.

Control group received simple visuo-motor co-ordination exercises.

Putcomes
Primary outcomes:
1. Global cognition
- MMSE
1. ROCFT Immediate and Delayed Recall
2. Selective Reminding Test
- Visual-spatial processing
1. Judgment of Line Orientation (JLO)
- Executive function/verbal fluency
1. Controlled Oral Word Association Test (COWAT)
- Sustained attention
1. Symbol Digit Modalities Test (SDMT)
- Information processing speed
1. Paced Auditory Serial Addition Test
2. Digit span forward/backward
3. Stroop test
4. TMTa, TMTb, and Trail Making Test B-A (TMTB-A)
- Depression
1. Beck Depression Inventory-II (BDI-II)
- Anxiety
1. State-Trait Anxiety Inventory
- Quality of life
1. Parkinson's Disease Questionnaire (PDQ-39)


Cerasa 2014 (Continued)

Risk of bias

\begin{tabular}{|c|c|c|}
\hline Bias & Authors' judgement & Support for judgement \\
\hline $\begin{array}{l}\text { Random sequence genera- } \\
\text { tion (selection bias) }\end{array}$ & Unclear risk & Mentions random assignment only. \\
\hline $\begin{array}{l}\text { Allocation concealment } \\
\text { (selection bias) }\end{array}$ & Unclear risk & No details provided. \\
\hline $\begin{array}{l}\text { Blinding of participants } \\
\text { and personnel (perfor- } \\
\text { mance bias) } \\
\text { All outcomes }\end{array}$ & Low risk & Participants were blind to treatment allocation. \\
\hline $\begin{array}{l}\text { Blinding of outcome as- } \\
\text { sessment (detection bias) } \\
\text { All outcomes }\end{array}$ & Low risk & Assessors were blind. \\
\hline $\begin{array}{l}\text { Incomplete outcome data } \\
\text { (attrition bias) } \\
\text { All outcomes }\end{array}$ & Low risk & Attrition and reasons reported. \\
\hline $\begin{array}{l}\text { Selective reporting (re- } \\
\text { porting bias) }\end{array}$ & Low risk & All outcomes reported. \\
\hline Other bias & Low risk & None identified. \\
\hline
\end{tabular}

\section{Costa 2014}

Methods RCT with 2 arms and a healthy control group

Participants

People with PD ( $\mathrm{n}=17$ ) defined according to UKPDBB criteria (Hughes 1992), and presence of $\mathrm{MCl}$ according to Litvan and colleagues criteria (Litvan 2012). Participants performed 1.5 Standard Deviations (SDs) below the normative population in 2 tests of a neuropsychological screening battery, 1 of which investigated executive function.

All treated with levodopa or dopamine agonists, or both.

Excluded participants with psychiatric disorder, significant apathy and depression, or neurological conditions other than PD. Number randomised $(n=17)$.

- 45-minute paper and pencil exercises involving different stimuli (e.g. letters, numbers, and shapes), modelled on existing paradigms sensitive to frontal-striatal activity requiring participants to alternately select between stimuli belonging to different semantic categories or different features that increased in difficulty (Macdonald 2011).

- 12 sessions in total over 4 weeks

Control group: performed language and respiratory exercises of similar frequency and duration to the cognitive training exercises, which included dictation and reordering of sentence sequences.

$\begin{array}{ll}\text { Outcomes } & \text { Verbal fluency } \\ \text { 1. Phonemic word fluency (verbal fluency alternate task) } & \text { 2. semantic fluency }\end{array}$


Costa 2014 (Continued)

3. alternating phonemic/semantic fluency

- Attention

1. TMTa and TMTb

\section{Notes}

\section{Risk of bias}

\begin{tabular}{|c|c|c|}
\hline Bias & Authors' judgement & Support for judgement \\
\hline $\begin{array}{l}\text { Random sequence genera- } \\
\text { tion (selection bias) }\end{array}$ & Unclear risk & Mentions only random assignment to the 2 treatment arms. \\
\hline $\begin{array}{l}\text { Allocation concealment } \\
\text { (selection bias) }\end{array}$ & Unclear risk & No details are provided. \\
\hline $\begin{array}{l}\text { Blinding of participants } \\
\text { and personnel (perfor- } \\
\text { mance bias) } \\
\text { All outcomes }\end{array}$ & Low risk & Participants were blind to treatment allocation. \\
\hline $\begin{array}{l}\text { Blinding of outcome as- } \\
\text { sessment (detection bias) } \\
\text { All outcomes }\end{array}$ & Low risk & Researcher conducting post-assessments was blind. \\
\hline $\begin{array}{l}\text { Incomplete outcome data } \\
\text { (attrition bias) } \\
\text { All outcomes }\end{array}$ & Low risk & No attrition in the study. \\
\hline $\begin{array}{l}\text { Selective reporting (re- } \\
\text { porting bias) }\end{array}$ & Low risk & All outcomes reported. \\
\hline Other bias & Low risk & None identified. \\
\hline
\end{tabular}

\section{Folkerts 2018}

\begin{tabular}{ll}
\hline Methods & RCT (cross-over RCT) \\
\hline Participants & $\begin{array}{l}\text { People with Parkinson's disease dementia (PDD) living in long-term care; diagnosed according to the } \\
\text { Movement Disorders Society (MDS) task force Level I guidelines and PDD diagnosed with the MMSE (10 } \\
\text { to } 25 \text { points). Number randomised }(n=12) .\end{array}$
\end{tabular}

Interventions

Although intervention is described as cognitive stimulation therapy, it was a structured standardised Cognitive Training (CT) programme (NEUROvitalis) adapted to the cognitive and psychomotor profile of participants; performed over 8 weeks, twice weekly for 60 minutes.

Control group received usual care (arts, sports, music).

\section{Outcomes}

\section{Cognition}

1. Consortium to Establish a Registry for Alzheimer's Disease test battery - "CERAD Plus" (plus a word fluency test and the TMT; total score as an index for global cognition (maximum 111 points)

Neuropsychiatric symptoms

1. Neuropsychiatric Inventory 
Folkerts 2018 (Continued)

\section{Depression}

1. Geriatric Depression Scale-Short form (GDS-15)

2. Cornell Scale for Depression in Dementia

Activities of daily living

1. Barthel Index

Quality of life

1. EQ-5D-5L

2. QUALIDEM

Notes

\section{Risk of bias}

Bias Authors' judgement Support for judgement

Random sequence genera- High risk Participants were randomised by picking a note with the participant's identifition (selection bias) cation code, comprised of 2 random letters and random numbers.

\begin{tabular}{|c|c|c|}
\hline $\begin{array}{l}\text { Allocation concealment } \\
\text { (selection bias) }\end{array}$ & Low risk & $\begin{array}{l}\text { Mentions that randomisation was done by a member of the staff not involved } \\
\text { in the study. }\end{array}$ \\
\hline
\end{tabular}

Blinding of participants $\quad$ Unclear risk $\quad$ No details provided.
and personnel (perfor-
mance bias)
All outcomes

\begin{tabular}{|c|c|c|}
\hline $\begin{array}{l}\text { Blinding of outcome as- } \\
\text { sessment (detection bias) } \\
\text { All outcomes }\end{array}$ & High risk & Not all assessors were blind. \\
\hline $\begin{array}{l}\text { Incomplete outcome data } \\
\text { (attrition bias) } \\
\text { All outcomes }\end{array}$ & Low risk & Attrition and reasons for each group are reported. \\
\hline $\begin{array}{l}\text { Selective reporting (re- } \\
\text { porting bias) }\end{array}$ & Low risk & All outcomes reported. \\
\hline Other bias & Low risk & None identified. \\
\hline
\end{tabular}

Lawrence 2018

$\begin{array}{ll}\text { Methods } & \text { RCT of standard CT vs tailored CT vs transcranial direct current stimulation vs standard CT + transcra- } \\ \text { nial direct current stimulation vs tailored CT + transcranial direct current stimulation vs control group. }\end{array}$

Participants People diagnosed with idiopathic PD in accordance with the UKPDBB criteria, with $\mathrm{MCl}$ in accordance with the MDS Parkinson's Disease-Mild Cognitive Impairment (PD-MCI) Level II diagnostic criteria. Number randomised $(n=42)$.

Interventions Standard cognitive training known as Smartbrain Pro targeting specific cognitive domains, for 45 minutes, 3 times a week for 4 weeks. Tailored cognitive training of the same format and duration where cognitive activities were individualised to participant's baseline neuropsychological test results. Both treatment arms were included in the meta-analyses. 
Lawrence 2018 (Continued)

Control group received no intervention.

\begin{tabular}{|c|c|}
\hline Outcomes & $\begin{array}{l}\text { - Executive function } \\
\text { 1. Stockings of Cambridge (of the Cambridge Neuropsychological Tests Automated Battery) } \\
\text { 2. COWAT } \\
\text { - Attention } \\
\text { 1. Letter-Number Sequencing } \\
\text { 2. Stroop (Colour-Word Interference) test } \\
\text { - Memory } \\
\text { 1. Hopkins Verbal Learning Test-Revised Immediate Recall subtest } \\
\text { 2. Paragraph Recall Test } \\
\text { - Visuo-spatial abilities } \\
\text { 1. JLO } \\
\text { 2. Hooper Visual Organization Test } \\
\text { - Language } \\
\text { 1. Boston Naming Test-Short Form } \\
\text { 2. Similarities Test } \\
\text { - Global cognition } \\
\text { 1. Parkinson's Disease-Cognitive Rating Scale } \\
\text { 2. MMSE } \\
\text { - Premorbid intelligence } \\
\text { 1. National Adult Reading Test } \\
\text { - Activities of daily living } \\
\text { 1. Unified Parkinson's Disease Rating Scale (Section II) } \\
\text { - Quality of life } \\
\text { 1. PDQ-39 }\end{array}$ \\
\hline
\end{tabular}

We included both the standard and the tailored cognitive training treatment groups in the analyses.

\section{Risk of bias}

\begin{tabular}{lll}
\hline Bias & Authors' judgement & Support for judgement \\
\hline $\begin{array}{l}\text { Random sequence genera- } \\
\text { tion (selection bias) }\end{array}$ & Low risk & Sequence generated by computer following CONSORT guidelines. \\
\hline $\begin{array}{l}\text { Allocation concealment } \\
\text { (selection bias) }\end{array}$ & Low risk & $\begin{array}{l}\text { Participants were randomised to treatment (5 intervention and 1 control) by a } \\
\text { computer-generated list using block randomisation at a ratio of 1:1. Probably } \\
\text { done. }\end{array}$ \\
\hline $\begin{array}{l}\text { Blinding of participants } \\
\text { and personnel (perfor- } \\
\text { mance bias) }\end{array}$ & Unclear risk & No further details provided. \\
All outcomes & & \\
\hline
\end{tabular}

Blinding of outcome as- High risk Authors mention that it was not possible to blind researchers.
sessment (detection bias) All outcomes

Incomplete outcome data Low risk Attrition reported. No details of reasons are provided.
(attrition bias)

All outcomes

Selective reporting (re- Low risk $\quad$ All outcomes reported.
porting bias)


Lawrence 2018 (Continued)
Other bias
Low risk
No other bias detected.

París 2011

\begin{tabular}{|c|c|}
\hline Methods & RCT of cognitive training vs control group \\
\hline Participants & $\begin{array}{l}\text { People who met UKPDBB diagnosis criteria for Parkinson's disease, with I-III Hoehn and Yahr, without } \\
\text { dementia (MMSE } \geq 23) \text {, including those who had } \mathrm{MCI}(50 \% \text { met Petersen and colleagues } 2005 \text { criteria } \\
\text { for } \mathrm{MCI} \text { ). } \\
\text { Number randomised }(\mathrm{n}=33) \text {. }\end{array}$ \\
\hline Interventions & $\begin{array}{l}\text { Cognitive training } 3 \text { times a week over } 4 \text { weeks with each session lasting } 45 \text { minutes. } \\
\text { Control group received speech group therapy. }\end{array}$ \\
\hline Outcomes & $\begin{array}{l}\text { - Cognition } \\
\text { 1. MMSE } \\
\text { 2. Addenbrooke's Cognitive Examination } \\
\text { - Premorbid intelligence } \\
\text { 1. Wechsler Adult Intelligence Scale III Vocabulary subtest } \\
\text { - Attention and working memory } \\
\text { 1. WAIS III-Digit Span Forward and Backward } \\
\text { 2. California Verbal Learning Test II-List A1 } \\
\text { - Information processing speed } \\
\text { 1. SDMT } \\
\text { 2. TMTa and TMTb } \\
\text { 3. Stroop test } \\
\text { - Verbal memory } \\
\text { 1. CVLT-II-Short-Delay Free Recall and Long-Delay Free Recall } \\
\text { 2. Wechsler Memory Scale-III-Logical Memory test } \\
\text { - Learning } \\
\text { 1. CVLT-II-List A Total } \\
\text { - Visual memory } \\
\text { 1. ROCFT Immediate and Delayed Recall } \\
\text { - Visuo-spatial abilities } \\
\text { 1. JLO } \\
\text { - Verbal fluency } \\
\text { 1. Phonemic-F-A-S Test } \\
\text { 2. Semantic-Animals F-A-S Test } \\
\text { - Executive function } \\
\text { 1. Tower of London-Total Moves, Total Correct, and Total-Rules Violations } \\
\text { 2. TMT-B } \\
\text { 3. Stroop test (Interference) } \\
\text { - Quality of life } \\
\text { 1. PDQ-39 } \\
\text { - Depression } \\
\text { 1. GDS-15 } \\
\text { - Cognitive difficulties in activities of daily living } \\
\text { 1. Cognitive Difficulties Scale }\end{array}$ \\
\hline
\end{tabular}


París 2011 (Continued)

Notes

\section{Risk of bias}

Bias Authors' judgement Support for judgement

Random sequence genera- Unclear risk Only mentions random allocation. No further details provided.
tion (selection bias)

Allocation concealment $\quad$ Low risk $\quad$ Mentions blind allocation. Probably done.
(selection bias)

\begin{tabular}{lll}
\hline $\begin{array}{l}\text { Blinding of participants } \\
\text { and personnel (perfor- } \\
\text { mance bias) }\end{array}$ & Unclear risk & No details provided. \\
All outcomes & \\
\hline $\begin{array}{l}\text { Blinding of outcome as- } \\
\text { sessment (detection bias) } \\
\text { All outcomes }\end{array}$ & Low risk & Assessors were blind to treatment allocation. \\
\hline $\begin{array}{l}\text { Incomplete outcome data } \\
\text { (attrition bias) }\end{array}$ & Unclear risk & $\begin{array}{l}\text { Mentions attrition and reasons, but also describes excluding participants com- } \\
\text { All outcomes }\end{array}$ \\
\hline
\end{tabular}

Selective reporting (re- Low risk $\quad$ All outcomes reported.
porting bias)

Other bias Low risk None identified.

Petrelli 2014

Methods RCT of structured cognitive training targeting specific cognitive functions plus psychoeducation elements vs unstructured cognitive training of randomly assembled cognitive tasks vs waiting-list control

Participants Idiopathic PD according to UKPDBB criteria, including people who had MCI according to MDS task force Level I guidelines (Litvan 2011). 23\% (15 of the 50) met Litvan and colleagues 2011 criteria for $\mathrm{MCl}$.

Number randomised $(n=70)$.

Interventions

"NEUROvitalis", a structured cognitive training intervention targeting several cognitive domains (attention, memory, executive function). Unstructured training called "Mentally fit" targeting attention, memory, and less specific functions such as language and creative thinking, 12 group sessions, 90 minutes each over 6 weeks.

Control group was waiting list.

\begin{tabular}{ll}
\hline Outcomes & 1. General cognitive function \\
& 2. DemTect \\
& - Attention \\
1. Brief Test of Attention & \\
& 1. Memory \\
1. Verbal short- and long-term memory DemTect & 2. Visual long-term memory DemTect
\end{tabular}


Petrelli 2014 (Continued)

- Executive functions

1. Working memory DemTect digit span reverse

2. Verbal phonemic and semantic fluency DemTect

- Visuo-construction

1. Rey's Complex Figure Test

- Depression

1. BDI-II

- Quality of life

1. PDQ-3

Notes We included both the structured ("NEUROvitalis") and the unstructured ("Mentally fit") cognitive training treatment groups in the analyses.

\section{Risk of bias}

\begin{tabular}{|c|c|c|}
\hline Bias & Authors' judgement & Support for judgement \\
\hline $\begin{array}{l}\text { Random sequence genera- } \\
\text { tion (selection bias) }\end{array}$ & Low risk & Mentions random allocation using a computer program. \\
\hline $\begin{array}{l}\text { Allocation concealment } \\
\text { (selection bias) }\end{array}$ & Unclear risk & No details provided. \\
\hline $\begin{array}{l}\text { Blinding of participants } \\
\text { and personnel (perfor- } \\
\text { mance bias) } \\
\text { All outcomes }\end{array}$ & Unclear risk & Only participants in the 2 treatment groups were blinded. \\
\hline $\begin{array}{l}\text { Blinding of outcome as- } \\
\text { sessment (detection bias) } \\
\text { All outcomes }\end{array}$ & Low risk & Assessors were blind. \\
\hline $\begin{array}{l}\text { Incomplete outcome data } \\
\text { (attrition bias) } \\
\text { All outcomes }\end{array}$ & Unclear risk & $\begin{array}{l}\text { Attrition and reasons were reported, but also describes excluding participants } \\
\text { completing less than } 75 \% \text { of sessions. }\end{array}$ \\
\hline $\begin{array}{l}\text { Selective reporting (re- } \\
\text { porting bias) }\end{array}$ & Low risk & All outcomes reported. \\
\hline Other bias & Low risk & None identified. \\
\hline
\end{tabular}

PD: Parkinson's disease

UKPDBB: UK Parkinson's Disease Society Brain Bank diagnostic criteria

$\mathrm{MCl}$ : mild cognitive impairment

MMSE: Mini-Mental State Examination

MoCA: Montreal Overall Cognitive Assessment

ROCF: Rey's Complex Figure Test

F-A-S Tests: Semantic fluency and phonological fluency

TMTa: Trail Making Test Part A

TMTb: Trail Making Test Part B

JLO: Judgment of Line Orientation

COWAT: Controlled Oral Word Association Test

SDMT: Symbol Digit Modalities Test

TMTB-A: Trail Making Test B-A

BDI-II: Beck Depression Inventory-II

PDQ-39: Parkinson's Disease Questionnaire

SDs: Standard Deviations 
PDD: Parkinson's disease dementia

CT: Cognitive Training

GDS-15: Geriatric Depression Scale-Short form

PD-MCI: Parkinson's Disease-Mild Cognitive Impairment

\section{Characteristics of excluded studies [ordered by study ID]}

\begin{tabular}{ll}
\hline Study & Reason for exclusion \\
\hline ACTRN12617000634370 & Ongoing RCT of a cognitive-plus-exercise-enrichment intervention vs standard care for people with \\
& PD and no cognitive impairment.
\end{tabular}

Adamski $2016 \quad$ Non-Randomised Controlled Trial (RCT), feasibility study of computerised cognitive training (BrainStim) in people with Parkinson's disease (PD) where only healthy controls were randomised. No control group, and people with PD had no cognitive impairment.

Atias 2015 Non-RCT feasibility pre-and-post study of cognitive training (AttenGo) designed to improve execu-
tive function in participants with PD with no cognitive impairment; (Mini-Mental State Examination
(MMSE) $>25$ ). No control group.
$(M M S E)>25)$. No control group.

Biundo 2015 RCT of the effects of computer-based cognitive training alone or combined with non-invasive brain stimulation in people with Parkinson's Disease-Mild Cognitive Impairment (PD-MCI). No control group.

Canning 2008 Non-RCT feasibility study of multiple-task walking training incorporating cognitive activities
(counting backwards, memory recall, generating category lists, and simple arithmetic tasks) in par-
ticipants with PD with no cognitive impairment (MMSE $\geq 24$ ).

Disbrow 2012

Pre-and-post experimental study of a computer-based cognitive and motor training programme designed to improve motor-related executive function in participants with PD. Participants were screened for dementia.

\begin{tabular}{ll}
\hline Díez-Cirarda 2017 & $\begin{array}{l}\text { Pre-and-post study of a group-based cognitive intervention for people with PD; no control group; } \\
\text { people with dementia were excluded. }\end{array}$
\end{tabular}

Edwards 2013 RCT of a self-administered cognitive speed-of-processing training (SOPT, InSight) designed to improve information processing speed in realistic visual contexts vs no-contact control condition in participants with PD (MMSE $\geq 24$ ). Participants with dementia were excluded. Primary outcome was field of view performance.

\begin{tabular}{ll}
\hline Farzana 2015 & $\begin{array}{l}\text { Non-RCT pre-and-post study of individual home-based cognitive stimulation in people with PD and } \\
\text { mild to moderate cognitive impairment (MMSE > 24); information on diagnosis of dementia/mild } \\
\text { cognitive impairment }(\mathrm{MCl}) \text { not reported. }\end{array}$
\end{tabular}

\begin{tabular}{ll}
\hline Fearon 2017 & $\begin{array}{l}\text { Pre-and-post evaluation of a virtual reality-based intervention combining motor and cognitive } \\
\text { training for people with PD and no cognitive impairment. }\end{array}$
\end{tabular}

Fellman $2018 \quad$ RCT of cognitive training of working memory vs quiz training in people with PD and no cognitive impairment; people with dementia were excluded.

Fernandez-del-Olmo 2018

RCT of cognitive training vs cognitive training with concurrent physical exercise in people with PD without cognitive impairment.

\section{Goedeken 2018}

RCT of an Implementations Intentions (encoding strategy training) intervention vs verbal rehearsal (control group) for people with PD. People with dementia were excluded.

Hindle 2016

RCT of cognitive rehabilitation in people with Parkinson's disease dementia (PDD) vs relaxation therapy vs treatment as usual. 


Study Reason for exclusion

Kim 2016

Pre and post study of cognitive training (PD-CoRE) in people with PD and executive dysfunction; no control group.

Maggio 2018

RCT of virtual reality cognitive rehabilitation versus standard cognitive training in people with PD and mild to moderate cognitive impairment (MMSE from 11 to 26); no control group.

Mahmoud 2018

RCT of a motor imagery training intervention vs cognitive remediation therapy for people with PD and cognitive dysfunction diagnosed by a cognitive assessment on RehaCom. No control group. All outcome measures were RehaCom tasks rather than standardised instruments.

McCormick 2018

RCT (ongoing) assessing the feasibility and acceptability of individual cognitive stimulation therapy for people with PD-related dementias (PD-MCI; PDD or Dementia with Lewy bodies) vs treatment as usual.

Mirelman 2011

Feasibility non-RCT of virtual reality training with cognitive components (attention, response selection, and processing visual stimuli) in participants with PD. People with dementia were excluded. No control group.

Mohlman 2011

Non-RCT feasibility study of a cognitive remediation programme to train attentional ability in people with PD. People with dementia were excluded. No control group.

Monticone 2015

RCT of a multidisciplinary intervention of task-oriented exercises, Cognitive Behavioral Therapy, and occupational therapy in people with PD. People with dementia or MMSE < 24 were excluded.

Motlagh 2017

RCT of cognitive training for freezing of gait in people with PD and no cognitive impairment vs control.

Naismith 2013

Non-RCT (controlled study) of computer-based cognitive training (based on the Neuropsychological Educational Approach to Remediation (NEAR)) with psychoeducation vs a waiting-list control group in people with PD, of whom some had $\mathrm{MCl}$. People with dementia were excluded.

NCT01156714 RCT of exercise training vs computerised memory training vs combined exercise and motor training vs control in people with PD and no cognitive impairment.

NCT01469741 RCT of prospective memory training for participants with PD treated with levodopa/carbidopa. People with dementia are excluded (ongoing trial).

NCT02826785

Pre and post feasibility study of a cognitive training strategy intervention for people with PD who experience at least 1 problem with their daily cognitive performance; people with dementia were excluded.

NCT02922530

RCT (ongoing) of a novel mobile cognitive tracking and training tool in people with PD with no cognitive impairment targeting depression and quality of life. Control group is a commercially available cognitive training intervention.

NCT03335150

Ongoing RCT of cognitive rehabilitation (Cognitive Symptom Management and Rehabilitation Therapy for Parkinson's disease: CogSMART-PD) for people with PD-MCI vs a support group intervention.

NCT03680170

RCT of web-based working memory updating training vs low-dose short-term memory training in people with PD without cognitive impairment.

NCT03836963

3-arm RCT of cognitive and memory strategy training in veterans with PD-MCl. Active comparators are cognitive and memory training as stand-alone interventions. 


\begin{tabular}{ll}
\hline Study & Reason for exclusion \\
\hline NCT04048122 & RCT of cognitive rehabilitation known as MC4PD strategy training versus standard care for people \\
with PD and subjective cognitive decline. People with dementia will be excluded (Montreal Overall \\
Cognitive Assessment $<21)$. Primary outcome is goal attainment.
\end{tabular}

Nombela 2011

Non-RCT, feasibility pre-and-post study of cognitive training incorporating Sudoku exercises (working memory using numerical items, whilst requiring no mathematical calculation) in participants with PD, with their performance matched to controls. No control group. Does not mention level of cognitive impairment (baseline MMSE = 25).

Peters 2012

Ongoing RCT of a multidisciplinary intervention (exercise rehabilitation, cognitive and speech activities) vs standard exercise rehabilitation in participants with PD. People with cognitive impairment that could affect their ability to participate in the intervention are excluded.

Peña 2014

RCT of integrative structured cognitive training programme (REHACOP; attention, memory, processing speed, language and executive function tasks) vs occupational group activities in participants with PD. People with dementia were excluded.

Piemonte 2016

RCT of declarative memory training targeting gait and activities of daily living in people with PD with no cognitive impairment.

Pompeu 2012

RCT of Nintendo Wii-based motor and cognitive training vs balance exercise therapy in participants with PD without $\mathrm{MCl}$ or dementia (MMSE $\geq 23$ ). The cognitive component of the training included attention and use of working memory to solve motor tasks, and performance management.

Pompeu 2016

RCT testing the efficacy of a European physiotherapy guideline vs Microsoft Kinect games training on postural control, cognition, and quality of life. People with PD had no cognitive impairment.

Quayhagen 2000

RCT of cognitive stimulation provided by carers (memory, problem-solving, and conversational fluency activities) vs dyadic counselling vs supportive seminars vs day care for people with Alzheimer's disease, cardiovascular, or PDD. No separate data are provided, and no formal criteria to diagnose dementia in PD were used.

Reuter 2012

RCT of cognitive training (attention, executive function, memory training) vs cognitive and transfer training vs cognitive, transfer, and psychomotor training in participants with Parkinson's disease and $\mathrm{MCl}$. No control group.

Sammer 2006

RCT of cognitive training (working memory tasks targeting executive function) vs control in participants with PD without cognitive impairment (average MMSE $=27$ ). Cognitive stage not defined.

Sinforiani 2004

Non-RCT, feasibility pre-post study of cognitive training (attention, abstract reasoning, visuo-spatial abilities) incorporating motor training in participants with PD presenting with mild cognitive deficits. No control group. People with severe cognitive impairment or dementia, or both were excluded.

Not an RCT. Testing the feasibility of brain mobile gaming (reducing cognitive interference) in people with vascular $\mathrm{MCl}$ and $\mathrm{PD}-\mathrm{MCl}$ and age-matched controls.

Strouwen 2017

Ongoing RCT of integrated gait and cognitive training (performing cognitive exercises, and functional training simultaneously) on activities of daily living vs consecutive gait and cognitive training (taking place separately) in participants with PD without cognitive impairment (MMSE $\geq 24$ ), aimed primarily at increasing gait performance (primary outcome).

Valdés 2017

RCT of speed of information processing vs delayed control group in people with PD with an MMSE score $\geq 24$.

Vlagsma 2020 RCT of cognitive rehabilitation vs computerised cognitive training for attention (CogniPlus) in people with PD and executive dysfunction. 


\begin{tabular}{|c|c|}
\hline Study & Reason for exclusion \\
\hline Walton 2016 & $\begin{array}{l}\text { RCT of computerised cognitive training targeting executive function, processing speed, and atten- } \\
\text { tion in people with PD with no cognitive impairment (MMSE } \geq 24) \text {. The primary outcome was freez- } \\
\text { ing of gait. }\end{array}$ \\
\hline Zimmermann 2014 & $\begin{array}{l}\text { RCT of cognition-specific computer-based cognitive training (CogniPlus) vs a non-cognition-specif- } \\
\text { ic computer sports game (Nintendo Wii) in participants with PD without cognitive impairment (av- } \\
\text { erage MMSE = 29). People with moderate or severe dementia were excluded. }\end{array}$ \\
\hline
\end{tabular}

RCT: Randomised Controlled Trial

PD: Parkinson's disease

MMSE: Mini-Mental State Examination

PD-MCI: Parkinson's Disease-Mild Cognitive Impairment

$\mathrm{MCl}$ : mild cognitive impairment

PDD: Parkinson's disease dementia

Characteristics of studies awaiting assessment [ordered by study ID]

\section{NCT01646333}

Methods RCT (ongoing) of memory and problem-solving training vs non-directive supportive therapy

Participants Clinical diagnosis of Parkinson's disease (PD)

- Clinical diagnosis of $\mathrm{MCl}$

Exclusion criteria: clinical diagnosis of dementia or other PD-associated comorbid conditions (e.g. severe anxiety, depression, excessive daytime sleepiness, or psychosis) that can influence cognitive testing.

Interventions Memory and problem-solving training consisting of a day calendar manual and note-taking system and problem-solving techniques focusing on memory compensation and problem-solving strategies.

Control group: supportive therapy (offering participants and carers the opportunity to discuss and reflect upon both PD and non-PD related problems).

Outcomes Primary outcome: verbal learning measured by the California Verbal Learning Test-II Long Delay Free Recall Scaled Score

Secondary outcomes: well-being measured by the Linear Analog Scale Assessment Overall Well Being scale

Outcomes measured at 2 and 6 months.

\section{NCT01647698}

\begin{tabular}{ll} 
Methods & $\begin{array}{l}\text { Randomised Controlled Trial (RCT) (ongoing) of the effectiveness of adaptive vs non-adaptive } \\
\text { working memory training (increasing in number of items required to be remembered) vs no train- } \\
\text { ing; ongoing trial, } 3 \text { arms }\end{array}$ \\
\hline Participants & $\begin{array}{l}\text { People with PD who self-report concerns about working memory or show deficits as identified by a } \\
\text { clinical examination (excludes people with dementia). }\end{array}$ \\
\hline
\end{tabular}


NCT01647698 (Continued)

Interventions
Computerised adaptive working memory training testing working memory capacity and non-adaptive working memory training.

Outcomes

Primary outcomes: working memory (measured by 3 separate tasks): operation span task, symmetry span task, Stenberg memory scanning task

Secondary outcomes: fluid intelligence (Cattell's Culture Fair Intelligence Test and Rave's Progressive Matrices), executive function: Dysexecutive Questionnaire

Outcomes measured at 5-, 10-, and 22-week follow-up.

Notes Unclear whether this sample has Parkinson's Disease-Mild Cognitive Impairment (PD-MCI). Trial is ongoing (control group receives no training); unable to contact author.

\section{NCT02920632}

\section{Methods}

RCT (ongoing) of online cognitive training (COGTIPS - COGnitive Training In Parkinson Study) vs online cognitive training of games that incorporate cognitive activities

\section{Participants}

- Subjective cognitive complaints, measured by the Parkinson's Disease Cognitive Functional Rating Scale score > 3 (PD-CFRS); a score above 3 indicates significant cognitive complaints that are milder than complaints associated with Parkinson's disease dementia. Questionnaire is filled in by the participant.

- Participants' Hoehn and Yahr stage is lower than 4

- Access to a computer or tablet and willing to sign informed consent

Exclusion criteria: indications for a dementia syndrome, measured by the self-administered Gerocognitive Examination (score $<14$ ) or the Montreal Cognitive Assessment (score <22).

Interventions 8-week training (COGTIPS) - training contains several games that are designed to train cognitive functions; 3 times a week for 45 minutes

Control group receives online gaming cognitive activities.

\section{Outcomes}

Primary outcome: executive function measured by the Tower of London

Secondary outcomes: subjective cognitive complaints measured by the PD-CFRS; executive function measured by the Stroop colour-word task, the Letter fluency task, and the Tower of London; risk reduction of PD-MCI/Parkinson's disease dementia (PDD) development at follow-up

Outcomes measured at 6 months, 1 year, and 2 years.

Notes

Although risk reduction of PD-MCl/PDD development at follow-up is an outcome for the study, participants may meet PD-MCl criteria at baseline. Trial is ongoing.

RCT: Randomised Controlled Trial

PD: Parkinson's disease

PD-MCI: Parkinson's Disease-Mild Cognitive Impairment

PDD: Parkinson's disease dementia

Characteristics of ongoing studies [ordered by study ID]

\section{ACTRN12618000999235}

Trial name or title
A randomised controlled trial of cognitive training and non-invasive brain stimulation in PD: the impact on cognition and quality of life 
ACTRN12618000999235 (Continued)

Methods

4-arm RCT of transcranial direct current stimulation and cognitive training vs sham transcranial direct current stimulation and cognitive training vs transcranial direct current stimulation and placebo cognitive training vs sham transcranial direct current stimulation and placebo cognitive training $(n=52)$.

\section{Participants}

1. Diagnosed with idiopathic PD by neurologist/geriatrician using UK Parkinson's Disease Society Brain Bank (UKPDBB) diagnostic criteria

2. Self-reported problems with cognition that do not significantly impact on functional independence

3. Presence of $\mathrm{MCl}$ in accordance with the Movement Disorder Society Task Force criteria for PD-MCI Level II diagnostic criteria, using an Standard Deviation (SD) level of 1.5

4. Stable response to antiparkinsonian medication for a minimum period of 2 months.

\begin{tabular}{l} 
Cognitive training \\
Control group receives sham cognitive training. \\
\hline Outcomes \\
1. Attention and working memory: Letter-Number Sequencing subtest from the Wechsler Adult In- \\
telligence Scale-IV (WAIS-IV) \\
2. Attention: Stroop (Colour-Word) Test \\
3. Executive function: Stockings of Cambridge (of the Cambridge Neuropsychological Tests Auto- \\
mated Battery) \\
4. Executive function: Controlled Oral Word Association Task \\
5. Language: Boston Naming Test \\
6. Language: Similarities subtest of the WAIS-IV \\
7. Memory: Hopkins Verbal Learning Test-Revised \\
8. Memory: Location Learning Test \\
9. Visuo-spatial processing: Judgement of Line Orientation test \\
10.Visuo-spatial processing: Hooper Visual Organization Test \\
•. Secondary outcomes: \\
1. Quality of life: Parkinson's Disease Questionnaire (PDQ-39) \\
Outcomes measured at 1 week and 12 weeks.
\end{tabular}

\begin{tabular}{ll}
\hline Starting date & August 2018 \\
\hline Contact information & n.gasson@curtin.edu.au \\
\hline
\end{tabular}

Notes

\section{NCT02225314}

\begin{tabular}{ll}
\hline Trial name or title & Computer-based cognitive training for individuals with PD-MCl \\
\hline Methods & $\begin{array}{l}\text { 3-arm RCT of computerised auditory and accuracy training vs visual processing and working mem- } \\
\text { ory training vs active control }(\mathrm{n}=25) .\end{array}$ \\
\hline Participants & $\begin{array}{l}\text { People speaking English with a confirmed medical diagnosis of Parkinson's disease and meeting } \\
\text { established criteria for MCl in PD (Litvan 2012), defined as individuals with performances of approx- } \\
\text { imately } 1 \text { to }-2 \text { SDs below the mean on at least } 2 \text { tests within } 5 \text { cognitive domains assessed in clini- } \\
\text { cal neuropsychological evaluations } \\
\text { People with dementia are excluded. }\end{array}$ \\
\hline
\end{tabular}


NCT02225314 (Continued)

Interventions
Treatment arm 1: computer-based cognitive training known as Brain Fitness, which consists of 6 types of exercises that train auditory processing speed and accuracy

Treatment arm 2: computer-based cognitive training known as InSight, a computer-based cognitive training programme that consists of 5 types of exercises that train visual processing and working memory

60 minutes per day, 5 days a week

Active-control training programme: computerised learning programme consisting of 5 programmes (i.e. Wright Brothers, History of Britain, Sister Wendy's American Collection, In Search of Shakespeare, and View the Cosmos) designed to improve knowledge about literature, art, and history.

Outcomes

Primary outcome: per cent accuracy on cognitive training quizzes (Brain Fitness; auditory processing and accuracy tasks; InSight: visual processing and working memory tasks)

Secondary outcomes: PDQ-39, California Verbal Learning Test-II Long Delay Free Recall Scaled Score Change

Outcomes measured at 3 months.

\begin{tabular}{ll}
\hline Starting date & 19 August 2014 \\
\hline Contact information & sklageman@vcu.edu
\end{tabular}

\section{NCT02525367}

Trial name or title

vulsive therapy

Interventions

RCT vs active control condition (double-blind) $(n=28)$.

- Diagnosed with Parkinson's disease UKPDBB diagnostic criteria

- Problems in cognition with deficits in executive function lying between 1 and 2 SDs below the mean of the healthy Dutch population

- Stable medication

Online computerised cognitive training (targeting executive functions, attention, working memory, and processing speed) over 8 weeks, 3 times a week for 45 to 60 minutes.

Control group: active control condition of cognitive activities based on crystallised intelligence.

Outcomes

Primary outcomes: feasibility over 8 weeks as reported by participants on a 4-point Likert-type scale.

Secondary outcomes:

1. Cognitive functioning: Trail Making Task

2. Subjective cognitive complaints: Cognitive Failures Questionnaire

3. Executive functions: Stroop (Colour Word) Test

4. Letter fluency, episodic memory: Rey Auditory Verbal Learning and Location Learning tests

Measured at 8 and 12 weeks 
NCT02525367 (Continued)

Starting date August 2015

Contact information oa.vandenheuvel@vumc.nl

Notes

$\begin{array}{ll}\text { Trial name or title } & \begin{array}{l}\text { Effect of computer-based cognitive training on attention and executive functions in patients with } \\ \text { Parkinson's disease }\end{array}\end{array}$

\begin{tabular}{ll}
\hline Methods & RCT (2 treatment arms) $(n=30)$. \\
\hline Participants & - Diagnosed with Parkinson's disease and executive dysfunction \\
& - Scoring between 22 and 28 on Montreal Cognitive Assessment \\
\hline
\end{tabular}

Interventions Computer-based cognitive training (either Brain + Evolution or Scientific Brain Training PRO) over 8 weeks.

Control group: receives no intervention (follow-up visits incorporating a computerised card game).

\begin{tabular}{|c|c|}
\hline Outcomes & $\begin{array}{l}\text { - Primary outcomes: } \\
\text { 1. Processing speed: Symbol Digit Modalities Test } \\
\text { 2. Quality of life: PDQ-39 } \\
\text { - Secondary outcomes: } \\
\text { 1. Depression: Hospital Anxiety and Depression Scale (HADS) } \\
\text { 2. Working memory: digit span from the WAIS-IV } \\
\text { 3. Verbal fluency: s-words; animal names; A/F-words } \\
\text { 4. Stroop colour/word test: Stroop; response inhibition } \\
\text { 5. Trail Making Test A and B: cognitive flexibility }\end{array}$ \\
\hline Starting date & October 2017 \\
\hline Contact information & annemette.loekkegaard@regionh.dk \\
\hline Notes & \\
\hline
\end{tabular}

\begin{tabular}{|c|c|}
\hline Trial name or title & Prospective memory training in Parkinson's disease \\
\hline Methods & Randomised Controlled Trial $(\mathrm{RCT})(\mathrm{n}=90)$. \\
\hline \multirow[t]{4}{*}{ Participants } & 1. Males and females over 50 years of age \\
\hline & 2. Meet criteria for typical idiopathic Parkinson's disease (PD) \\
\hline & 3. Hoehn and Yahr stage I-III \\
\hline & $\begin{array}{l}\text { 4. Have Parkinson's Disease-Mild Cognitive Impairment (PD-MCI) according to Movement Disorder } \\
\text { Society Level II diagnostic criteria }\end{array}$ \\
\hline
\end{tabular}


NCT03582670 (Continued)

Interventions
Strategy training (specific memory strategy training with training games, as well as feedback on accuracy and performance) vs process training (event- and time-based prospective memory tasks but no strategy training or feedback) vs control intervention (does not attend any sessions).
Primary outcome measures:

1. Virtual Week [Time Frame: 4 to 6 weeks]. A computerised board game that simulates daily life and real-world prospective memory challenges. Main outcome variable is the proportion of correct prospective memory responses for each task type (12 event based, 12 time based). Change of performance on the Virtual Week from the pre- and post-session will also be measured.

2. Prospective and Retrospective Memory Questionnaire [Time Frame: through completion of the study, up to 16 weeks]. Change in scores on this questionnaire will be measured.

\begin{tabular}{ll}
\hline Starting date & July 2018 \\
\hline Contact information & erfoster@wustl.edu \\
\hline
\end{tabular}

Notes

van de Weijer 2016

\begin{tabular}{ll}
\hline Trial name or title & Effect of health games on cognitive function in Parkinson's disease - The Parkin'play study \\
\hline Methods & Multicentre RCT $(\mathrm{n}=222)$. \\
\hline Participants & Diagnosis of idiopathic PD according to UKPDBB diagnostic criteria \\
& - Cognitive impairment at baseline in line with the Level 1 criteria for $\mathrm{MCl}$ and a cutoff of $1.5 \mathrm{SD}$ \\
- Aged 40 to 75 years & Not receiving any other cognitive therapy/intense physical activity \\
- Stable dopaminergic medication (for the last 3 months) \\
Excludes people with advanced problems in cognitive functioning.
\end{tabular}

Interventions

Web-based computerised cognitive training 'health game' targeting multiple cognitive domains over 12 weeks (via MyCognition AquaSnap).

Control group: waiting list.

- Primary outcome: cognition as measured by standard neuropsychological assessment
1. Executive function: Stroop Colour Word Test; category and letter fluency
2. Memory: Rey Auditory Verbal Learning
3. Visual perception: Judgement of Line Orientation
4. Visuoconstruction: Rey-Osterrieth Complex Figure
5. Language: Boston Naming Test - Short Form; and compound score of overall (global) cognition
and online assessment (MyCQ; MyCognition Quotient; 5 domains: attention, psychomotor speed,
working memory, episodic memory, executive function)
- Secondary outcomes:
1. Movement Disorder Society-Sponsored Revision of the Unified Parkinson's Disease Rating Scale
(MDS-UPDRS) to measure motor function
2. Depression: HADS
3. Self-report evaluation of perception
4. Memory and motor-function in daily life: Cognitive Failures Questionnaire


van de Weijer 2016 (Continued)

5. Functional abnormalities associated to cognitive impairment: Parkinson's Disease Cognitive Functional Rating Scale

6. Functional disability: re-Rasch-built Overall Disability Scale

7. Quality of life: PDF-39

8. Impulsive behaviour: Barratt Impulsiveness Scale 11

Biological outcomes: change in activity of the resting-state network associated with executive functions measured by functional magnetic resonance imaging

Outcomes measured at 12 and 24 weeks.

\begin{tabular}{ll}
\hline Starting date & 7 January 2016 \\
\hline Contact information & mark.kuijf@mumc.nl \\
\hline
\end{tabular}

Notes

RCT: Randomised Controlled Trial

PD: Parkinson's disease

PD-MCl: Parkinson's Disease-Mild Cognitive Impairment

UKPDBB: UK Parkinson's Disease Society Brain Bank diagnostic criteria

SD: Standard Deviation

WAIS-IV: Wechsler Adult Intelligence Scale-IV

PDQ-39: Parkinson's Disease Questionnaire

HADS: Hospital Anxiety and Depression Scale

\section{DATA AND ANALYSES}

\section{Comparison 1. Cognitive training versus control group}

\begin{tabular}{|c|c|c|c|c|}
\hline Outcome or subgroup title & $\begin{array}{l}\text { No. of } \\
\text { studies }\end{array}$ & $\begin{array}{l}\text { No. of } \\
\text { partici- } \\
\text { pants }\end{array}$ & Statistical method & Effect size \\
\hline 1 Global cognition post-treatment & 6 & 178 & $\begin{array}{l}\text { Std. Mean Difference (IV, Random, 95\% } \\
\mathrm{CI})\end{array}$ & $0.28[-0.03,0.59]$ \\
\hline 2 Executive function post-treatment & 5 & 112 & $\begin{array}{l}\text { Std. Mean Difference (IV, Random, 95\% } \\
\mathrm{Cl} \text { ) }\end{array}$ & $0.10[-0.28,0.48]$ \\
\hline 3 Attention post-treatment & 5 & 160 & $\begin{array}{l}\text { Std. Mean Difference (IV, Random, 95\% } \\
\mathrm{Cl} \text { ) }\end{array}$ & $0.36[0.03,0.68]$ \\
\hline 4 Verbal memory post-treatment & 5 & 160 & $\begin{array}{l}\text { Std. Mean Difference (IV, Random, 95\% } \\
\mathrm{Cl} \text { ) }\end{array}$ & $0.37[0.04,0.69]$ \\
\hline 5 Visual processing post-treatment & 3 & 64 & $\begin{array}{l}\text { Std. Mean Difference (IV, Random, 95\% } \\
\mathrm{CI})\end{array}$ & $0.30[-0.21,0.81]$ \\
\hline $\begin{array}{l}6 \text { Activities of daily living post-treat- } \\
\text { ment }\end{array}$ & 3 & 67 & $\begin{array}{l}\text { Std. Mean Difference (IV, Random, 95\% } \\
\mathrm{Cl} \text { ) }\end{array}$ & $0.03[-0.47,0.53]$ \\
\hline 7 Quality of life post-treatment & 5 & 147 & $\begin{array}{l}\text { Std. Mean Difference (IV, Random, 95\% } \\
\mathrm{Cl} \text { ) }\end{array}$ & $-0.01[-0.35,0.33]$ \\
\hline
\end{tabular}




\begin{tabular}{llllll}
\hline Outcome or subgroup title & $\begin{array}{l}\text { No. of } \\
\text { studies }\end{array}$ & $\begin{array}{l}\text { No. of } \\
\text { partici- } \\
\text { pants }\end{array}$ & Statistical method & Effect size \\
\hline 8 Global cognition long term & 2 & 41 & Mean Difference (IV, Random, 95\% Cl) & $0.28[-1.73,2.28]$ \\
\hline 9 Executive function long term & 2 & 41 & $\begin{array}{l}\text { Std. Mean Difference (IV, Random, 95\% } \\
\text { Cl) }\end{array}$ & $-0.22[-0.85,0.41]$ \\
\hline 10 Attention long term & 2 & 41 & Std. Mean Difference (IV, Random, 95\% & $0.21[-0.59,1.01]$ \\
\hline 11 Verbal memory long term & 2 & 41 & St) & \\
\hline
\end{tabular}

Analysis 1.1. Comparison 1 Cognitive training versus control group, Outcome $1 \mathrm{Global}$ cognition post-treatment.

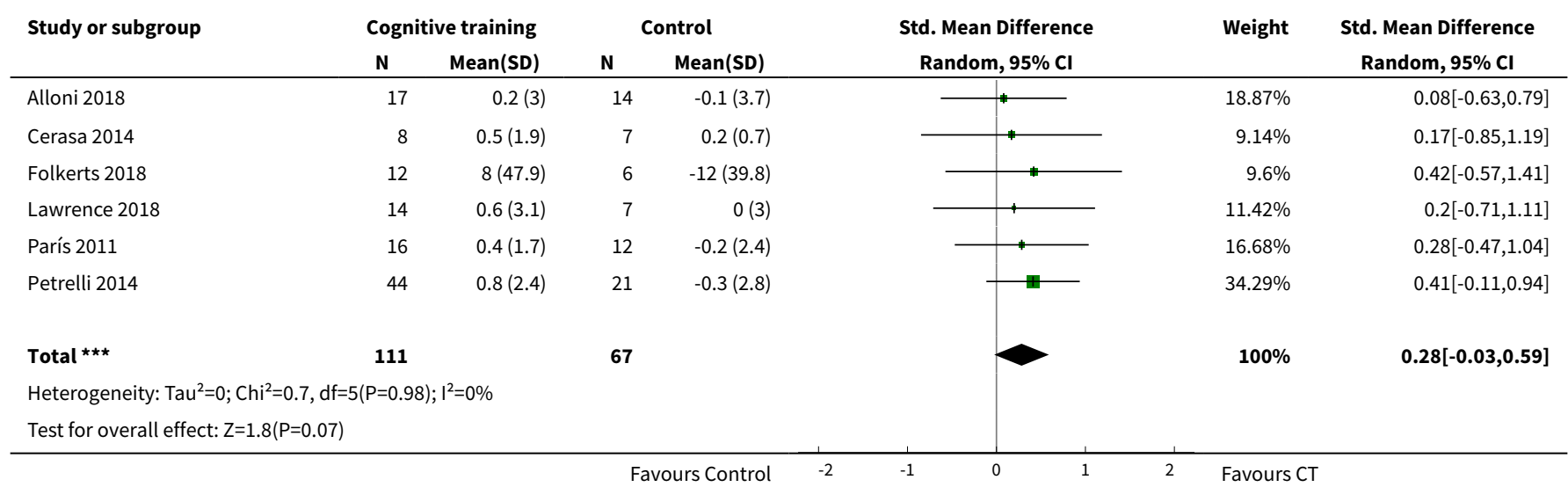

Analysis 1.2. Comparison 1 Cognitive training versus control group, Outcome 2 Executive function post-treatment.

\begin{tabular}{|c|c|c|c|c|c|c|c|}
\hline \multirow[t]{2}{*}{ Study or subgroup } & \multicolumn{2}{|c|}{ Cognitive training } & \multicolumn{2}{|c|}{ Control } & \multirow{2}{*}{$\begin{array}{c}\text { Std. Mean Difference } \\
\text { Random, } 95 \% \mathrm{Cl}\end{array}$} & \multirow[t]{2}{*}{ Weight } & \multirow{2}{*}{$\begin{array}{c}\text { Std. Mean Difference } \\
\text { Random, } 95 \% \mathrm{CI}\end{array}$} \\
\hline & $\mathbf{N}$ & Mean(SD) & $\mathbf{N}$ & Mean(SD) & & & \\
\hline Alloni 2018 & 17 & $39.4(114.5)$ & 14 & $2.4(126)$ & \begin{tabular}{l|l} 
\\
\end{tabular} & $28.47 \%$ & $0.3[-0.41,1.01]$ \\
\hline Cerasa 2014 & 8 & $10.7(81.9)$ & 7 & $26(69.6)$ & + & $14.04 \%$ & $-0.19[-1.21,0.83]$ \\
\hline Costa 2014 & 9 & $71.9(81.9)$ & 8 & $20.1(93.1)$ & & $15.23 \%$ & $0.56[-0.41,1.54]$ \\
\hline Lawrence 2018 & 14 & $-0.8(2.9)$ & 7 & $1.3(3.6)$ & $\longrightarrow$ & $16.69 \%$ & $-0.64[-1.57,0.29]$ \\
\hline París 2011 & 16 & $26.8(117.1)$ & 12 & $\begin{array}{r}-11.9 \\
(197.1)\end{array}$ & & $25.58 \%$ & $0.24[-0.51,0.99]$ \\
\hline 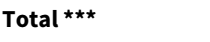 & 64 & & 48 & & & $100 \%$ & $0.1[-0.28,0.48]$ \\
\hline \multicolumn{8}{|c|}{ Heterogeneity: $\mathrm{Tau}^{2}=0 ; \mathrm{Chi}^{2}=4.04, \mathrm{df}=4(\mathrm{P}=0.4) ; \mathrm{I}^{2}=0.96 \%$} \\
\hline \multicolumn{3}{|c|}{ Test for overall effect: $Z=0.51(P=0.61)$} & & & & & \\
\hline
\end{tabular}


Analysis 1.3. Comparison 1 Cognitive training versus control group, Outcome 3 Attention post-treatment.

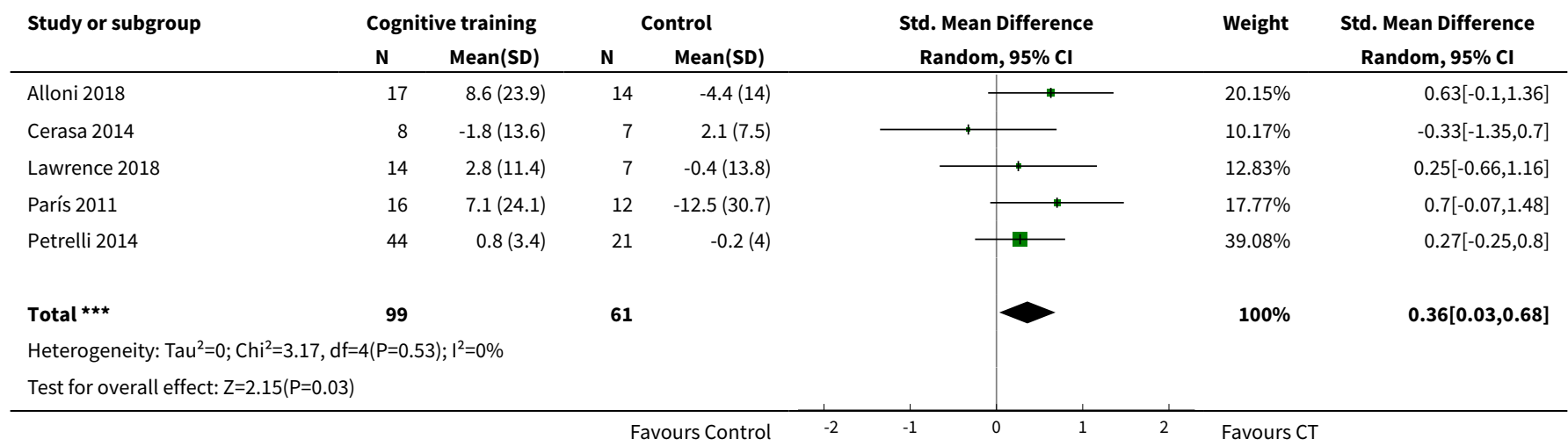

Analysis 1.4. Comparison 1 Cognitive training versus control group, Outcome 4 Verbal memory post-treatment.

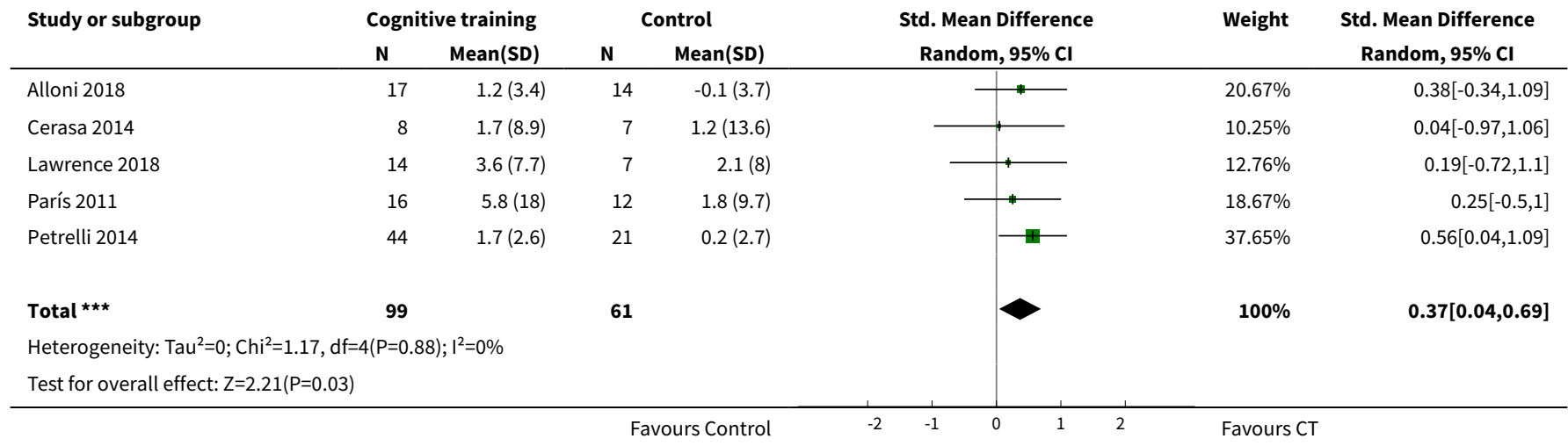

Analysis 1.5. Comparison 1 Cognitive training versus control group, Outcome 5 Visual processing post-treatment.

\begin{tabular}{|c|c|c|c|c|c|c|c|}
\hline \multirow[t]{2}{*}{ Study or subgroup } & \multicolumn{2}{|c|}{ Cognitive training } & \multicolumn{2}{|c|}{ Control } & \multirow{2}{*}{$\begin{array}{c}\text { Std. Mean Difference } \\
\text { Random, } 95 \% \mathrm{Cl}\end{array}$} & \multirow[t]{2}{*}{ Weight } & \multirow{2}{*}{$\begin{array}{c}\text { Std. Mean Difference } \\
\text { Random, } 95 \% \mathrm{Cl}\end{array}$} \\
\hline & $\mathbf{N}$ & $\operatorname{Mean}(S D)$ & $\mathbf{N}$ & $\operatorname{Mean}(S D)$ & & & \\
\hline Cerasa 2014 & 8 & $1(4.4)$ & 7 & $1.4(4.4)$ & $\longrightarrow$ & $25.05 \%$ & $-0.09[-1.1,0.93]$ \\
\hline Lawrence 2018 & 14 & $1(5.6)$ & 7 & $-0.3(10.2)$ & & $31.23 \%$ & $0.17[-0.74,1.08]$ \\
\hline París 2011 & 16 & $1.6(4.1)$ & 12 & $-0.9(3.9)$ & + & $43.71 \%$ & $0.62[-0.15,1.38]$ \\
\hline Total $\star \star \star ~$ & 38 & & 26 & & & $100 \%$ & $0.3[-0.21,0.81]$ \\
\hline \multicolumn{8}{|c|}{ Test for overall effect: $Z=1.15(P=0.25)$} \\
\hline
\end{tabular}


Analysis 1.6. Comparison 1 Cognitive training versus control group, Outcome 6 Activities of daily living post-treatment.

\begin{tabular}{|c|c|c|c|c|c|c|c|}
\hline \multirow[t]{2}{*}{ Study or subgroup } & \multicolumn{2}{|c|}{ Cognitive training } & \multicolumn{2}{|c|}{ Control } & \multirow{2}{*}{$\begin{array}{c}\text { Std. Mean Difference } \\
\text { Random, } 95 \% \mathrm{Cl}\end{array}$} & \multirow[t]{2}{*}{ Weight } & \multirow{2}{*}{$\begin{array}{c}\text { Std. Mean Difference } \\
\text { Random, } 95 \% \mathrm{Cl}\end{array}$} \\
\hline & $\mathbf{N}$ & $\operatorname{Mean}(S D)$ & $\mathbf{N}$ & Mean(SD) & & & \\
\hline Folkerts 2018 & 12 & $0.5(17.8)$ & 6 & $0(11.5)$ & 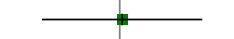 & $25.77 \%$ & $0.03[-0.95,1.01]$ \\
\hline Lawrence 2018 & 14 & $-0.1(0.8)$ & 7 & $-0.1(1.2)$ & & $30.07 \%$ & $0.02[-0.89,0.92]$ \\
\hline París 2011 & 16 & $3(35.2)$ & 12 & $1.4(33.5)$ & & $44.17 \%$ & $0.04[-0.7,0.79]$ \\
\hline 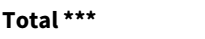 & 42 & & 25 & & & $100 \%$ & $0.03[-0.47,0.53]$ \\
\hline \multicolumn{8}{|c|}{ Test for overall effect: $Z=0.13(P=0.9)$} \\
\hline
\end{tabular}

\section{Analysis 1.7. Comparison 1 Cognitive training versus control group, Outcome 7 Quality of life post-treatment.}

\begin{tabular}{|c|c|c|c|c|c|c|c|}
\hline \multirow[t]{2}{*}{ Study or subgroup } & \multicolumn{2}{|c|}{ Cognitive training } & \multicolumn{2}{|c|}{ Control } & \multirow{2}{*}{$\begin{array}{c}\text { Std. Mean Difference } \\
\text { Random, } 95 \% \mathrm{Cl}\end{array}$} & \multirow[t]{2}{*}{ Weight } & \multirow{2}{*}{$\begin{array}{c}\text { Std. Mean Difference } \\
\text { Random, } 95 \% \mathrm{Cl}\end{array}$} \\
\hline & $\mathbf{N}$ & Mean(SD) & $\mathbf{N}$ & $\operatorname{Mean}(S D)$ & & & \\
\hline Cerasa 2014 & 8 & $2.4(25.7)$ & 7 & $-4.5(33.1)$ & 1 & $11.12 \%$ & $0.22[-0.8,1.24]$ \\
\hline Folkerts 2018 & 12 & $0.5(13.3)$ & 6 & $-1.6(7.2)$ & & $11.97 \%$ & $0.17[-0.81,1.15]$ \\
\hline Lawrence 2018 & 14 & $3.4(11.7)$ & 7 & $0.3(20.8)$ & & $13.94 \%$ & $0.2[-0.71,1.11]$ \\
\hline París 2011 & 16 & $-2.3(34.2)$ & 12 & $8.8(29.2)$ & & $20.28 \%$ & $-0.33[-1.09,0.42]$ \\
\hline Petrelli 2014 & 44 & $1.1(15.6)$ & 21 & $1.6(15.6)$ & + & $42.69 \%$ & $-0.03[-0.55,0.49]$ \\
\hline Total $\star \star \star ~$ & 94 & & 53 & & & $100 \%$ & $-0.01[-0.35,0.33]$ \\
\hline \multicolumn{8}{|c|}{ Heterogeneity: $\mathrm{Tau}^{2}=0 ; \mathrm{Chi}^{2}=1.25, \mathrm{df}=4(\mathrm{P}=0.87) ; \mathrm{I}^{2}=0 \%$} \\
\hline \multicolumn{3}{|c|}{ Test for overall effect: $Z=0.06(P=0.96)$} & & & & & \\
\hline
\end{tabular}

Analysis 1.8. Comparison 1 Cognitive training versus control group, Outcome $8 \mathrm{Global}$ cognition long term.

\begin{tabular}{|c|c|c|c|c|c|c|c|}
\hline \multirow[t]{2}{*}{ Study or subgroup } & \multicolumn{2}{|c|}{ Cognitive training } & \multicolumn{2}{|c|}{ Control } & \multirow{2}{*}{$\begin{array}{l}\text { Mean Difference } \\
\text { Random, } 95 \% \mathrm{CI}\end{array}$} & \multirow[t]{2}{*}{ Weight } & \multirow{2}{*}{$\begin{array}{l}\text { Mean Difference } \\
\text { Random, } 95 \% \mathrm{Cl}\end{array}$} \\
\hline & $\mathbf{N}$ & Mean(SD) & $\mathbf{N}$ & $\operatorname{Mean}(\mathrm{SD})$ & & & \\
\hline Alloni 2018 & 11 & $-0.1(3.1)$ & 13 & $-1.2(3.7)$ & - & $54.46 \%$ & $1.08[-1.64,3.8]$ \\
\hline Lawrence 2018 & 11 & $0.8(2.8)$ & 6 & $1.4(3.1)$ & $千$ & $45.54 \%$ & $-0.68[-3.65,2.29]$ \\
\hline 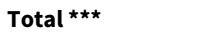 & 22 & & 19 & & & $100 \%$ & $0.28[-1.73,2.28]$ \\
\hline \multicolumn{8}{|c|}{ Heterogeneity: $\mathrm{Tau}^{2}=0 ; \mathrm{Chi}^{2}=0.73, \mathrm{df}=1(\mathrm{P}=0.39) ; \mathrm{I}^{2}=0 \%$} \\
\hline
\end{tabular}

Analysis 1.9. Comparison 1 Cognitive training versus control group, Outcome 9 Executive function long term.

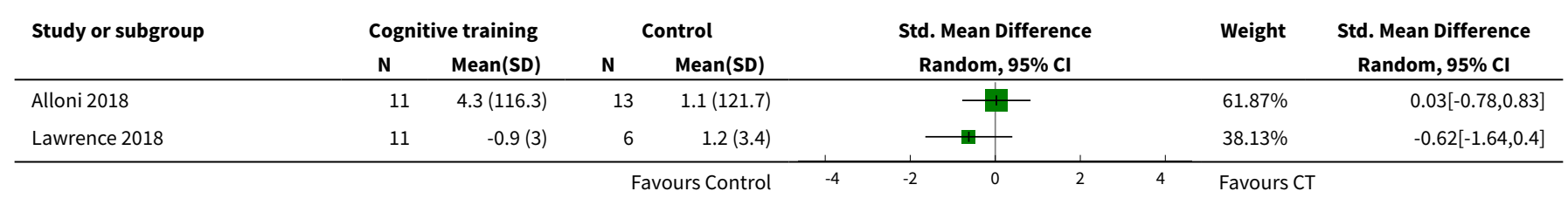




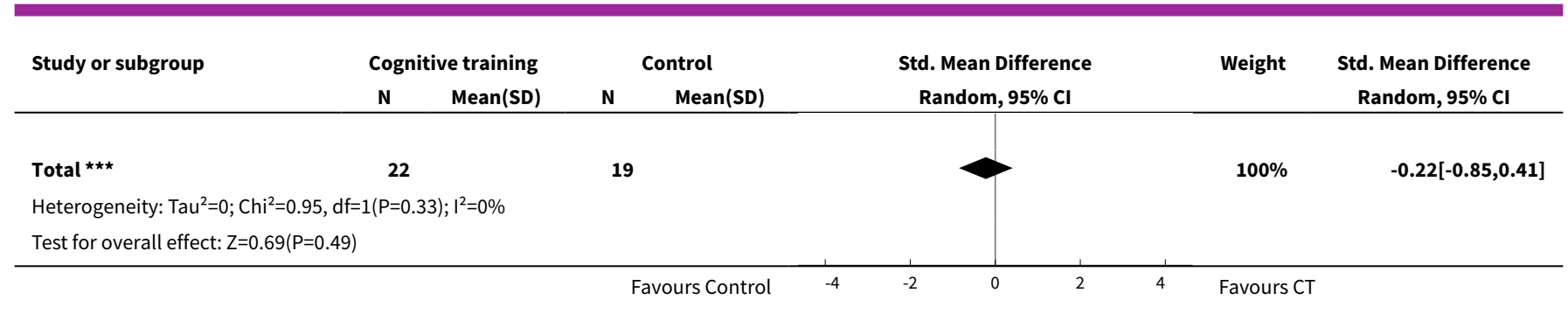

Analysis 1.10. Comparison 1 Cognitive training versus control group, Outcome 10 Attention long term.

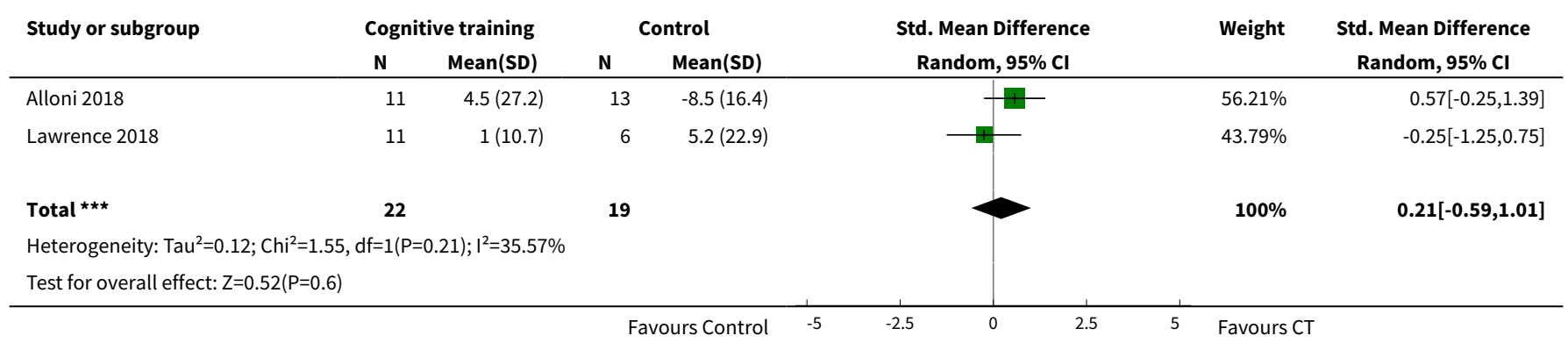

Analysis 1.11. Comparison 1 Cognitive training versus control group, Outcome 11 Verbal memory long term.

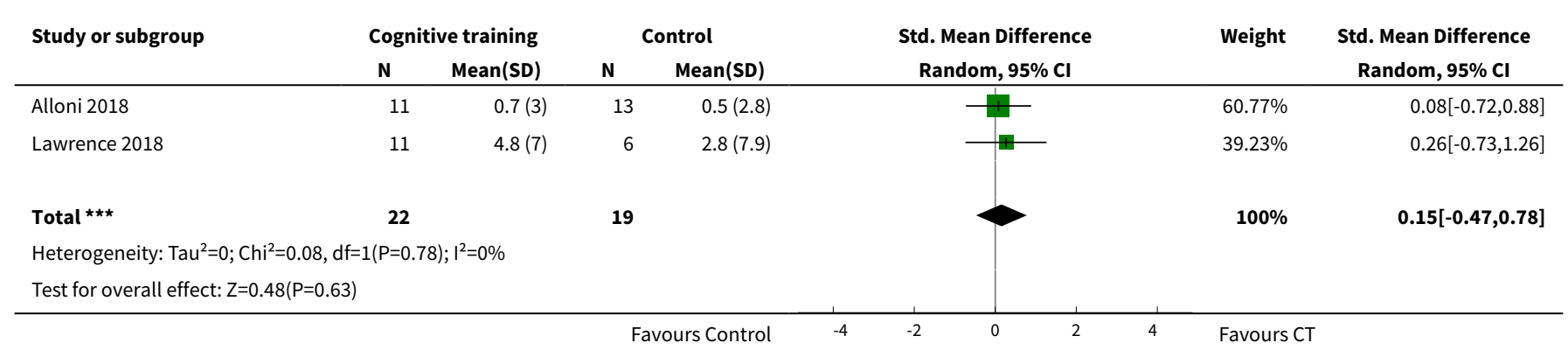

\section{Comparison 2. Sensitivity analyses: cognitive training versus control group}

\begin{tabular}{llllll}
\hline Outcome or subgroup title & $\begin{array}{l}\text { No. of } \\
\text { studies }\end{array}$ & $\begin{array}{l}\text { No. of } \\
\text { partici- } \\
\text { pants }\end{array}$ & Statistical method & Effect size \\
\hline 1 Attention post-treatment & 4 & 95 & Std. Mean Difference (IV, Random, 95\% Cl) & $0.41[-0.01,0.83]$ \\
\hline 2 Verbal memory post-treatment & 4 & 95 & Std. Mean Difference (IV, Random, 95\% Cl) & $0.25[-0.16,0.66]$ \\
\hline
\end{tabular}


Analysis 2.1. Comparison 2 Sensitivity analyses: cognitive training versus control group, Outcome 1 Attention post-treatment.

\begin{tabular}{|c|c|c|c|c|c|c|c|}
\hline \multirow{3}{*}{$\begin{array}{l}\text { Study or subgroup } \\
\text { Alloni } 2018\end{array}$} & \multicolumn{2}{|c|}{ Cognitive training } & \multicolumn{2}{|c|}{ Control } & \multirow{2}{*}{$\begin{array}{c}\text { Std. Mean Difference } \\
\text { Random, } 95 \% \mathrm{Cl}\end{array}$} & \multirow[t]{2}{*}{ Weight } & \multirow{2}{*}{$\begin{array}{c}\text { Std. Mean Difference } \\
\text { Random, } 95 \% \mathrm{Cl}\end{array}$} \\
\hline & $\mathbf{N}$ & $\operatorname{Mean}(S D)$ & $\mathbf{N}$ & Mean(SD) & & & \\
\hline & 17 & $8.6(23.9)$ & 14 & $-4.4(14)$ & 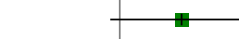 & $33.08 \%$ & $0.63[-0.1,1.36]$ \\
\hline Cerasa 2014 & 8 & $-1.8(13.6)$ & 7 & $2.1(7.5)$ & & $16.7 \%$ & $-0.33[-1.35,0.7]$ \\
\hline Lawrence 2018 & 14 & $2.8(11.4)$ & 7 & $-0.4(13.8)$ & & $21.06 \%$ & $0.25[-0.66,1.16]$ \\
\hline París 2011 & 16 & $7.1(24.1)$ & 12 & $-12.5(30.7)$ & - & $29.16 \%$ & $0.7[-0.07,1.48]$ \\
\hline \multicolumn{8}{|c|}{ Heterogeneity: $\operatorname{Tau}^{2}=0 ; \mathrm{Chi}^{2}=3, \mathrm{df}=3(\mathrm{P}=0.39) ; \mathrm{I}^{2}=0.07 \%$} \\
\hline \multicolumn{8}{|c|}{ Test for overall effect: $\mathrm{Z}=1.93(\mathrm{P}=0.05)$} \\
\hline
\end{tabular}

\section{Analysis 2.2. Comparison 2 Sensitivity analyses: cognitive training} versus control group, Outcome 2 Verbal memory post-treatment.

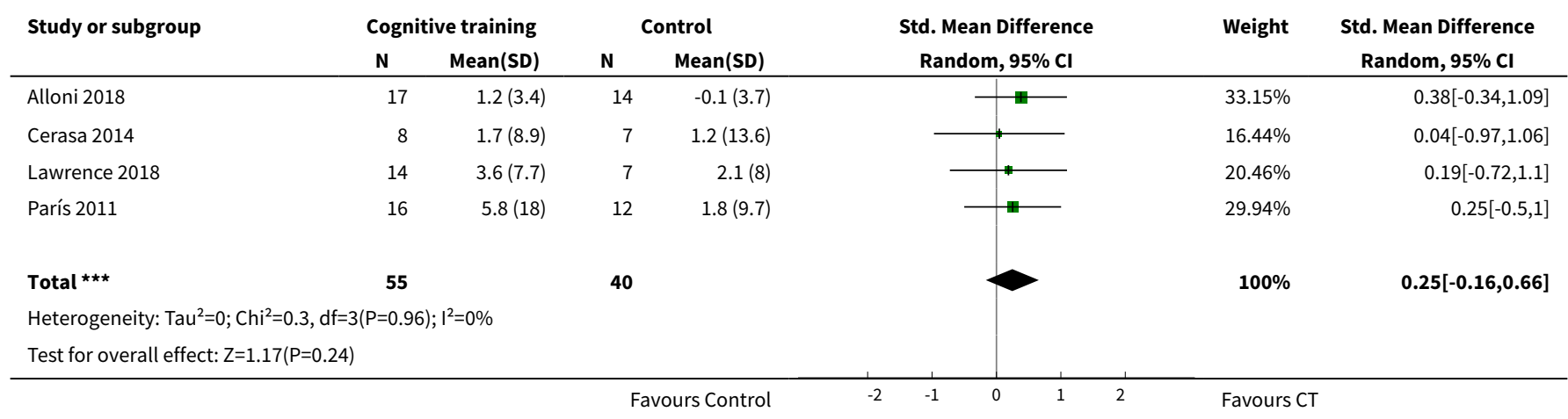

\section{APPENDICES}

\section{Appendix 1. Sources searched and search strategies}

\begin{tabular}{|c|c|c|}
\hline Source & Search strategy & Hits retrieved \\
\hline \multirow{5}{*}{$\begin{array}{l}\text { 1. ALOIS (www.medi- } \\
\text { cine.ox.ac.uk/alois) } \\
\text { [Date of most recent } \\
\text { search: } 8 \text { August 2019] }\end{array}$} & $\begin{array}{l}\text { Advanced search: (PDD OR PD OR Parkinson OR Parkinsons) AND Non-pharmaco- } \\
\text { logical }\end{array}$ & Jan 2016: 26 \\
\hline & & Jan 2017: 0 \\
\hline & & Dec 2017: 0 \\
\hline & & Sep 2018: 2 \\
\hline & & Aug 2019: 6 \\
\hline \multirow{3}{*}{$\begin{array}{l}\text { 2. MEDLINE In-process } \\
\text { and other non-indexed } \\
\text { citations and MEDLINE } \\
\text { 1950-present (Ovid SP) }\end{array}$} & 1. *Cognitive Therapy/ & Jan 2016: 92 \\
\hline & 2. (cognit* adj2 stimulation).ti,ab. & Jan 2017: 15 \\
\hline & 3. (cognit ${ }^{\star}$ adj2 rehabilitation).ti,ab. & Dec 2017: 31 \\
\hline
\end{tabular}


(Continued)

[Date of most recent search: 8 August 2019]
4. (cognit* adj2 training).ti,ab.

Sep 2018: 19

5. (cognit* adj2 retrain*).ti,ab.

Aug 2019: 21

6. "cognitive support".ti,ab.

7. "memory function*".ti,ab.

8. (memory adj2 rehabilitation).ti,ab.

9. (memory adj2 therap $\left.{ }^{\star}\right)$.ti,ab.

10. "memory aid*".ti,ab.

11. "memory group*".ti,ab.

12. "memory training".ti,ab.

13. ("memory retraining" or "memory re-training").ti,ab.

14. "memory support".ti,ab.

15. "memory stimulation".ti,ab.

16. "memory strateg*".ti,ab.

17. "memory management".ti,ab.

18. or/1-17

19. randomized controlled trial.pt.

20. controlled clinical trial.pt.

21. randomized.ab.

22. placebo.ab.

23. randomly.ab.

24. trial.ab.

25. groups.ab.

26. or/19-25

27. (animals not (humans and animals)).sh.

28. 26 not 27

29. parkinson*.ti,ab.

30. exp Parkinson's Disease/

31. exp Parkinsonism/

32. PDD.ti,ab.

33. MCI-PD.ti,ab.

34. PD-MCl.ti,ab.

35. or/29-34

36. 28 and 35 
(Continued)

1974-2017 December 10

2. (cognit* adj2 rehabilitation).ti,ab.

Jan 2017: 13

(Ovid SP)

[Date of most recent search: 8 August 2019]

3. (cognit* adj2 training).ti,ab.

Dec 2017: 23

4. (cognit* adj2 retrain*).ti,ab.

Sep 2018: 35

5. "cognitive support".ti,ab.

Aug 2019: 36

6. (memory adj2 rehabilitation).ti,ab.

7. (memory adj2 therap*).ti,ab.

8. "memory aid*".ti,ab.

9. "memory group*".ti,ab.

10. "memory training".ti,ab.

11. ("memory retraining" or "memory re-training").ti,ab.

12. "memory support".ti,ab.

13. "memory stimulation".ti,ab.

14. "memory strateg*".ti,ab.

15. "memory management".ti,ab.

16. or/1-15

17. randomly.ab.

18. placebo*.ti,ab

19. "double-blind"*ti,ab.

20. randomized controlled trial/

21. trial.ti,ab.

22. or/17-21

23. 22 and 16

24. parkinson*.ti,ab.

25. exp Parkinson's Disease/

26. exp Parkinsonism/

27. PDD.ti,ab.

28. MCl-PD.ti,ab.

29. PD-MCl.ti,ab.

30. or $/ 24-29$

31.22 and 30

4. PSYCINFO

1. (cognit* adj2 stimulation).ti,ab.

Jan 2016: 17

1806-December week 1

2. (cognit* adj2 rehabilitation).ti,ab.

Jan 2017: 6 2017 (Ovid SP)

[Date of most recent search: 8 August 2019]

3. (cognit* adj2 training).ti,ab.

Dec 2017: 9

4. (cognit* adj2 retrain*).ti,ab.

Sep 2018: 9 
6. (memory adj2 rehabilitation).ti,ab.

7. (memory adj2 therap*).ti,ab.

8. "memory aid*".ti,ab.

9. "memory group*".ti,ab.

10. "memory training".ti,ab.

11. ("memory retraining" or "memory re-training").ti,ab.

12. "memory support".ti,ab.

13. "memory stimulation".ti,ab.

14. "memory strateg*".ti,ab.

15. "memory management".ti,ab.

16. or/1-15

17. randomly.ab.

18. randomi?ed.ab.

19. placebo*.ti,ab.

20. trial.ti,ab.

21. RCT.ti,ab.

22. groups.ab.

23. or/17-22

24. 16 and 23

25. parkinson*.ti,ab.

26. exp Parkinson's Disease/

27. exp Parkinsonism/

28. PDD.ti,ab.

29. MCI-PD.ti,ab.

30. PD-MCl.ti,ab.

31. or $/ 25-30$

32. 24 and 31

$\begin{array}{llr}\text { 5. CINAHL (EBSCOhost) } & \text { S1 (MH "Parkinson Disease") } & \text { Jan } 2016: 461 \\ \begin{array}{ll}\text { [Date of most recent } \\ \text { search: 8 August 2019] }\end{array} & \text { S2 TX Parkinson* } & \text { Jan } 2017: 33 \\ & \text { S3 TX PDD } & \text { Dec 2017: } 65 \\ & \text { S4 TX MCI-PD } & \text { Sep 2018: } 83 \\ & \text { S5 TX PD-MCI } & \text { Aug 2019: } 153\end{array}$

\section{S6 S1 OR S2 OR S3 OR S4 OR S5}


(Continued)

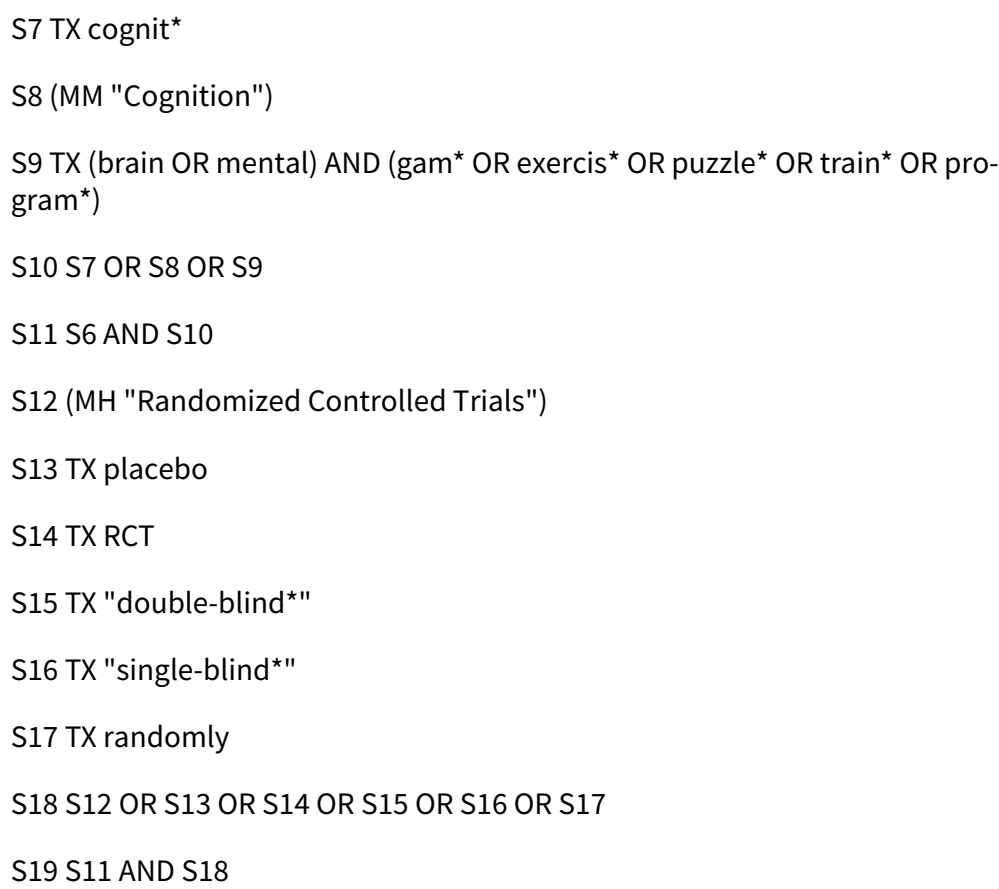

6. Web of Science Core ((parkinson* dement $\left.^{\star}\right)$ OR PDD OR "MCI-PD" OR "PD-MCI") AND TOPIC: ("cognit* Collection train ${ }^{\star}$ OR mental OR (brain* gam*) OR (brain exercis*) OR (memory exercis*) OR puzzle OR sudoku OR crossword ${ }^{\star}$ ) AND TOPIC: (randomly OR randomised OR randomized OR placebo OR "double-blind*" OR trial OR RCT OR CCT)

Jan 2016: 556

[Date of most recent search: 8 August 2019]

Timespan: All years.

$2017: 25$

Search language=Auto

Sep 2018: 44

Aug 2019: 36

$\begin{array}{ll}\text { 7. LILACS (BIREME) } & \begin{array}{l}\text { parkinson OR parkinsons OR PDD [Words] and cognition OR cognitive OR brain } \\ \text { OR mental Or memory [Words] and randomly OR randomised OR randomized OR } \\ \text { trial OR ensaio clínico OR control OR controlled [Words] }\end{array} \\ \begin{array}{ll}\text { search: } 8 \text { August 2019] } & \end{array}\end{array}$

Jan 2016: 71

Jan 2017: 0

Dec 2017: 3

Sep 2018: 6

Aug 2019: 6

\section{CENTRAL (the}

Cochrane Library) (Issue 11,2019 )

[Date of most recent search: 8 August 2019]
\#1 MeSH descriptor: [Parkinson Disease] explode all trees

\#2 parkinson *

\#3 PDD

\#4 MCI-PD

\#5 PD-MCI

\#6 \#1 or \#2 or \#3 or \#4 or \#5

\#7 MeSH descriptor: [Cognition] explode all trees

\#8 cognit*

\#9 "brain* train*"

\#10 "mental exercis*"
Jan 2016: 618

Jan 2017: 132

Dec 2017: 286

Sep 2018: 302

Aug 2019: 421 
(Continued)

\author{
\#11 sudoku or puzzle* or crossword* or IQ \\ $\# 12$ \#7 or \#8 or \#9 or \#10 or \#11 \\ \#13 \#6 and \#12 in Trials
}

\section{ClinicalTrials.gov (www.clinicaltrials.gov)}

[Date of most recent search: 8 August 2019]
[Condition: Parkinson OR parkinsons OR parkinson's OR PD] AND [Intervention: cognitive training OR cognitive exercise OR brain training OR memory training OR memory exercise]

limit to Interventional studies
Jan 2016: 0

Jan 2017: 0

Dec 2017: 14

Sep 2018: 11

Aug 2019: 0

Jan 2016: 56

Jan 2017: 26

Dec 2017: 2

Sep 2018: 7

Aug 2019: 6 cal Trial Registry; Clinical Trials Registry - India; Clinical Research Information Service Republic of Korea; German Clinical Trials Register; Iranian Registry of Clinical Trials; Japan Primary Registries Network; Pan African Clinical Trial Registry; Sri Lanka Clinical Trials Registry; The Netherlands National Trial Register]

[Date of most recent search: 8 August 2019]

[Condition: Parkinson OR parkinsons OR parkinson's OR PD] AND [Intervention: cognitive training OR cognitive exercise OR brain training OR memory training OR memory exercise]

Recruitment status: all
3849

\title{
CONTRIBUTIONSOF AUTHORS
}

VO: correspondence; drafting of review versions; selection of randomised controlled trials; data extraction; data entry; data analysis; interpretation of statistical analyses; editing and revising the review.

KM: selection of randomised controlled trials; data extraction; data entry; data analysis; interpretation of statistical analyses; editing and revising the review.

EP: interpretation of statistical analyses; editing and revising the review

$\mathrm{JVH}$ : interpretation of statistical analyses; editing and revising the review.

LC: interpretation of statistical analyses; editing and revising the review. 
IL: proposed concept of the review; selection of randomised controlled trials; data extraction; data entry; data analysis; interpretation of statistical analyses; editing and revising the review.

\section{DECLARATIONS OF INTEREST}

Vasiliki Orgeta: none known.

Kathryn R McDonald: none known.

Ellen Poliakoff: none known.

John Vincent Hindle: none known.

Linda Clare: none known.

Iracema Leroi: none known.

\section{SOURCES OF SUPPORT}

\section{Internal sources}

- No sources of support supplied

\section{External sources}

- National Institute for Health Research (NIHR), UK.

This review was supported by the National Institute for Health Research (NIHR) via the Cochrane Infrastructure Funding to the Cochrane Dementia and Cognitive Improvement Group. The views and opinions expressed therein are those of the authors and do not necessarily reflect those of the Systematic Reviews Programme, NIHR, National Health Service (NHS), or the Department of Health.

\section{DIFFERENCES BETWEEN PROTOCOLANDREVIEW}

We included studies that reported on the effectiveness of cognitive training in mixed populations, where only a proportion of the sample had cognitive impairment as verified by performance on a standardised test.

\section{INDEX TERMS}

\section{Medical Subject Headings (MeSH)}

Activities of Daily Living; Cognitive Dysfunction [rehabilitation] [*therapy]; Dementia [rehabilitation] [therapy]; Parkinson Disease [*psychology]; Quality of Life; Randomized Controlled Trials as Topic; Task Performance and Analysis

\section{MeSH check words}

Aged; Aged, 80 and over; Humans 